\title{
IUCN
}

Guidelines for the application of IUCN Red List of Ecosystems Categories and Criteria

Lucie M. Bland, David A. Keith, Rebecca M. Miller, Nicholas J. Murray and Jon Paul Rodríguez (eds)
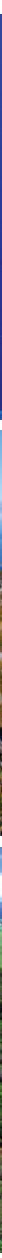

INTERNATIONAL UNION FOR CONSERVATION OF NATURE 


\section{Guidelines for the application of IUCN Red List of Ecosystems Categories and Criteria}

Lucie M. Bland, David A. Keith, Rebecca M. Miller, Nicholas J. Murray and Jon Paul Rodríguez (eds) Version 1.0 
The designation of geographical entities in this book, and the presentation of the material, do not imply the expression of any opinion whatsoever on the part of IUCN concerning the legal status of any country, territory, or area, or of its authorities, or concerning the delimitation of its frontiers or boundaries.

The views expressed in this publication do not necessarily reflect those of IUCN.

Published by: IUCN, Gland, Switzerland

Copyright: @ 2016 IUCN, International Union for Conservation of Nature and Natural Resources

The Guidelines for the application of IUCN Red List of Ecosystems Categories and Criteria is an open access publication licensed under a Creative Commons Attribution-NonCommercial-NoDerivatives 4.0 International (CC BY-NC-ND 4.0).

Reproduction of this publication for educational or other non-commercial uses is authorized without prior written permission from the copyright holder provided the source is fully acknowledged.

Reproduction of this publication for resale or other commercial purposes is prohibited without prior written permission of the copyright holder.

Citation: $\quad$ Bland, L.M., Keith, D.A., Miller, R.M., Murray, N.J. and Rodríguez, J.P. (eds.) (2016). Guidelines for the application of IUCN Red List of Ecosystems Categories and Criteria, Version 1.0. Gland, Switzerland: IUCN. ix + 94pp.

ISBN: $\quad$ 978-2-8317-1769-2

DOI: $\quad$ http://dx.doi.org/10.2305/IUCN.CH.2016.RLE.1.en

Cover photos: @ R Ferrari Legorreta, @ RM Miller, @ NJ Murray

All photographs used in this publication remain the property of the original copyright holder.

Photographs should not be reproduced or used in other contexts without written permission from the copyright holder.

Available from: IUCN (International Union for Conservation of Nature)

Global Ecosystem Management Programme

Commission on Ecosystem Management

Rue Mauverney 28

1196 Gland

Switzerland

Tel +41229990000

Fax +41229990002

www.iucn.org/publications

These guidelines are also freely available online on https://portals.iucn.org/library/node/45794 and the IUCN Red List of Ecosystems website (www.iucnrle.org). The guidelines are conceived as a 'living document' and will be updated periodically. Please submit your comments and suggestions to http://iucnrle.org/work-with-us/contact-us/.

Numerous experts from around the world participated in the development of these guidelines. The complete list of contributors is located in Appendix 1. 


\section{Table of Contents}

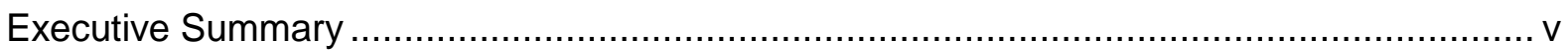

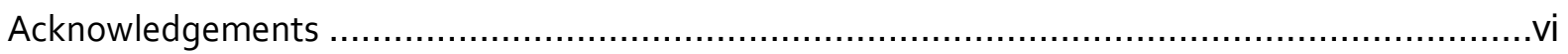

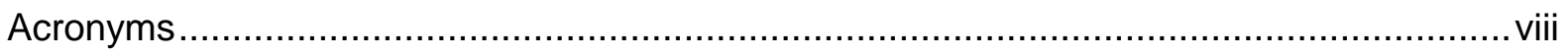

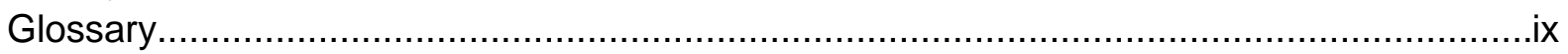

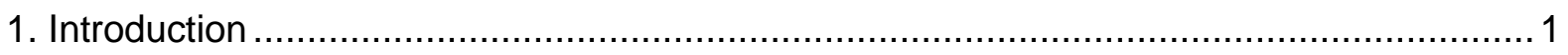

1.1 Objectives of the IUCN Red List of Ecosystems …......................................... 1

1.2 Development of the IUCN Red List of Ecosystems............................................ 2

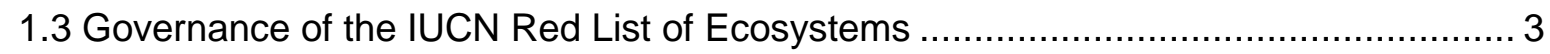

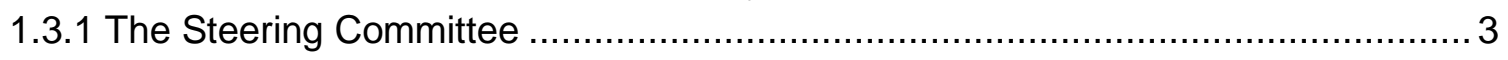

1.3.2 The Committee for Scientific Standards ......................................................... 4

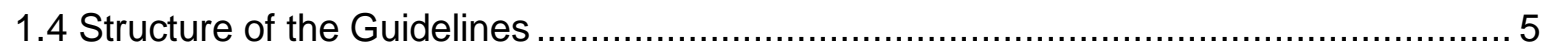

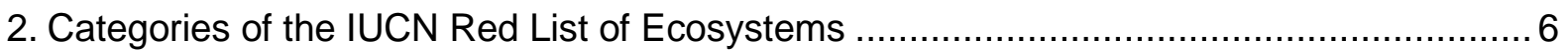

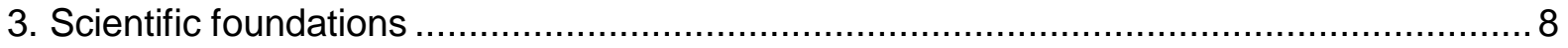

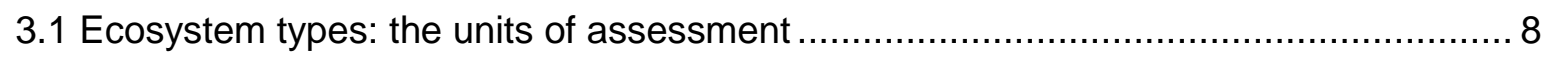

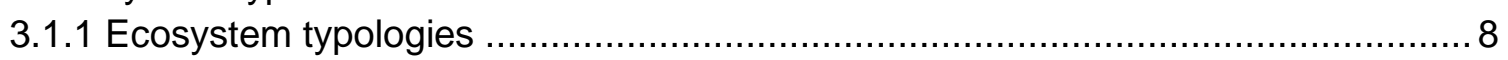

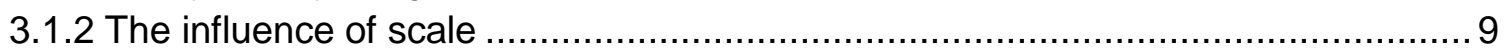

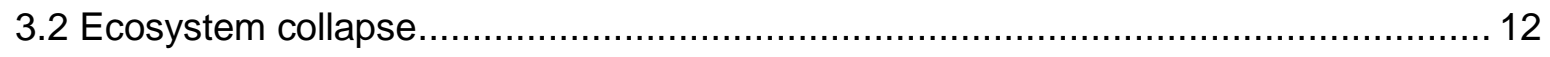

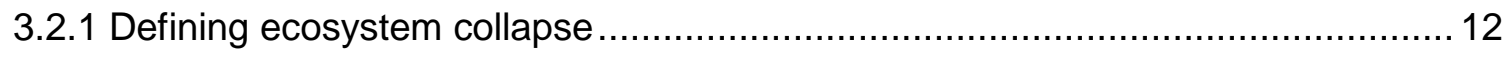

3.2.2 Uncertainties in the endpoints for risk assessment .................................... 15

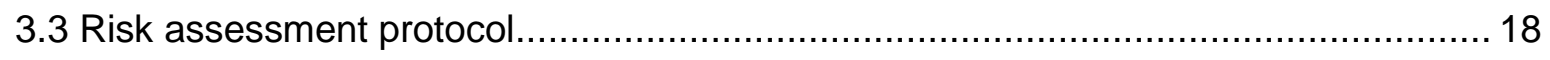

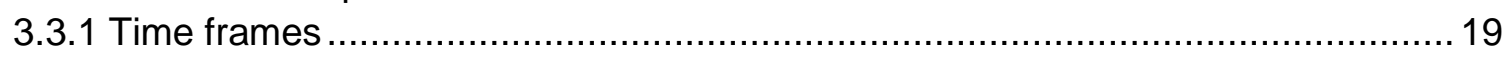

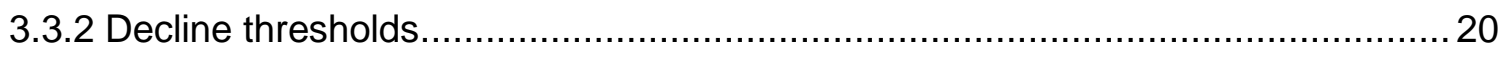

3.3.3 Standards of evidence and dealing with uncertainty ...................................... 21

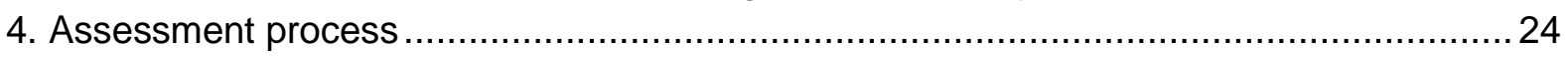

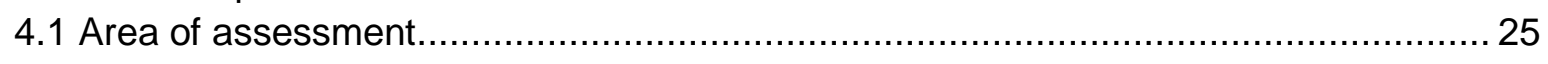

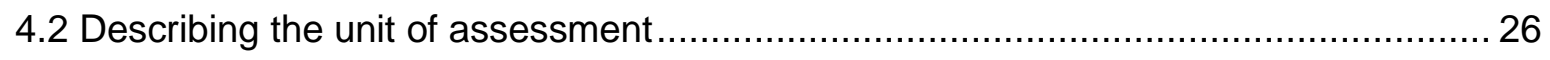

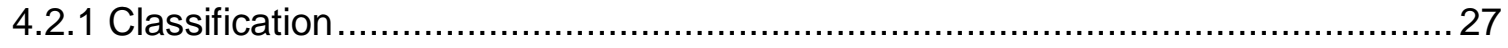

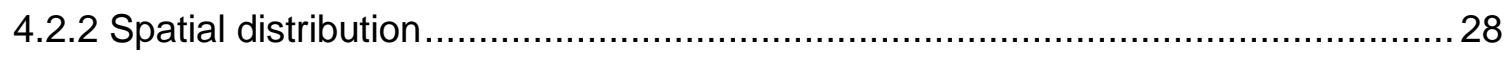

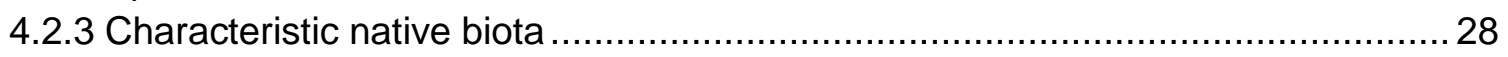

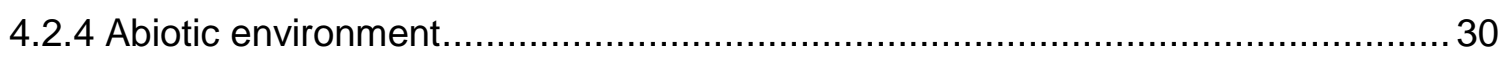

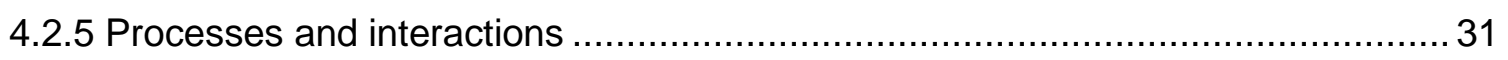

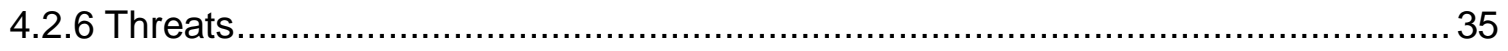

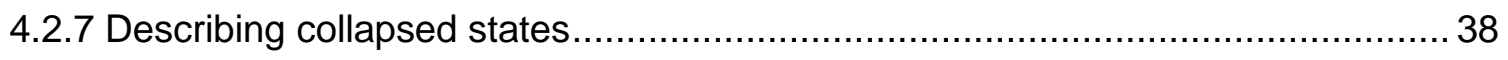

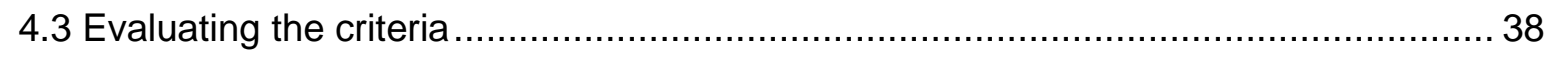

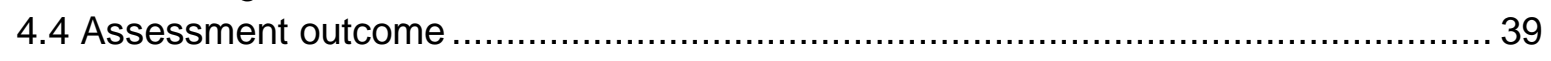

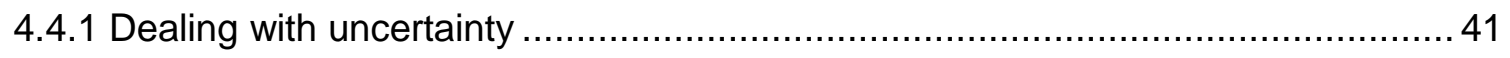

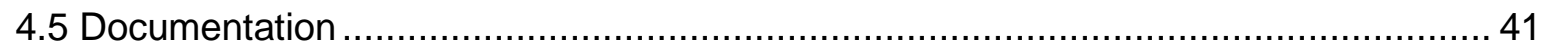

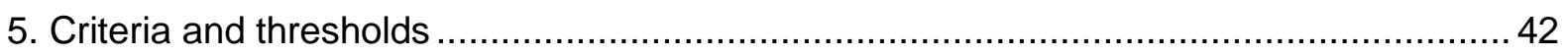

5.1 Criterion A. Reduction in geographic distribution ......................................... 43

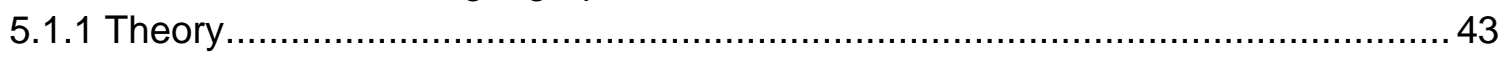

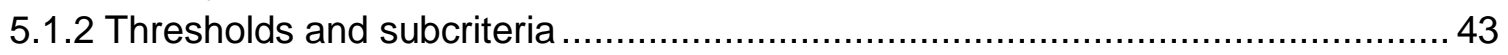




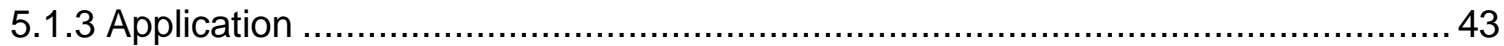

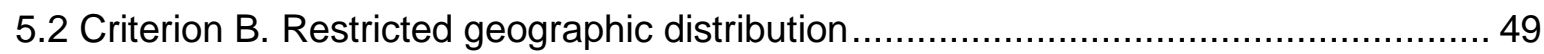

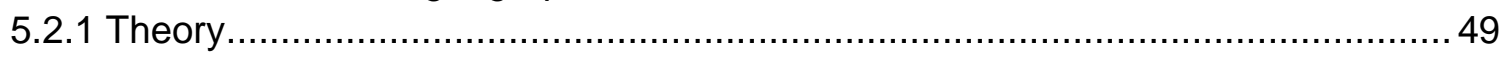

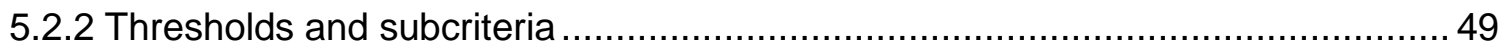

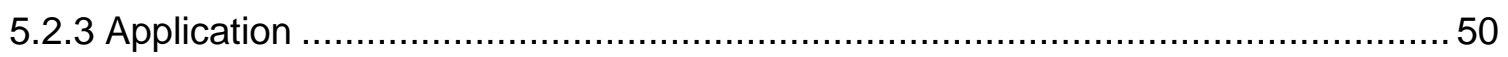

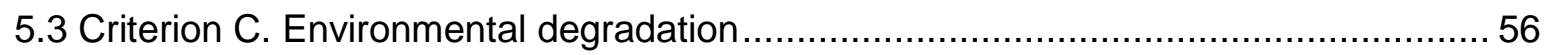

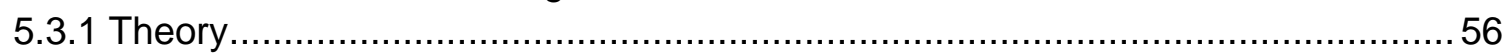

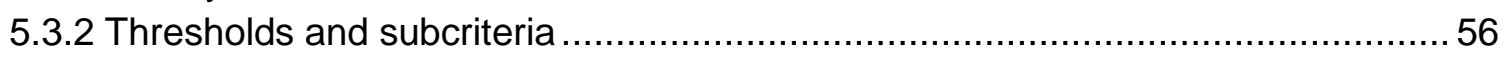

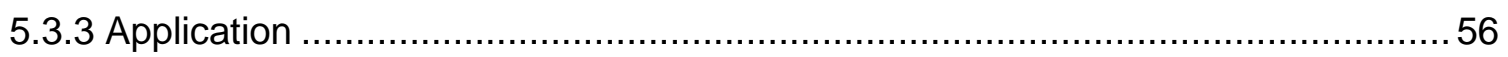

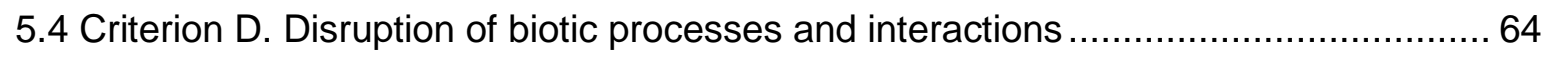

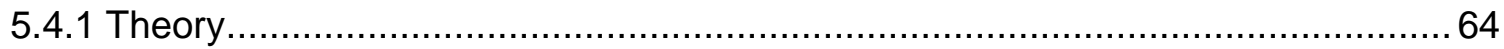

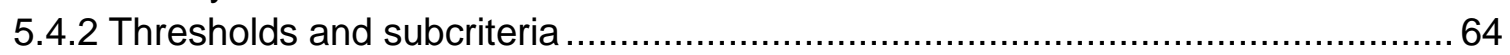

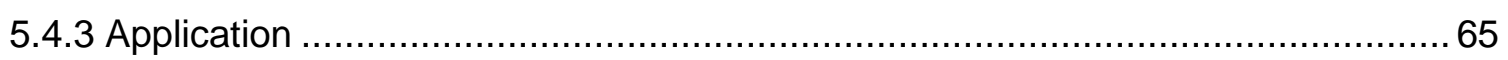

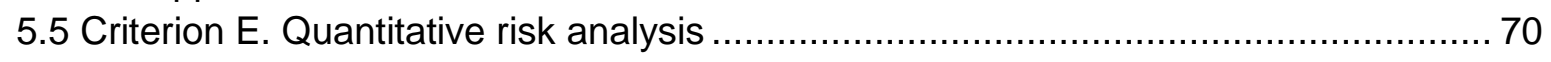

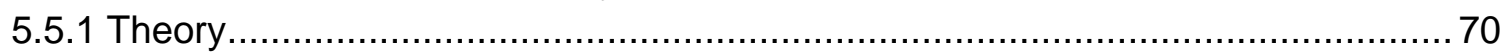

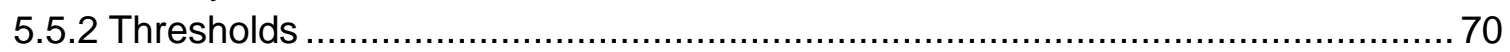

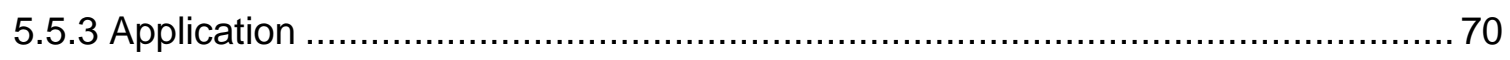

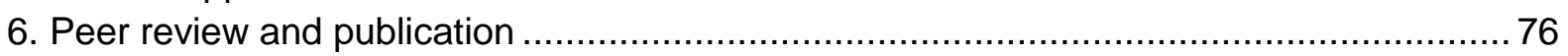

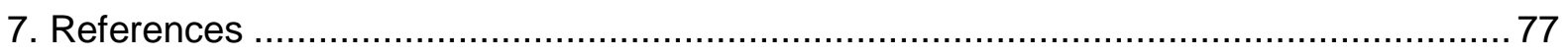

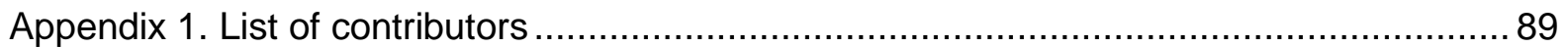

Appendix 2. IUCN Red List of Ecosystems Criteria, Version 2.1 ..................................... 91

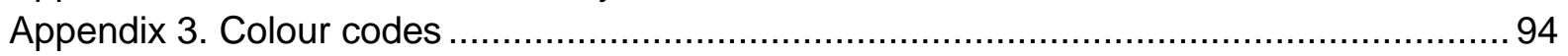




\section{Executive Summary}

The IUCN Red List of Ecosystems is a new global framework for monitoring the status of ecosystems. It is part of the growing toolbox for assessing risks to biodiversity and aims to support conservation, resource use, and management decisions by identifying ecosystems most at risk of biodiversity loss. By targeting a level of biological organisation above species, the IUCN Red List of Ecosystems complements The IUCN Red List of Threatened Species ${ }^{\mathrm{TM}}$. The IUCN Red List of Ecosystems Categories and Criteria are designed to be: widely applicable across ecosystem types and geographical areas; transparent and scientifically rigorous; and easily understood by policy makers and the public.

\section{The IUCN Red List of Ecosystems Categories and Criteria}

The basis of the IUCN Red List of Ecosystems is the IUCN Red List of Ecosystems Categories and Criteria, a set of eight categories and five criteria that provide a consistent method for assessing the risk of ecosystem collapse. The eight categories of ecosystem risk are: Collapsed (CO), Critically Endangered (CR), Endangered (EN), Vulnerable (VU), Near Threatened (NT), Least Concern (LC), Data Deficient (DD), and Not Evaluated (NE).

The IUCN Red List of Ecosystems protocol comprises five rule-based criteria (A-E) for assigning ecosystems to a risk category. Two of these criteria assess spatial symptoms of ecosystem collapse: declining distribution (A) and restricted distribution (B). Two criteria assess functional symptoms of ecosystem collapse: environmental degradation (C) and disruption of biotic processes and interactions (D). Multiple threats and symptoms can be integrated in a model of ecosystem dynamics to produce quantitative estimates of the risk of collapse $(E)$. The Guidelines include comprehensive sections to support application of each of the five criteria, including information on relevant theory, thresholds and examples.

\section{Application and documentation standards}

The Guidelines assist correct implementation of the IUCN Red List of Ecosystems Categories and Criteria by providing information on the development of the protocol and a detailed overview of the scientific foundations supporting the categories and criteria. They define assessment units (ecosystem types); define ecosystem collapse; discuss the influence of scale; and explain the structure of the risk assessment protocol. The Guidelines also provide detailed definitions of the terms used in the IUCN Red List of Ecosystems Categories and Criteria.

The Guidelines aim to support the practical implementation of the IUCN Red List of Ecosystems Categories and Criteria from subnational to global areas of assessment. The Guidelines therefore outline the necessary steps to: define the assessment area; define the unit under assessment; apply the criteria; and prepare the assessment documentation for peer review and publication. All the steps are illustrated with examples spanning a wide range of ecosystem types, geographical locations and levels of data availability.

\section{The future of the IUCN Red List of Ecosystems}

The IUCN Red List of Ecosystems programme will assess the global status of the world's terrestrial, marine, freshwater and subterranean ecosystems. In addition, the programme aims to support the development of national and regional Red Lists to inform conservation planning and sustainable development. For more information on the IUCN Red List of Ecosystems please consult the IUCN Red List of Ecosystems website (www.iucnrle.org). 


\section{Acknowledgements}

IUCN gratefully acknowledges the dedication and efforts of the hundreds of scientists and practitioners who have contributed to the scientific development and practical testing of the IUCN Red List of Ecosystems Categories and Criteria since 2008. These experts have cumulatively participated in nearly 50 meetings and workshops in more than 20 countries around the world, as well as submitted comments and suggestions remotely. To all we are most indebted. Key contributors to this process are listed in Appendix 1.

The process to develop Red List criteria for ecosystems was launched with Resolution 4.020 at the Fourth IUCN World Conservation Congress in 2008, and consolidated with Resolution 5.055 adopted by the Fifth World Conservation Congress in 2012. This process culminated in the adoption of the IUCN Red List of Ecosystems Categories and Criteria by the IUCN Council in May 2014. Further information on the development of the IUCN Red List of Ecosystems is available in Section 1.2.

The work on the IUCN Red List of Ecosystems has been made possible through generous support from: Agence Française de Développement; Australian Research Council; ConocoPhilips; Embassy of the Netherlands in Brazil; European Commission; Gordon and Betty Moore Foundation; IUCN Netherlands National Committee; IUCN Secretariat; IUCN Commission on Ecosystem Management; MAVA Foundation; New South Wales Office of Environment and Heritage; and South Australian Department of Environment, Water and Natural Resources. 


\section{IUCN Red List of Ecosystems}

Website www.iucnrle.org

Steering Committee

Jon Paul Rodríguez, Chair, Steering Committee

David A. Keith, Chair, Committee for Scientific Standards

Edmund G. Barrow

Thomas M. Brooks

Rebecca M. Miller

Emily Nicholson

María A. (Tina) Oliveira-Miranda

Piet Wiet

Staff

Cambridge, UK Rebecca M. Miller, Red List of Ecosystems Senior Programme Coordinator

Caracas

María A. (Tina) Oliveira-Miranda, Scientific Officer

Gland

Kaia Boe, Social Science and Ecosystems Programme Officer

Nairobi

Edmund G. Barrow, Director, Global Ecosystem Management Programme

\section{IUCN Commission on Ecosystem Management (2013-2016)}

Website $\quad$ www.iucn.org/about/union/commissions/cem/

Steering Committee

Piet Wit, Chair

Dominique Noome, Assistant to Chair

Angela Andrade, Deputy Chair

Birguy Lamizana, Vice Chair Drylands and Capacity Building

Said Damhoureyeh, Vice Chair

Kelvin Passfield, Vice Chair Marine and Coastal Ecosystems

Steve Edwards, Vice Chair Resilience and Social Learning

Red List of Ecosystems Thematic Group

Jon Paul Rodríguez, Lead

David A. Keith, Co-lead

\section{About IUCN}

IUCN is a membership Union uniquely composed of both government and civil society organisations. It provides public, private and non-governmental organisations with the knowledge and tools that enable human progress, economic development and nature conservation to take place together.

Created in 1948, IUCN is now the world's largest and most diverse environmental network, harnessing the knowledge, resources and reach of 1,300 Member organisations and some 15,000 experts. It is a leading provider of conservation data, assessments and analysis. Its broad membership enables IUCN to fill the role of incubator and trusted repository of best practices, tools and international standards.

IUCN provides a neutral space in which diverse stakeholders including governments, NGOs, scientists, businesses, local communities, indigenous peoples organisations and others can work together to forge and implement solutions to environmental challenges and achieve sustainable development.

Working with many partners and supporters, IUCN implements a large and diverse portfolio of conservation projects worldwide. Combining the latest science with the traditional knowledge of local communities, these projects work to reverse habitat loss, restore ecosystems and improve people's well-being.www.iucn.org 


\section{Acronyms}

\begin{tabular}{|ll|}
\hline Acronym & Definition \\
\hline AOO & Area of occupancy \\
\hline ARD & Absolute rate of decline \\
\hline CEM & IUCN Commission on Ecosystem Management \\
\hline CO & Collapsed \\
\hline CR & Critically Endangered \\
\hline DD & Data Deficient \\
\hline EN & Endangered \\
\hline EOO & Extent of occurrence \\
\hline GEMP & IUCN Global Ecosystem Management Programme \\
\hline GSP & IUCN Global Species Programme \\
\hline IUCN & International Union for Conservation of Nature \\
\hline LC & Least Concern \\
\hline NE & Not Evaluated \\
\hline NT & Near Threatened \\
\hline PRD & Proportional rate of decline \\
\hline RLE & IUCN Red List of Ecosystems \\
\hline RLTS & The IUCN Red List of Threatened Species ${ }^{\text {TM }}$ \\
\hline SSC & IUCN Species Survival Commission \\
\hline VU & Vulnerable \\
\hline
\end{tabular}




\section{Glossary}

\begin{tabular}{|c|c|}
\hline Term & Definition \\
\hline Area of assessment & Defines the implementation bounds of the assessment. \\
\hline Area of occupancy & $\begin{array}{l}\text { Area of occupancy (AOO) is a standardised measure of the area } \\
\text { that is occupied by an ecosystem type. }\end{array}$ \\
\hline Characteristic native biota & $\begin{array}{l}\text { Biological features that define the identity of an ecosystem type } \\
\text { and distinguish it from other ecosystem types and/or drive } \\
\text { ecosystem dynamics and function, e.g. ecological processes, } \\
\text { ecosystem engineers, trophic or structural dominants, } \\
\text { functionally unique elements, species interactions. }\end{array}$ \\
\hline Continuing decline & $\begin{array}{l}\text { A gradual or episodic decline in distribution or ecological process } \\
\text { that is likely to continue into the future, and is non-trivial in } \\
\text { magnitude and its effect on the sustainability of characteristic } \\
\text { native biota. }\end{array}$ \\
\hline Ecosystem collapse & $\begin{array}{l}\text { Collapse is a transformation of identity, a loss of defining } \\
\text { features, and a replacement by a different ecosystem type. }\end{array}$ \\
\hline Extent of occurrence & $\begin{array}{l}\text { Extent of occurrence (EOO) is a standardised measure of the } \\
\text { area within which all occurrences of an ecosystem type exist. }\end{array}$ \\
\hline Ecosystem type & The unit of assessment. \\
\hline Geographic distribution & $\begin{array}{l}\text { The geographic distribution of an ecosystem type represents all } \\
\text { spatial occurrences of an ecosystem type. }\end{array}$ \\
\hline Grain size & $\begin{array}{l}\text { The size of the spatial unit (e.g. grid cell, polygon segment) used } \\
\text { to measure a distribution. }\end{array}$ \\
\hline Location & $\begin{array}{l}\text { A geographically or ecologically distinct area in which a single } \\
\text { threatening event can rapidly affect all occurrences of an } \\
\text { ecosystem type. }\end{array}$ \\
\hline Relative severity & $\begin{array}{l}\text { The estimated magnitude of past or future environmental } \\
\text { degradation or disruption to biotic processes, expressed as a } \\
\text { percentage relative to a change large enough to cause } \\
\text { ecosystem collapse. }\end{array}$ \\
\hline Spatial extent & $\begin{array}{l}\text { The total area of the geographic distribution of an ecosystem } \\
\text { type estimated with a specified metric. }\end{array}$ \\
\hline Temporal resolution & The units of time over which trends are measured. \\
\hline Thematic scale & $\begin{array}{l}\text { A measure of the similarity of features within and among } \\
\text { ecosystem types. May be represented by the levels of a } \\
\text { hierarchical classification. }\end{array}$ \\
\hline Time frame & The total period over which ecosystem change is assessed. \\
\hline
\end{tabular}




\section{Introduction}

The IUCN Red List of Ecosystems was developed to promote a consistent global framework for monitoring the status of ecosystems (Keith et al., 2015). It is part of the growing toolbox for assessing risks to biodiversity and aims to support conservation, resource use and management decisions by identifying ecosystems most at risk of biodiversity loss. By targeting a level of biological organisation above species, the IUCN Red List of Ecosystems complements The IUCN Red List of Threatened Species ${ }^{\mathrm{TM}}$ (IUCN, 2015), together providing simultaneous assessment of broad- and fine-scale biodiversity. A combined approach is more likely to achieve the aim of comprehensive, effective and representative conservation outcomes and will improve the ability to monitor the status of biodiversity on Earth.

The basis of the IUCN Red List of Ecosystems is the IUCN Red List of Ecosystems Categories and Criteria (Appendix 2), a set of five criteria and associated thresholds that provide a repeatable, globally consistent method for classifying the risk of ecosystem collapse (Rodríguez et al., 2015; Keith et al., 2013). Ensuring accurate and comparable assessments for all ecosystem types included on the IUCN Red List of Ecosystems is a key challenge for the IUCN Red List of Ecosystems programme. These Guidelines provide the information required to meet this challenge.

The Guidelines assist users to correctly implement the IUCN Red List of Ecosystems Categories and Criteria by accompanying the assessor through the IUCN Red List of Ecosystems assessment process, from understanding the scientific foundations through to finalising assessments for publication. They provide information on the development of the protocol (Section 1) and a detailed overview of the scientific foundations that support the development of the categories and criteria (Sections 2 and 3). The Guidelines outline steps required to define the area and units of assessment, and the key ecosystem processes that will permit accurate application of the five criteria (Section 4). In addition, the Guidelines contain comprehensive sections on each of the five criteria, including information on relevant theory, thresholds and applications of each criterion (Section 5). Finally, the process of preparing an assessment for peer review and publication are described (Section 6).

\subsection{Objectives of the IUCN Red List of Ecosystems}

The primary goal of the IUCN Red List of Ecosystems (RLE) is to support conservation in resource use and management decisions by identifying ecosystems most at risk of biodiversity loss (Keith et al., 2013; Keith et al., 2015). By assessing relative risks of biodiversity loss at the ecosystem level, the RLE accounts for broad scale ecological processes and important dependencies and interactions among species (Keith et al., 2015). The IUCN Red List of Ecosystems also shines a light on common species, which define the identity of many ecosystems, are involved in key interactions with large numbers of cooccurring species, and can have major influences on ecosystem form and function (Gaston \& Fuller, 2008). To achieve the primary goal of the RLE, listing categories and criteria were designed to be: 
1. A standard method for assessing and comparing risks of ecosystem collapse.

2. Easily understood by policy makers and the public.

3. Transparent, objective and scientifically rigorous.

4. Applicable to terrestrial, marine, freshwater and subterranean systems.

5. Applicable to risk assessments of local to global areas.

6. Flexible to use data of varying quality and coverage.

7. Consistent with and complementary to The IUCN Red List of Threatened Species.

Although the primary goal of the RLE is focused on biodiversity conservation, the data associated with the RLE may inform a wide range of other activities, including the sustainable management of ecosystem services. Such applications will usually require additional tools to achieve effective planning outcomes (Keith et al., 2015).

\subsection{Development of the IUCN Red List of Ecosystems}

Although the desire to create a global Red List of Ecosystems (RLE) is not new within IUCN (Rodríguez et al., 2012a), the adoption of Resolution 4.020 on Quantitative Thresholds for Categories and Criteria of Threatened Ecosystems (Fourth World Conservation Congress, Barcelona, 2008) actively promoted the development of formal categories and criteria. The resolution requested IUCN to "initiate a consultation process for the development, implementation and monitoring of a global standard for the assessment of ecosystem status, applicable at local, regional and global levels." Over the following four years, and with significant contributions from the scientific, government and conservation sectors, the IUCN Red List of Ecosystems Thematic Group of the Commission on Ecosystem Management (CEM) drafted an initial set of criteria (Version 1.0; Rodríguez et al., 2011). In subsequent years, the criteria were disseminated and tested globally across a suite of ecosystem types by a range of external partners and in collaboration with the IUCN Global Ecosystem Management Programme (GEMP).

One major output of the global consultation led by the CEM was a substantial advance in the scientific knowledge underpinning the RLE. The process resulted in a thorough review of the relevant literature on ecosystem structure and functioning, documentation of the theoretical basis for the RLE criteria, development of a model for ecosystem risk assessment, and application of this new model to 20 ecosystems worldwide (Keith et al., 2013). This revised set of IUCN Red List of Ecosystems Categories and Criteria (Keith et al., 2013) has been refined following further application of the criteria to case studies, now spanning many ecosystem types across all continents (Keith et al., 2015; Keith, 2015).

The Fifth World Conservation Congress (Jeju, 2012) adopted Resolution 5.055 on the Consolidation of the IUCN Red List of Ecosystems, which acknowledged the progress of the RLE development and requested the IUCN Council to "take the necessary steps for formal approval of the categories and criteria as an official IUCN data analysis protocol for use by the Members and any other stakeholder interested in ecosystem risk assessment". Council examined the IUCN Red List of Ecosystems Categories and Criteria documentation and on 21 May 2014 adopted them as the official global standard for assessing the risk to ecosystems. 


\subsection{Governance of the IUCN Red List of Ecosystems}

The Red List of Ecosystems is jointly coordinated by two IUCN bodies, the Commission on Ecosystem Management (CEM) and the Global Ecosystem Management Programme (GEMP). It is governed by two interacting committees with specific functions: (i) the Steering Committee, and (ii) a Committee for Scientific Standards. It is supported by the Red List of Ecosystems Thematic Group of the CEM, which is a group of volunteer experts that undertake diverse duties in support of the objectives of the RLE. The RLE Programme Unit—based in Cambridge, United Kingdom; Gland, Switzerland; and Nairobi, Kenyaadministers the RLE and ensures global coordination of the experts involved in research, implementation and peer reviewing activities.

\subsubsection{The Steering Committee}

The RLE Steering Committee oversees the implementation of the IUCN Red List of Ecosystems Categories and Criteria at global and sub-global levels. The Steering Committee is composed of the Lead (and if applicable, the Co-lead) of the Red List of Ecosystems Thematic Group of the CEM (appointed by the Chair of the CEM), the Chair of the RLE Committee for Scientific Standards, the Chair of the CEM, the Director of the GEMP, the Head of the IUCN Science and Knowledge Unit, as well as additional members representing CEM, the IUCN Secretariat, and/or key RLE Partners appointed by the Chair of the CEM because of their specific technical or organisational expertise. The GEMP Director and the Head of the IUCN Science and Knowledge Unit represent the IUCN Secretariat.

The Steering Committee has the following functions:

1. Develop and manage the strategy and work plan for the implementation of the RLE worldwide, to achieve the goal of assessing all ecosystems at a global level by 2025 .

2. Establish a mechanism for periodically updating global assessments.

3. Identify and approach potential sources of financial support for assessments and their dissemination.

4. Supervise a team of professional staff within the RLE Programme Unit, and build a network of volunteers to implement the RLE work plan both within the CEM and the IUCN Secretariat.

5. Actively engage the CEM in developing and peer reviewing assessments at the global and sub-global levels.

6. Develop training materials and guidelines in the three official IUCN languages to support assessments.

7. Recommend appointments to the RLE Committee for Scientific Standards.

8. Ensure that progress of the RLE is reported back to the IUCN Council and Secretariat senior management.

9. Ensure that progress and outcomes of the RLE are well communicated in the scientific literature and media.

10. Ensure the execution of the RLE work plan and maintain cooperation among collaborating organisations.

11. Actively engage with others involved in the development, testing, and applications of Knowledge Products mobilised by IUCN. 


\subsubsection{The Committee for Scientific Standards}

The RLE Committee for Scientific Standards (CSS) is the principal scientific body that provides expertise in the development, application and review of all issues related to the RLE. The Committee consists of scientific experts with balanced expertise spanning a range of skills, including risk assessment, ecological modelling, remote sensing, ecosystem classification and mapping, decision theory, and ecology of terrestrial, freshwater, marine and subterranean ecosystems. The combined expertise of the members of the Committee for Scientific Standards covers the full diversity of ecosystem types and geographical regions.

Members of the Committee for Scientific Standards, including the Chair and Deputy Chair, are proposed by the RLE Steering Committee. The Chair of the CEM is ultimately responsible for appointing members to a maximum four-year term, which expires at the following session of the IUCN World Conservation Congress. One seat of the Committee for Scientific Standards is reserved for a representative of The IUCN Red List of Threatened Species designated by the Species Survival Commission (SSC) and the Global Species Programme (GSP).

The Committee for Scientific Standards promotes the application of high scientific standards to the implementation of the IUCN Red List of Ecosystems Categories and Criteria, and ensures that the intent of the categories and criteria is not compromised. The specific functions of the Committee for Scientific Standards are:

1. Develop and maintain technical guidelines in the three IUCN official languages to support the application of the IUCN Red List of Ecosystems Categories and Criteria, including details on implementation standards and data quality.

2. Provide scientific advice on the categories and criteria to the RLE Steering Committee and the Programme Unit.

3. Provide scientific advice and support to the Programme Unit on the development of databases, training materials and other resources.

4. Provide scientific advice on the design and implementation of systematic ecosystem risk assessment projects that could contribute to the global RLE.

5. Manage a peer review process of all classifications and maps of ecosystem types proposed for use in the global RLE.

6. Manage a peer review process for all assessments proposed for inclusion in the global RLE and, subject to the outcomes of the review process, submit recommendations to the Steering Committee on the inclusion or rejection of these assessments.

7. Critically review all applications of criterion $\mathrm{E}$.

8. Provide scientific support and training for sub-global assessments of ecosystem types via the RLE Programme Unit and other RLE partners.

9. Promote and undertake research to improve ecosystem risk assessment methodologies underpinning the IUCN Red List of Ecosystems Categories and Criteria.

10. All formal decisions and recommendations of the RLE Committee for Scientific Standards are submitted to the Steering Committee for review and formal adoption. 


\subsection{Structure of the Guidelines}

The Guidelines for the application of IUCN Red List of Ecosystems Categories and Criteria provide the information necessary to conduct a robust and repeatable ecosystem risk assessment suitable for inclusion on the RLE. Section 1 (Introduction) offers an overview of the motivation and history of the RLE, describing its general objectives and governing structure. Section 2 (Categories of the IUCN Red List of Ecosystems) presents the categories. Section 3 (Scientific Foundations) summarises the science underlying the categories and criteria, and presents the RLE risk assessment model. Section 4 (Assessment Process) guides assessors through a full assessment suitable for submission. The Criteria and Thresholds section (Section 5) outline the scientific theory underpinning each criterion, the estimation of variables for assessment, and the values of the thresholds for each category. Section 6 (Peer Review and Publication) describes the standards for evaluating the quality of a risk assessment. Throughout, a series of worked examples and cases studies are provided to assist assessors with the implementation of the categories and criteria.

A summary sheet of the current version of the IUCN Red List of Ecosystems Categories and Criteria is included as Appendix 2. More information on the IUCN Red List of Ecosystems, links to relevant documents, and summaries of case studies are available in multiple languages on the IUCN Red List of Ecosystems website (www.iucnrle.org). 


\section{Categories of the IUCN Red List of Ecosystems}

The IUCN Red List of Ecosystems includes eight categories: Collapsed (CO), Critically Endangered (CR), Endangered (EN), Vulnerable (VU), Near Threatened (NT), Least Concern (LC), Data Deficient (DD), and Not Evaluated (NE; Fig 1). The first six categories (CO, CR, EN, VU, NT and LC) are ordered in decreasing risk of collapse. The categories Data Deficient and Not Evaluated do not indicate a level of risk.

The categories Critically Endangered, Endangered and Vulnerable indicate threatened ecosystems and are defined by quantitative and qualitative criteria described in Section 5 and Appendix 2. These categories are nested, so that an ecosystem type meeting a criterion for Critically Endangered will also meet the criteria for Endangered and Vulnerable. The three threatened ecosystem categories are complemented by several qualitative categories that accommodate: (i) ecosystem types that almost meet the quantitative criteria for Vulnerable (Near Threatened); (ii) ecosystems that unambiguously meet none of the quantitative criteria (Least Concern); (iii) ecosystems for which too few data exist to apply any criterion (Data Deficient); (iv) ecosystems that have not yet been assessed (Not Evaluated). Following the precautionary principle (Precautionary Principle Project, 2005), the overall status of an ecosystem type is the highest risk category obtained through any criterion.

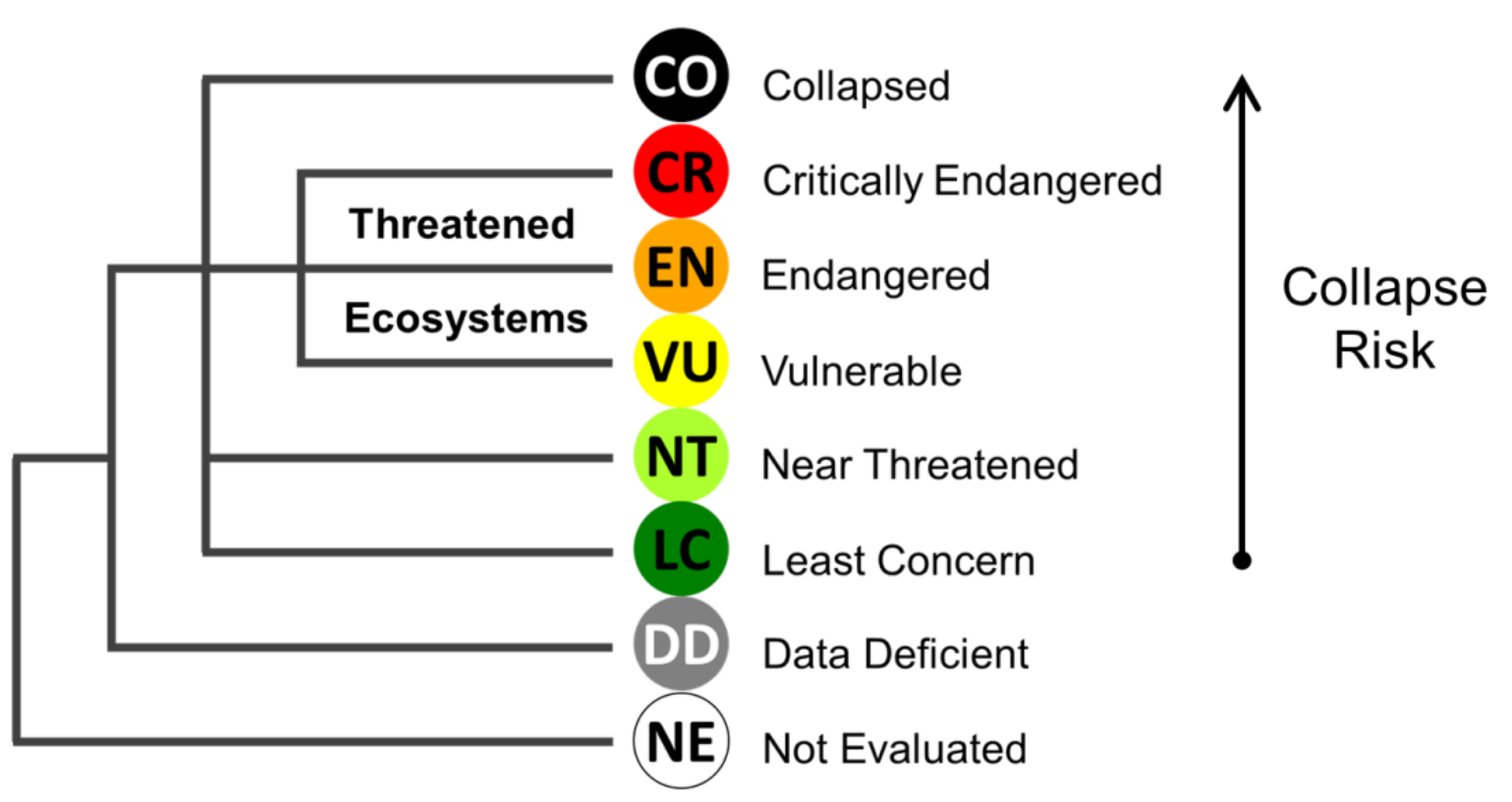

Figure 1. Structure of the IUCN Red List of Ecosystems categories. 
Collapsed (CO)

An ecosystem is Collapsed when it is virtually certain (Table 3 ) that its defining biotic or abiotic features are lost from all occurrences, and the characteristic native biota are no longer sustained. Collapse may occur when most of the diagnostic components of the characteristic native biota are lost from the system, or when functional components (biota that perform key roles in ecosystem organisation) are greatly reduced in abundance and lose the ability to recruit.

\section{Critically Endangered (CR)}

An ecosystem is Critically Endangered when the best available evidence indicates that it meets any of the criteria A to E for Critically Endangered. It is therefore considered to be at an extremely high risk of collapse.

\section{Endangered (EN)}

An ecosystem is Endangered when the best available evidence indicates that it meets any of the criteria $A$ to $E$ for Endangered. It is therefore considered to be at a very high risk of collapse.

\section{Vulnerable (VU)}

An ecosystem is Vulnerable when the best available evidence indicates that it meets any of the criteria $A$ to $E$ for Vulnerable. It is therefore considered to be at a high risk of collapse.

\section{Near Threatened (NT)}

An ecosystem is Near Threatened when it has been evaluated against the criteria but does not qualify for Critically Endangered, Endangered or Vulnerable now, but is close to qualifying for or is likely to qualify for a threatened category in the near future.

\section{Least Concern (LC)}

An ecosystem is Least Concern when it has been evaluated against the criteria and does not qualify for Critically Endangered, Endangered, Vulnerable or Near Threatened. Widely distributed and relatively undegraded ecosystems are included in this category.

\section{Data Deficient (DD)}

An ecosystem is Data Deficient when there is inadequate information to make a direct, or indirect, assessment of its risk of collapse based on decline in distribution, disruption of ecological function or degradation of the physical environment. Data Deficient is not a category of threat, and does not imply any level of collapse risk. Listing of ecosystems in this category indicates that their situation has been reviewed, but that more information is required to determine their risk status.

Not Evaluated (NE)

An ecosystem is Not Evaluated when it is has not yet been evaluated against the criteria. 


\section{Scientific foundations}

\subsection{Ecosystem types: the units of assessment}

The IUCN Red List of Ecosystems (RLE) protocol is a robust and generic risk assessment framework that can be applied to internally consistent classifications of ecosystem types. It has flexibility to assess risks to ecosystems that vary greatly in biological and environmental characteristics, scales of organisation, and amounts of available data. The clear definition and description of ecosystem types is therefore an essential first step to a RLE assessment.

Ecosystems are complexes of organisms and their associated physical environment within a specified area (Tansley, 1935). They have four essential elements: a biotic complex, an abiotic environment, the interactions within and between them, and a physical space in which these operate (Pickett and Cadenasso, 1995). Guidance on how to apply these concepts to define and describe suitable units for RLE assessment is given in section 4.2 Describing the unit of assessment.

\subsubsection{Ecosystem typologies}

The IUCN Red List of Ecosystems Categories and Criteria may be applied systematically to a set of ecosystem types within a specified area of assessment (global or sub-global) or to single ecosystem types. Standalone assessments of single ecosystem types can be useful diagnostic tools for ecosystem management (Keith et al., 2015). So long as the unit of assessment is clearly defined and delineated, standalone assessments are less reliant on a classification (typology) of ecosystem types than systematic assessments of multiple ecosystems. These systematic assessments require a typology to ensure consistent and comparable ecosystem risk assessments across the area of assessment. The classification may simply delineate units at a particular thematic scale, or may describe their relationships using hierarchies or nested arrangements that span a range of thematic scales (Rodríguez et al., 2011).

A number of jurisdictions have developed suitable typologies to support RLE assessments of national jurisdictions (Kontula \& Raunio, 2009; Lindgaard \& Henriksen, 2011; Driver et al., 2012). At the continental level, a RLE assessment of several hundred terrestrial ecosystem types for the Americas is based on an international classification framework for terrestrial vegetation (Faber-Langendoen et al., 2014; Rodríguez et al., 2012b). The thematic scale of ecosystem types in this assessment corresponds to the group and macrogroup levels in the International Vegetation Classification system (Faber-Langendoen et al., 2014), and is appropriate for global RLE assessments.

Sub-global assessments may be based on established national or regional ecosystem classifications, providing the units of assessment conform to the definition of ecosystem types (see 3.1 Ecosystem types: the units of assessment, above). These units should be justified as suitable proxies for ecological assemblages and should be cross-referenced to national, regional or global classification systems. 
Development of a global ecosystem typology is currently underway (led by the RLE Committee for Scientific Standards, and the CEM RLE Thematic Group). This work is guided by recent research on classifications of terrestrial vegetation (Faber-Langendoen et al., 2014) and marine environments (Gregr et al., 2012), and seeks to promote transparent and repeatable crosswalks among sub-global typologies meeting certain specifications (Section 4.1). In the interim, the IUCN Habitats Classification Scheme (www.iucnredlist.org/technicaldocuments/classification-schemes/habitats-classification-scheme-ver3) provides a useful comparative framework for assessments of contrasting ecosystem types at a range of thematic scales.

Globally recognisable ecosystem types should not be confused with biogeographic or biophysical ecoregions (Spalding et al., 2007), or biomes (Allen \& Hoekstra, 1990). Ecoregions and biomes are areas that share common macro-environmental or biogeographical features and contain complexes of contrasting, but co-occurring ecosystem types (Spalding et al., 2007). The potential heterogeneity of ecoregions and biomes makes them unsuitable for most RLE applications (Rodríguez et al., 2015; Keith et al., 2015; Keith et al., 2013). Other terms applied in conservation assessments -such as ecological communities, habitats, biotopes, and (largely in the terrestrial context) vegetation types - are regarded as operational synonyms of ecosystem type (Nicholson et al., 2009) providing they are adequately defined in accordance with the procedures described in the assessment process (Section 4.2).

\subsubsection{The influence of scale}

The RLE risk assessment protocol was designed to be flexible for application at multiple spatial scales and with a range of data types (Rodríguez et al., 2015; Keith et al., 2015; Keith et al., 2013). However, there are practical limits to the spatial, temporal and thematic scales of units that can be assessed, and within these limits the assessment outcomes are sensitive to scale. Assessments of units that are too broadly or narrowly defined, or failure to implement methods or standardisation procedures (Section 5) could lead to scale mismatches, incomparable assessments across scales, or invalid assessment outcomes (Keith et al., 2013). A range of measures in the RLE protocol address the influence of scale:

1. Research is underway to support the interpretation of the RLE criteria for assessments of different geographic areas. The categories and criteria were primarily designed for assessments at the global level, but are applicable to sub-global assessments (Section 3.1.1). Many of these sub-global assessments will work within ecologically arbitrary boundaries (e.g. national borders), and therefore will consider only parts of the global distribution of some ecosystem types. Methods for interpreting and scaling threat categories or their thresholds to account for these scenarios are currently under investigation.

2. A growing number of national and subnational assessments provide guidance on appropriate thematic scales (classification level or strength; Hermoso et al., 2013) for ecosystem risk assessments (Table 1). The ecosystem typologies provide examples of ecosystem classifications designed to support different regulatory frameworks and 
conservation planning applications among jurisdictions. The development of a global typology will provide further guidance on the thematic scale of assessments for the global RLE.

3. Standard scales for assessing geographical distribution: the grain size (e.g. pixel resolution) at which an ecosystem distribution is mapped can greatly affect the estimate of distribution size. To maintain consistency with the fixed thresholds for assessing distribution size (criterion $\mathrm{B}$ ), distributions are measured at a standard grain size (10x10 km grid) for estimating $\mathrm{AOO}$ and a standard geometric method (minimum convex polygon) for estimating EOO. This generalising process is sufficiently broad to accommodate processes relevant to persistence in a wide range of ecosystem types (Section 5.2). A range of tools are made available to assist with upscaling and downscaling distribution data, and completing assessments under criteria A and B (Section 5).

4. Standard time frames for assessment: temporally, ecosystems may develop, persist and change over time frames that vary from hours to millennia. They appear stable at some temporal scales, while undergoing trends or fluctuations at others (Wiens, 1989; Carpenter \& Turner, 2001). The categories assess ecosystem change over standard time frames that represent trends over present, future and historical time scales. Present and future time frames are set at 50 years to balance the need to diagnose trends with reasonable certainty (requiring long time frames) with the need for timely responses to adverse trends. Historical time frames are included to accommodate the effects of ecological lags in assessments (Section 5). 
Table 1. Examples of ecosystem typologies and similar classifications supporting national ecosystem risk assessments for various conservation planning and regulatory applications (adapted from Keith et al., 2015)

\begin{tabular}{|c|c|c|c|}
\hline Jurisdiction & Application & Assessment unit & Reference \\
\hline $\begin{array}{l}\text { European } \\
\text { Union }\end{array}$ & $\begin{array}{l}\text { Habitats Directive } \\
\text { 92/43/EEC (European } \\
\text { Commission) }\end{array}$ & $\begin{array}{l}\text { Habitat type. 'Plant and animal } \\
\text { communities as the } \\
\text { characterising elements of the } \\
\text { biotic environment, together } \\
\text { with abiotic factors operating } \\
\text { together at a particular scale.' }\end{array}$ & $\begin{array}{l}\text { Council of the } \\
\text { European } \\
\text { Commission (1992) }\end{array}$ \\
\hline Germany & $\begin{array}{l}\text { Red List of biotopes } \\
\text { (Federal Environment } \\
\text { Agency) }\end{array}$ & $\begin{array}{l}\text { Biotope. 'Habitat of a } \\
\text { community of fauna and flora } \\
\text { living in the wild.' }\end{array}$ & $\begin{array}{l}\text { Riecken et al. (2009); } \\
\text { Riecken et al. (2006) }\end{array}$ \\
\hline Finland & $\begin{array}{l}\text { Red List of habitat types } \\
\text { (Finnish Environment } \\
\text { Institute) }\end{array}$ & $\begin{array}{l}\text { Habitat type. 'Spatially } \\
\text { definable land or aquatic areas } \\
\text { with characteristic } \\
\text { environmental conditions and } \\
\text { biota which are similar between } \\
\text { these areas but differ from } \\
\text { areas of other habitat types.' }\end{array}$ & $\begin{array}{l}\text { Kontula \& Raunio } \\
\text { (2009) }\end{array}$ \\
\hline Norway & $\begin{array}{l}\text { Red List of ecosystems } \\
\text { and habitat types } \\
\text { (Norwegian Biodiversity } \\
\text { Information Centre) }\end{array}$ & $\begin{array}{l}\text { Habitat type. 'A homogeneous } \\
\text { environment, including all plant } \\
\text { and animal life and } \\
\text { environmental factors that } \\
\text { operate there.' }\end{array}$ & $\begin{array}{l}\text { Lindgaard \& } \\
\text { Henriksen (2011) }\end{array}$ \\
\hline Venezuela & $\begin{array}{l}\text { National Red List of } \\
\text { ecosystems (Provita) }\end{array}$ & $\begin{array}{l}\text { Major vegetation types for } \\
\text { national assessment; satellite- } \\
\text { derived land types for } \\
\text { subnational assessments. }\end{array}$ & $\begin{array}{l}\text { Rodríguez et al. } \\
\text { (2010) }\end{array}$ \\
\hline Canada & $\begin{array}{l}\text { State threatened species } \\
\text { and ecosystems } \\
\text { legislation (Manitoba } \\
\text { Conservation and Water } \\
\text { Stewardship Department) }\end{array}$ & $\begin{array}{l}\text { Ecosystem. 'A dynamic } \\
\text { complex of plant, animal and } \\
\text { microorganism communities } \\
\text { and their nonliving environment } \\
\text { interacting as a functional unit.' }\end{array}$ & $\begin{array}{l}\text { Government of } \\
\text { Manitoba (2014) }\end{array}$ \\
\hline Australia & $\begin{array}{l}\text { Lists of threatened } \\
\text { ecological communities at } \\
\text { national and state levels } \\
\text { (Federal Department of } \\
\text { Environment, state } \\
\text { environment agencies) }\end{array}$ & $\begin{array}{l}\text { Ecological community. 'An } \\
\text { assemblage of native species } \\
\text { that inhabits a particular area in } \\
\text { nature.' }\end{array}$ & $\begin{array}{l}\text { Commonwealth of } \\
\text { Australia (2000); } \\
\text { Keith (2009); } \\
\text { Nicholson et al. } \\
\text { (2015) }\end{array}$ \\
\hline $\begin{array}{l}\text { South } \\
\text { Africa }\end{array}$ & $\begin{array}{l}\text { National biodiversity } \\
\text { legislation (South African } \\
\text { National Biodiversity } \\
\text { Institute) }\end{array}$ & $\begin{array}{l}\text { Ecosystem. 'A dynamic } \\
\text { complex of animal, plant and } \\
\text { micro-organism } \\
\text { communities and their nonliving } \\
\text { environment interacting as a } \\
\text { functional unit.' }\end{array}$ & $\begin{array}{l}\text { Republic of South } \\
\text { Africa (2004); Driver } \\
\text { et al. (2012) }\end{array}$ \\
\hline
\end{tabular}




\subsection{Ecosystem collapse}

To achieve a robust application of the IUCN Red List of Ecosystems Categories and Criteria, assessors must synthesise diverse causes, mechanisms and pathways of ecosystem decline within the generic risk assessment framework. To estimate risk-the probability of an adverse outcome over a specified time frame-it is necessary to define the endpoint of ecosystem decline, the point at which an ecosystem is considered collapsed. The definition of the endpoint to ecosystem decline must be sufficiently discrete to permit an assessment of risk, but sufficiently general to encompass the broad range of contexts in which risk assessments are needed. The RLE protocol has two elements to deal with this trade-off: (i) a definition of ecosystem collapse as the endpoint to ecosystem decline; (ii) a risk assessment model that identifies the multiple pathways to ecosystem collapse and forms the basis for the criteria.

Within the IUCN Red List of Ecosystems Categories and Criteria, "an ecosystem is Collapsed when it is virtually certain (Table 3 ) that its defining biotic or abiotic features are lost from all occurrences, and the characteristic native biota are no longer sustained. Collapse may occur when most of the diagnostic components of the characteristic native biota are lost from the system, or when functional components (biota that perform key roles in ecosystem organisation) are greatly reduced in abundance and lose the ability to recruit."

\subsubsection{Defining ecosystem collapse}

Unlike species, ecosystems do not disappear; rather they transform into novel ecosystems with different characteristic biota and mechanisms of organisation (Hobbs et al., 2006; Keith et al., 2015; Keith et al., 2013). Many characteristic features may disappear long before the last characteristic species disappears from the last ecosystem occurrence (assemblage extinction; Gaston \& Fuller, 2008). The novel systems may retain some of the characteristic biota of the collapsed systems that they replace, but the abundance of those species, their interactions or ecological functions are altered. Acknowledging the contrasts with species extinction, the concept of ecosystem collapse is defined as the transition beyond a bounded threshold in one or more variables that define the identity of the ecosystem. Collapse is a transformation of identity, a loss of defining features, and/or replacement by a different ecosystem. An ecosystem is collapsed when all occurrences lose defining biotic or abiotic features, no longer sustain the characteristic native biota, and have moved outside their natural range of spatial and temporal variability in composition, structure and/or function. This can be illustrated by the familiar 'marble' model of state and transition theory (Fig. 2) and by key examples such as the Aral Sea (Box 1). Ecosystem collapse may in theory be reversible-given a long time frame, or via the reintroduction of characteristic biota and/or the restoration of ecosystem function—but in many systems recovery will not be possible.

Transitions to collapse may be gradual, sudden, linear, non-linear, deterministic or highly stochastic. These include regime shifts (Scheffer et al., 2001), but also other types of transitions that may not involve reinforcing feedbacks. The dominant dynamic in an ecosystem will depend on abiotic or external influences (e.g. weather patterns or human disturbance), internal biotic processes (e.g. competition, predation, or epidemics), historical legacies (e.g. climatic history, extinction debts or exploitation), and spatial context (e.g. 
location, size and dispersion of distribution). An ecosystem may thus be driven to collapse by different threatening processes and through multiple pathways. Trophic cascades (Estes et al., 2011), loss of foundation species (Diamond, 2007), environmental degradation (UNEP, 2001), and climatic forcing (Grebmeier et al., 2006) are common pathways to ecosystem collapse. Symptoms of collapse may differ depending on the characteristics of the ecosystem, the nature of threatening processes, and the pathways of decline that these generate. The RLE protocol has flexibility to allow thresholds of collapse to be expressed in appropriate terms for very different kinds of ecosystems.

The definition of ecosystem collapse may be clearest for ecosystems that have already collapsed and for which time series data exist for relevant variables. It will often be possible to infer characteristics of collapse from occurrences within the ecosystem distribution where defining features have been lost, even if the majority of the ecosystem remains extant. Major changes in functionally similar ecosystems can also provide guidance for defining the symptoms of collapse in systems of interest. This can provide a basis for defining the spatial and functional symptoms of ecosystem collapse.

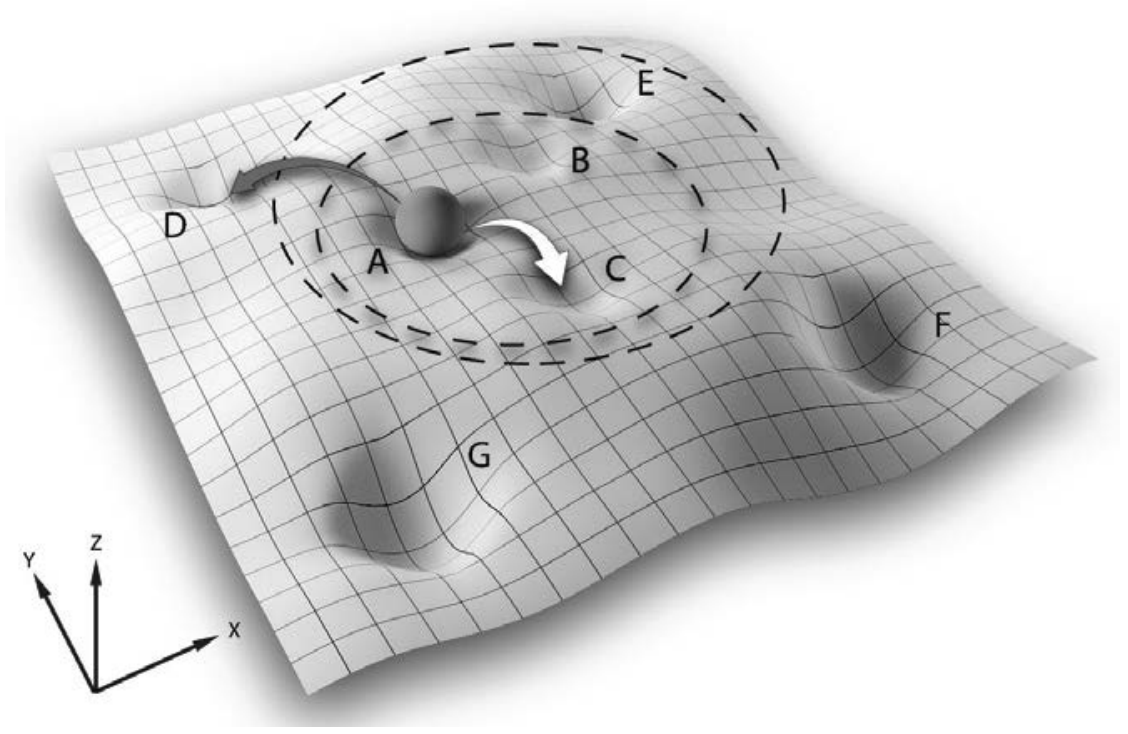

Figure 2. Generalised schematic illustrating the interpretation of ecosystem collapse in a state and transition framework (Keith et al., 2015). States A-G are defined by two state variables represented on the $X$ and $Y$ axes. The vertical axis $(Z)$ represents potential for change. The two broken lines represent alternative interpretations of ecosystem collapse. For the inner line, transitions between states A, B and C (e.g. white arrow) represent natural variability without loss of key defining features, while transitions across broken lines (e.g. grey arrow) to states D, E, F and G represent collapse and replacement by novel ecosystems. Progression along different pathways of collapse is assessed with variables $\mathrm{X}$ and $\mathrm{Y}$, or other ecosystem-specific diagnostic variables that reflect the loss of characteristic native biota and function. The outer broken line represents an alternative interpretation of ecosystem collapse in which state $E$ is included within natural variation of the ecosystem type. 
Box 1. Ecosystem collapse in the Aral Sea

The Aral Sea - the world's fourth largest continental water body - is fed by two major rivers, the Syr Dar'ya and Amu Dar'ya (Aladin \& Plotnikov, 1993). Its characteristic native biota includes freshwater fish (20 species), a unique invertebrate fauna (>150 species) and shoreline reed beds, which provide habitat for waterbirds, including migratory species (Keith et al., 2013).

Hydrologically, the sea was approximately stable during 1911-1960, with inflows balancing net evaporation (Micklin \& Aladin, 2008). Intensification of water extraction to support expansion of irrigated agriculture lead to shrinkage and salinisation of the sea. By 2005, only 28 aquatic species (including fish and invertebrates) were recorded, reed beds had dried and disappeared, the sea had contracted to a fraction of its former volume and surface area, and salinity had increased tenfold (Micklin \& Aladin, 2008).

Consistent with the definition of ecosystem collapse, these changes suggest the Aral Sea has undergone a transformation of identity, lost many of its defining features (aquatic biota, reed beds, waterbirds, hydrological balance and brackish hydrochemistry) and has been replaced by novel ecosystems (saline lakes and desert plains). Under this interpretation, collapse occurred before the volume and surface area of standing water declined to zero. Although the exact point of ecosystem collapse is uncertain, time series data for several variables are suitable for defining a functional reference state (prior to onset of change from 1960) and a bounded threshold of collapse, assuming this occurred sometime between 1976 and 1989 when most biota disappeared (Keith et al., 2013).

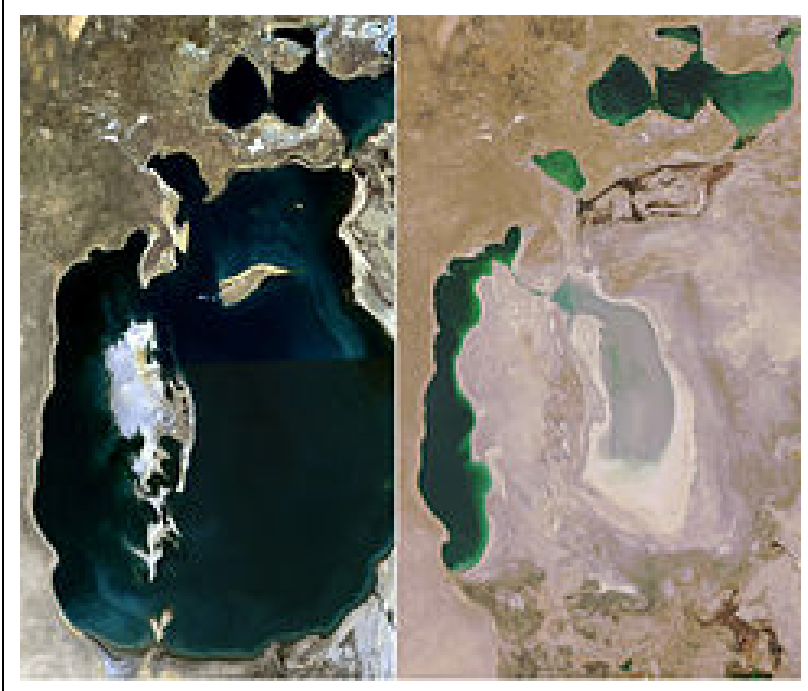

The choice of available variables for assessing the status of the ecosystem will depend on how closely they represent the ecosystem's defining features, the quantity and quality of the data, and the sensitivity of alternative variables to ecological change. Of those listed above, fish species richness and abundance may be the most proximal biotic variable to the features that define the identity of the Aral Sea ecosystem. Sea volume may be a reasonable abiotic proxy, because volume is functionally linked with salinity, which in turn mediates persistence of the characteristic freshwater/brackish aquatic fauna. Sea surface area is less directly related to these features and processes, but can be readily estimated by remote sensing and may be useful for assessment when data are unavailable for other variables.

Collapse of the Aral Sea ecosystem may or may not be reversible. While it may be possible to restore the hydrological regime over a small part of the former sea (Micklin \& Aladin, 2008), some components of the characteristic biota are apparently extinct (e.g. the Aral salmon, Salmo trutta aralensis), preventing reconstruction of the pre-collapse ecosystem. Image: @ NASA 
Risk assessment relies on the definition of an adverse outcome, typically a discrete endpoint or event that affects the asset under evaluation. The implementation of risk assessment confronts uncertainties in two key areas: the definition of the asset itself, and the definition of the endpoint. The boundary which delineates an ecosystem type may be uncertain due to imperfect knowledge of natural variability within the ecosystem, continuous patterns of variability with other ecosystems, and changes in ecosystem classification through time, as well as uncertainties associated with mapping distributions (Keith et al., 2013). Defining ecosystem collapse is also subject to uncertainty which can affect the estimation of spatial and functional symptoms of collapse (Fig. 3). All applications the IUCN Red List of Ecosystems Categories and Criteria should consider these sources of uncertainty and discuss them in the assessment documentation. Examples of how uncertainties can be dealt with through the assessment process are described below, acknowledging that uncertainties in spatial and functional systems are often related.

\section{Uncertainty in spatial symptoms}

During decline, an ecosystem may transition to collapsed state(s) in some parts of its distribution before others. In areas where these transitions have occurred, the ecosystem may be described as 'locally collapsed'. Spatially, an ecosystem is considered collapsed when all extant occurrences of the ecosystem have collapsed (i.e. area of occupancy $=0$ $10 \times 10 \mathrm{~km}$ grid cells and extent of occurrence $=0 \mathrm{~km}^{2}$ ). To quantify past declines in distribution and declines in function, assessors must identify where the ecosystem type is currently extant, and where it was previously extant (within the time frame of assessment) and is now in a collapsed state. Similarly, to quantify future declines in distribution and function, assessors must project the area in which the ecosystem will collapse during the future time frame of the assessment. All of these estimations and projections involve uncertainties. Epistemic uncertainty (i.e. uncertainty due to a lack of knowledge, as opposed to inherent uncertainty due to variability in the system) exists due to a range of measurement and classification errors:

1. Thematic uncertainties caused by decisions relating to the threshold at which an ecosystem type is considered to have moved outside of its natural bounds of variability, and must then be considered a different ecosystem type (Payet et al., 2013).

2. Measurement error due to imperfect measurements or mapping techniques resulting in area estimates that are not precisely repeatable and randomly fluctuate (Elith et al., 2002; Olofsson et al., 2014; Fuller et al., 2003).

3. Systematic error due to mapping methods that consistently produce biased area estimates (Congalton \& Green, 2008).

4. Classification errors that result in misclassification of pixels in a distribution map, generally termed omission or commission errors (Congalton \& Green, 2008; Foody, 2011). 
5. Errors of scale where the grain size at which an ecosystem is mapped results in area estimates that are dependent on the scale at which they are mapped (Hartley \& Kunin, 2003; Gaston \& Fuller, 2009).

\section{Uncertainty in functional symptoms}

A collapsed ecosystem may be replaced by a novel ecosystem with strongly contrasting features. When grasslands replace forests, the change in vegetation structure is readily detected by a range of proximal and remotely sensed methods. In other cases, ecosystems may lose defining features and collapse, but the novel system may resemble the antecedent one, making symptoms of collapse more difficult to detect. Burns et al. (2015) describe an example of a forest ecosystem characterised by biota associated with large old trees. When densities of large old trees fall below a critical level, characteristic native biota is lost from the system. This includes birds and mammals that nest or shelter in tree hollows, and invertebrates that live under loose bark and in deep leaf litter beds. After such transitions, the novel ecosystem still retains a forest structure, albeit one characterised by smaller trees and lacking biota associated with large trees. Similarly, Barrett \& Yates (2015) described collapse of a species-rich shrubland as the elimination of groups of plant species eliminated by a soil-borne disease. The novel ecosystem replacing the antecedent one was a structurally similar, but compositionally and functionally different shrubland. These and other examples illustrate uncertainties in delineating extant and collapsed states, which depend on the features of the antecedent ecosystem, the pathway of collapse, and the features of the novel ecosystem. Sources of uncertainty include:

1. Definition of reference ecosystem states, and the natural variability within those.

2. Definition of collapsed ecosystem states, which represent critical deviations from natural variability. Transition points from original to novel ecosystems are inherently uncertain but can be estimated within plausible bounds (Fig. 3). The first value represents no doubt that the ecosystem has collapsed, whereas the second is a plausible value based on observations or inferences.

3. Variation in collapsed states caused by different threatening processes. Catastrophic threats may cause total functional and spatial collapse of the ecosystem. Other threats, such as environmental degradation or the spread of invasive species may cause different functional changes in characteristic biota. These different pathways of collapse should be reflected within the risk assessment.

4. Uncertainty in the measurement of variables representing ecosystem function and collapse. As with spatial variables, measurement error in functional variables may affect the assessment of ecosystem collapse through random errors or systematic bias. 

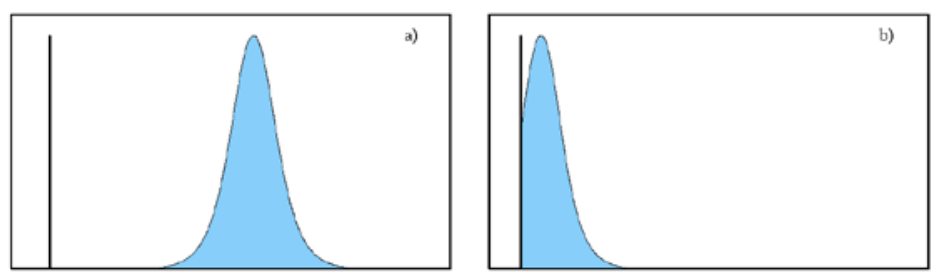

-.. Uncertain quasi-extinction threshold

...... Uncertain collapse threshold

口 Probability that variable is definitely

greater than threshold

Probability that variable may be
greater than threshold
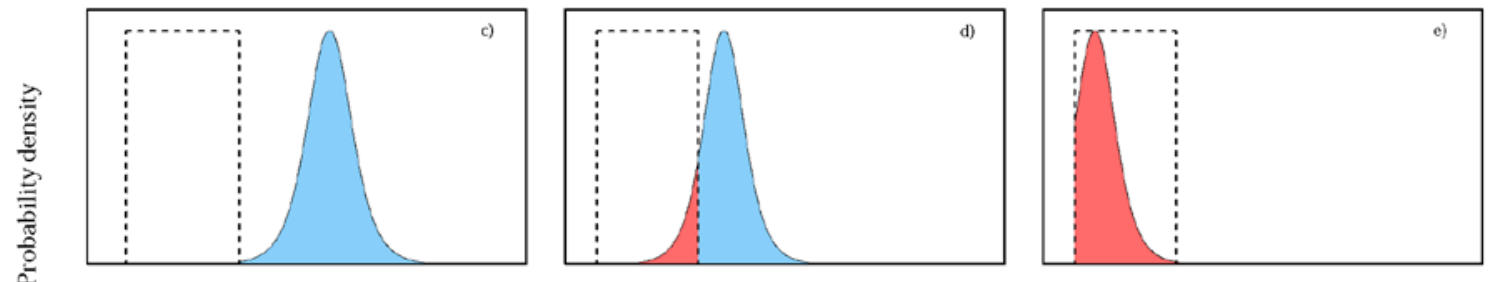

Population variable
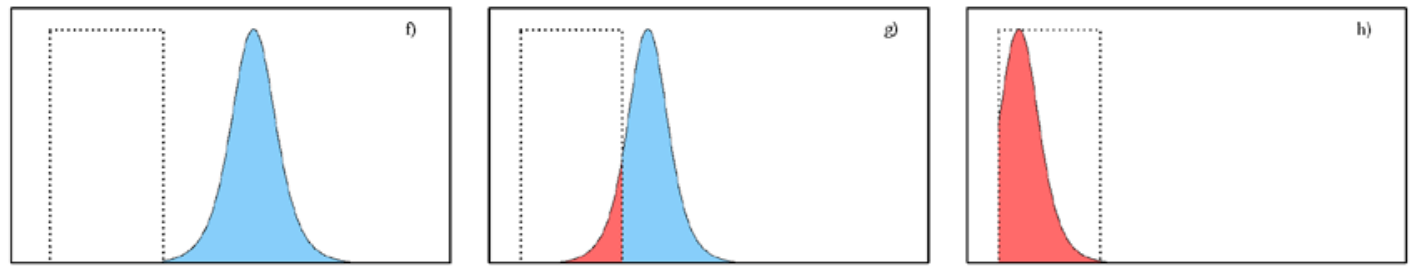

Ecosystem variable

Figure 3. Probability density functions for the population and ecosystem variables that measure proximity to the thresholds that define species extinction $(a, b)$, species quasiextinction (c-e), and ecosystem collapse (f-h). For species, the population threshold that defines extinction is known with certainty (e.g. zero abundance, described by the vertical line in (a) and (b)). In practice, Population Viability Analyses are calibrated on a quasi-extinction threshold higher than the extinction threshold, to account for prediction and management uncertainty. A lower bound on the value of extinction (zero abundance), and a putative upper bound for the value of quasi-extinction can be depicted as a dashed box (c-e). For ecosystems (f-h) the $\mathrm{x}$-axis could represent key features or processes (e.g. spatial distribution, number of species, water quality). The bounded definition of collapse is analogous to the definition of quasi-extinction in species. The width of the dashed box represents uncertainty in the collapse definition. The blue area represents the probability that the ecosystem is definitely extant, whereas the red area represents the probability that the ecosystem may be extant (adapted from Keith et al., 2013). 


\subsection{Risk assessment protocol}

The RLE protocol comprises five rule-based criteria for assessing risks to ecosystems. Risks to ecosystems may be caused by a variety of threatening processes that are expressed through different symptoms of ecosystem collapse (Keith, 2015). The RLE protocol groups symptoms of ecosystem collapse into four major types and identifies the corresponding mechanisms that link the symptoms to the risk that an ecosystem will lose its defining features (Fig. 4). Two of the four mechanisms produce distributional symptoms: (A) declines in distribution, which reduce carrying capacity for dependent biota; and (B) restricted distribution, which predisposes the system to spatially explicit threats. Two other mechanisms produce functional symptoms: (C) degradation of the abiotic environment, reducing habitat quality or abiotic niche diversity for component biota; and (D) disruption of biotic processes and interactions, resulting, for example, in the loss of mutualisms, biotic niche diversity, or exclusion of some component biota by others. Interactions between two or more of these four contrasting mechanisms may produce additional symptoms of transition towards ecosystem collapse. Multiple mechanisms and their interactions may be integrated into a simulation model of ecosystem dynamics to produce quantitative estimates of the risk of collapse (E). These five groups of symptoms form the basis of the RLE criteria. An ecosystem type under assessment should be evaluated using all of the criteria for which data are available. The overall risk status of the ecosystem type is assigned as the highest category of risk obtained through any criterion.

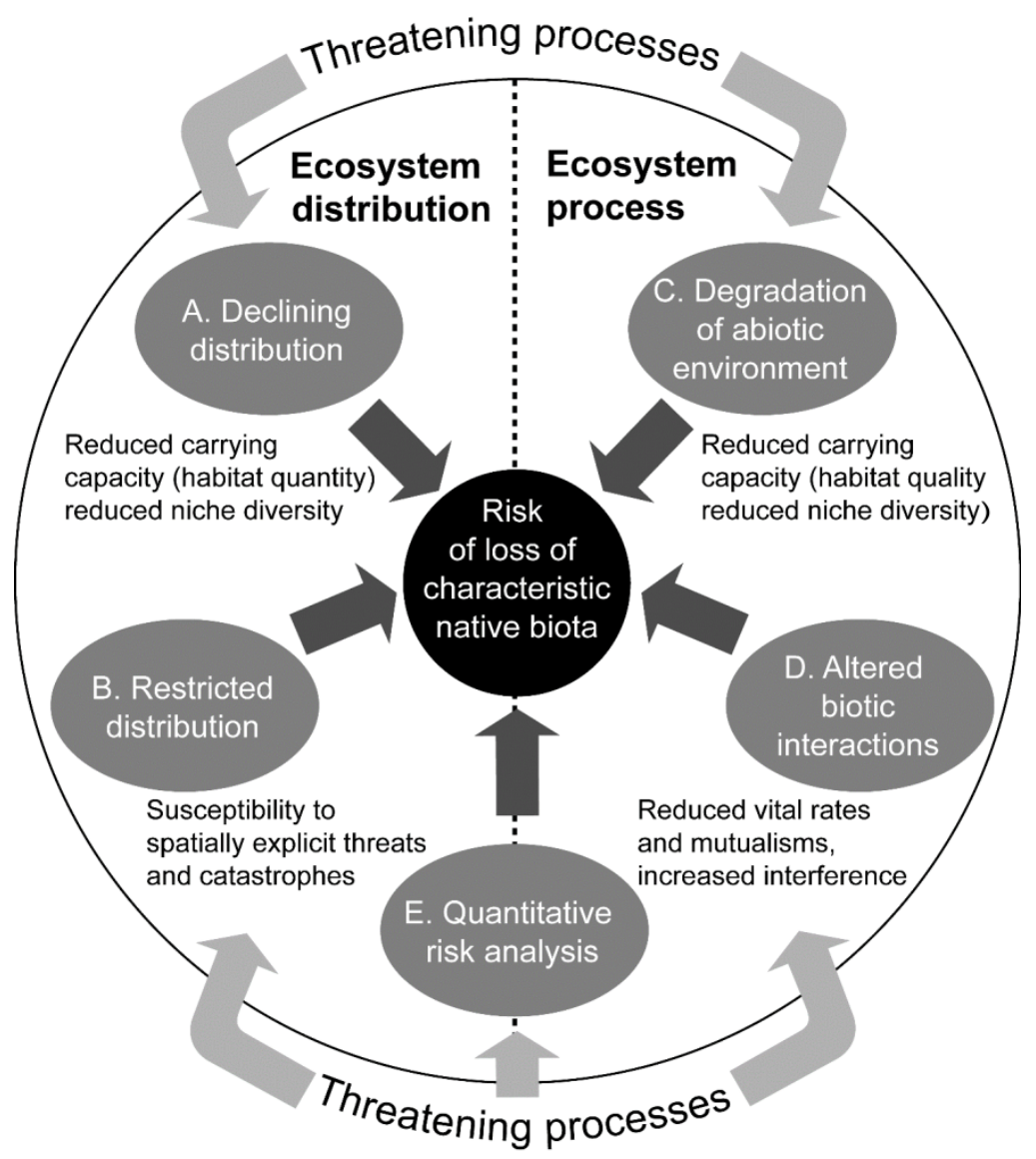

Figure 4. Mechanisms of ecosystem collapse and symptoms of collapse risk (source: Keith et al., 2013). 


\subsubsection{Time frames}

The criteria assess declines over four specified time frames: the recent past, the present, the future, and the historical past (Fig. 5). The 'recent past' time frame encompasses the past 50 years, which is sufficiently recent to capture current trends but long enough to distinguish directional change from natural variability. The RLE protocol assumes that declines over this time frame are indicative of future risk irrespective of cause.

Assessment of future declines requires predictions of changes over the next 50 years or any 50-year period including the present and future (Fig. 5). Past declines may provide a basis for such predictions, but other information may support predictions and inferences about rates of future decline even when the ecosystem is currently stable. Such predictions require a defensible assumption about the pattern of future change (e.g. accelerating, constant, decelerating). Plausible alternative models of change should be explored where appropriate, but a constant proportional rate of decline is often a reasonable default assumption (Section 5).

Assessments of historical declines are essential for ecosystems containing biota with long generation lengths and slow population turnover (Mace et al., 2008). They are also essential for foundation species with short generation lengths which may have suffered extensive historical declines (e.g. oyster reefs: Kirby, 2004; Beck et al., 2011). Even where future rates of decline abate, historical reductions in distribution or function may predispose an ecosystem to additional threats and reduce its ability to absorb adverse changes (Folke et al., 2004). Historical declines are assessed relative to ecosystem status at a notional reference date of 1750 , corresponding approximately to the earliest onset of industrial-scale exploitation of ecosystems. In parts of the world where industrial-scale exploitation of ecosystems commenced earlier or later than 1750 , it is justifiable to assess historical declines with a different baseline. Distribution models with environmental predictors may be used to estimate historical declines based on the difference between the current state of an ecosystem and its expected state in the absence of industrial-scale anthropogenic effects. Such approaches are most useful in regions where landscape-scale change did not occur before the industrial era. 


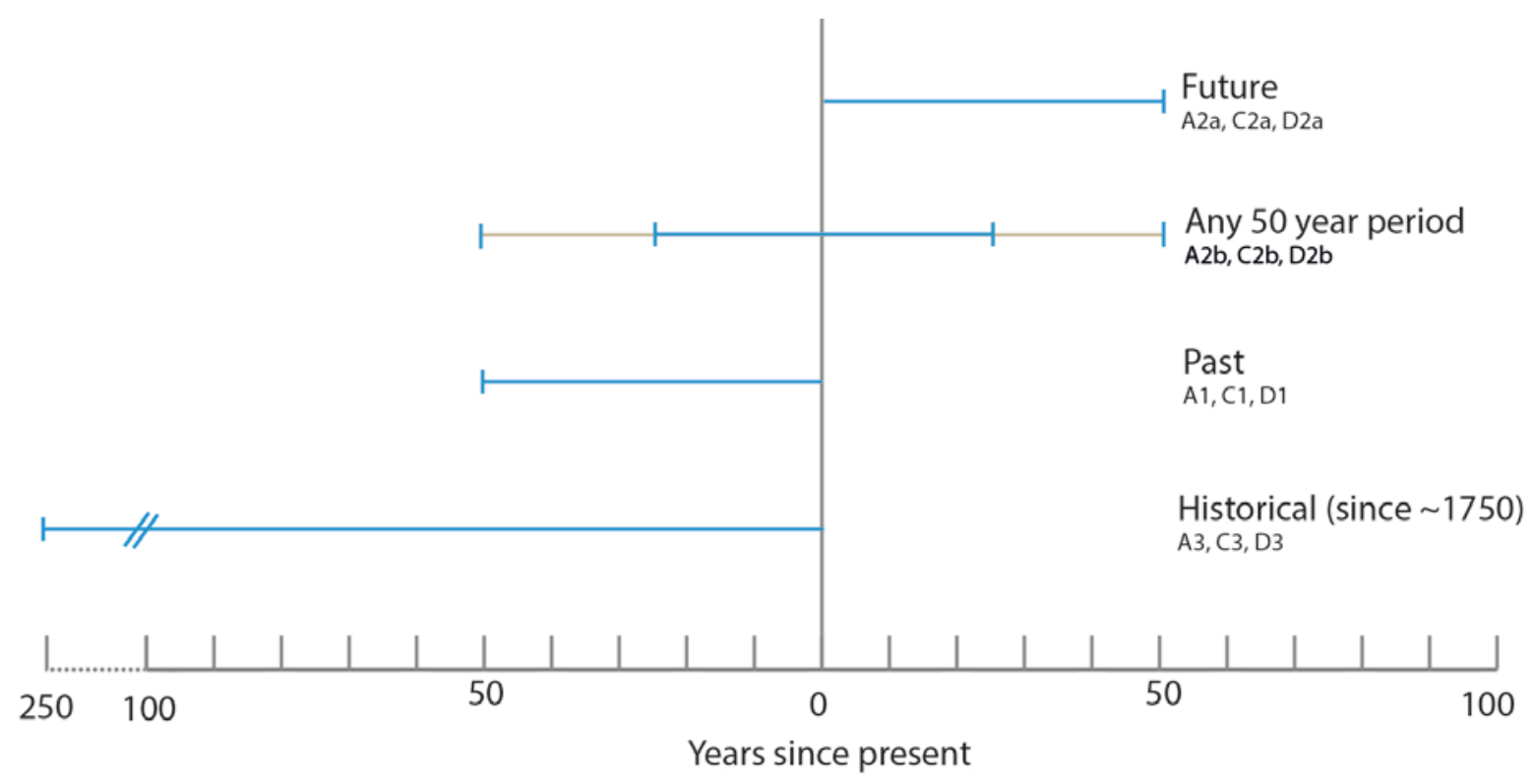

Figure 5. Time frames for assessment of change under criteria $A, C$, and $D$ (adapted from Keith et al., 2013).

\subsubsection{Decline thresholds}

The ordinal categories of risk (Section 3) are delimited by thresholds defined in the IUCN Red List of Ecosystems Categories and Criteria (Appendix 2). The rationale for the criteria and ordinal categories is grounded in theory (Keith et al., 2013). However, the threshold values that delimit categories are based partly on theoretical considerations and partly on utilitarian considerations (Keith et al., 2015). Theory provides a qualitative basis for ordered thresholds for decline, but offers limited guidance for setting their absolute values. The purpose of these decision thresholds is to rank ecosystems in informative ordinal categories of risk, rather than estimate precise probabilities of collapse. Consequently, for criteria A, C, and $D$, threshold values were set at relatively even intervals for current and future declines in ecosystem distribution or function (Vulnerable: $30 \%$, Endangered: $50 \%$, Critically Endangered: 80\%). The range of thresholds between 0 and $100 \%$ seeks to achieve an informative rather than highly skewed ranking of ecosystems among categories. The lowest threshold for a threatened ecosystem type (30\%) recognises that evidence of an appreciable decline in ecosystem distribution or function is necessary to support listing in a threatened category. These thresholds are consistent with thresholds for population reduction in The IUCN Red List of Threatened Species (IUCN, 2001, 2012). Thresholds for historical declines are higher (A3, C3, D3; 50\%, 70\%, 90\%) because times frames for assessment are longer.

Declines within $5-10 \%$ of thresholds for the Vulnerable category may warrant listing as Near Threatened, although there are no quantitative thresholds for this category (Section 3). For example, an ecosystem type with an extent of occurrence of 50,000 to $55,000 \mathrm{~km}^{2}$ that qualifies for at least one of the three subcriteria of criterion B could qualify for listing as Near Threatened. An ecosystem type with a decline in an abiotic variable of $20 \%$ to $30 \%$ relative severity and $100 \%$ extent could qualify as Near Threatened under subcriteria C1 or C2. 


\subsubsection{Standards of evidence and dealing with uncertainty}

Achieving a robust and repeatable assessment for an ecosystem type requires extensive data, often from disparate sources. The categories and criteria were specifically designed to allow the inclusion of various data types from a range of sources, but it is the onus of the assessor to critically evaluate whether data quantity and quality are sufficient to support determinate outcome of an assessment. For guidance on this evaluation, assessors are referred to the principles adopted by the Intergovernmental Panel on Climate Change for consistent treatment of uncertainty (Mastrandrea et al., 2010). In summary, key principles include:

1. Evaluating the type (Table 2), amount, quality, and consistency of evidence (summary descriptors: "limited," "medium," or "robust");

2. Evaluating the degree of agreement between different sources of evidence (summary descriptors: "low," "medium," or "high");

3. Providing a traceable account describing the evaluation of evidence and agreement;

4. Evaluating the likelihood (Table 3) of alternative categories as outcomes of an assessment;

5. Communicating the uncertainty in the outcomes of an assessment by reporting the most likely category and as well as categories that represent plausible upper and lower bounds of the assessment outcome (Section 4.4.1).

The standard of evidence for the RLE must be sufficient to support inferences that:

1. Some categories (LC, NT, VU, EN or CR) are 'very unlikely' outcomes of assessment (i.e. probability $<10 \%$, Table 3 ). If no category is a very unlikely outcome of assessment, then the status should be assigned as Data Deficient (DD);

2. The plausible bounds of assessment outcomes include all categories necessary to ensure that collectively they are 'very likely' to encompass the true status (i.e. probability $>90 \%$, Table 3 ). If all categories (LC-CR) are within the plausible bounds, then the status should be assigned as Data Deficient (DD);

3. The best overall status (i.e. categorisation of an ecosystem) is more likely than any alternative categorisation and within the plausible bounds; and

4. All categorisations of overall status in the Collapsed category $(\mathrm{CO})$ are 'virtually certain' (i.e. $>99 \%$ certain, Table 3). Where this is not the case and CO is the most likely category, the best overall status should be assigned to $\mathrm{CR}$, and $\mathrm{CO}$ reported as the upper bound of the assessment outcome. 
Table 2. Descriptors for types of evidence (IUCN, 2001, 2012) will typically support inferences during an assessment. These apply to quantitative variables (such as rates of change in distribution) and binary inferences (such as whether or not there is a continuing decline in distribution).

\begin{tabular}{|c|c|}
\hline Descriptor & Explanation \\
\hline Observed & $\begin{array}{l}\text { Information that is directly based on well-documented records of all known } \\
\text { occurrences of the ecosystem (IUCN Standards and Petitions Subcommittee, } \\
\text { 2014). }\end{array}$ \\
\hline Estimated & $\begin{array}{l}\text { Information that is based on calculations that may include statistical assumptions } \\
\text { about sampling, or biological assumptions about the relationship between an } \\
\text { observed variable and the variable of interest (e.g. relationship between an index } \\
\text { of abundance and the number of mature individuals; IUCN Standards and } \\
\text { Petitions Subcommittee, 2014). These assumptions should be stated and } \\
\text { justified in the assessment documentation. Estimation may also involve } \\
\text { interpolation in time to calculate the variable of interest for a particular time step } \\
\text { (e.g. a } 50 \text {-year reduction in distribution based on observations of distribution } 40 \\
\text { and } 60 \text { years ago). }\end{array}$ \\
\hline Inferred & $\begin{array}{l}\text { Information that is based on indirect evidence and on variables that are indirectly } \\
\text { related to the variable of interest, but in the same general type of units (IUCN } \\
\text { Standards and Petitions Subcommittee, 2014). Inferred values rely on more } \\
\text { assumptions than estimated values. For example, inferring disruption of biotic } \\
\text { interactions from catch statistics not only requires statistical assumptions (e.g. } \\
\text { random sampling) and biological assumptions (about the relationship of the } \\
\text { harvested section of the population to the total population), but also assumptions } \\
\text { about trends in effort, efficiency, and the spatial and temporal distribution of } \\
\text { harvest in relation to the population. Inference may also involve extrapolating an } \\
\text { observed or estimated quantity from known ecosystem occurrences to calculate } \\
\text { the same quantity for other occurrences. Whether there are enough data to } \\
\text { make such an inference will depend on how large the known occurrences are as } \\
\text { a proportion of the whole distribution, and the applicability of threats and trends } \\
\text { observed in the known occurrences to the rest of the ecosystem. }\end{array}$ \\
\hline Projected & $\begin{array}{l}\text { Same as estimated, but the variable of interest is extrapolated in time towards } \\
\text { the future (IUCN Standards and Petitions Subcommittee, 2014). Projected } \\
\text { variables require a discussion of the method of extrapolation (e.g. justification of } \\
\text { the statistical assumptions or the ecosystem model used) as well as the } \\
\text { extrapolation of current or potential threats into the future, including their rates of } \\
\text { change. }\end{array}$ \\
\hline
\end{tabular}


Table 3. Calibrated language for describing quantified uncertainty (source: Mastrandrea et al., 2010). It can be used to express a probabilistic estimate of a quantity, a binary inference or an assessment outcome (e.g. a magnitude of change in distribution, whether or not there has been a change, whether the status of an ecosystem is within a given range). Likelihood may be based on statistical or modelling analyses, elicitation of expert views, or other quantitative analyses. The categories defined in this table can be considered to have "fuzzy" boundaries (Kauffman \& Gupta, 1991).

\begin{tabular}{|ll|}
\hline Term & $\begin{array}{l}\text { Likelihood of outcome } \\
\text { (probability) }\end{array}$ \\
\hline Virtually certain & $99-100 \%$ \\
\hline Very likely & $90-100 \%$ \\
\hline Likely & $66-100 \%$ \\
\hline More likely than not & $50-100 \%$ \\
\hline About as likely as not & $33-66 \%$ \\
\hline Unlikely & $0-33 \%$ \\
\hline Very unlikely & $0-10 \%$ \\
\hline Exceptionally unlikely & $0-1 \%$ \\
\hline
\end{tabular}




\section{Assessment process}

Assessing an ecosystem type against the IUCN Red List of Ecosystems Categories and Criteria is a sequential process. All components must be completed before submission of the assessment (Fig. 6).

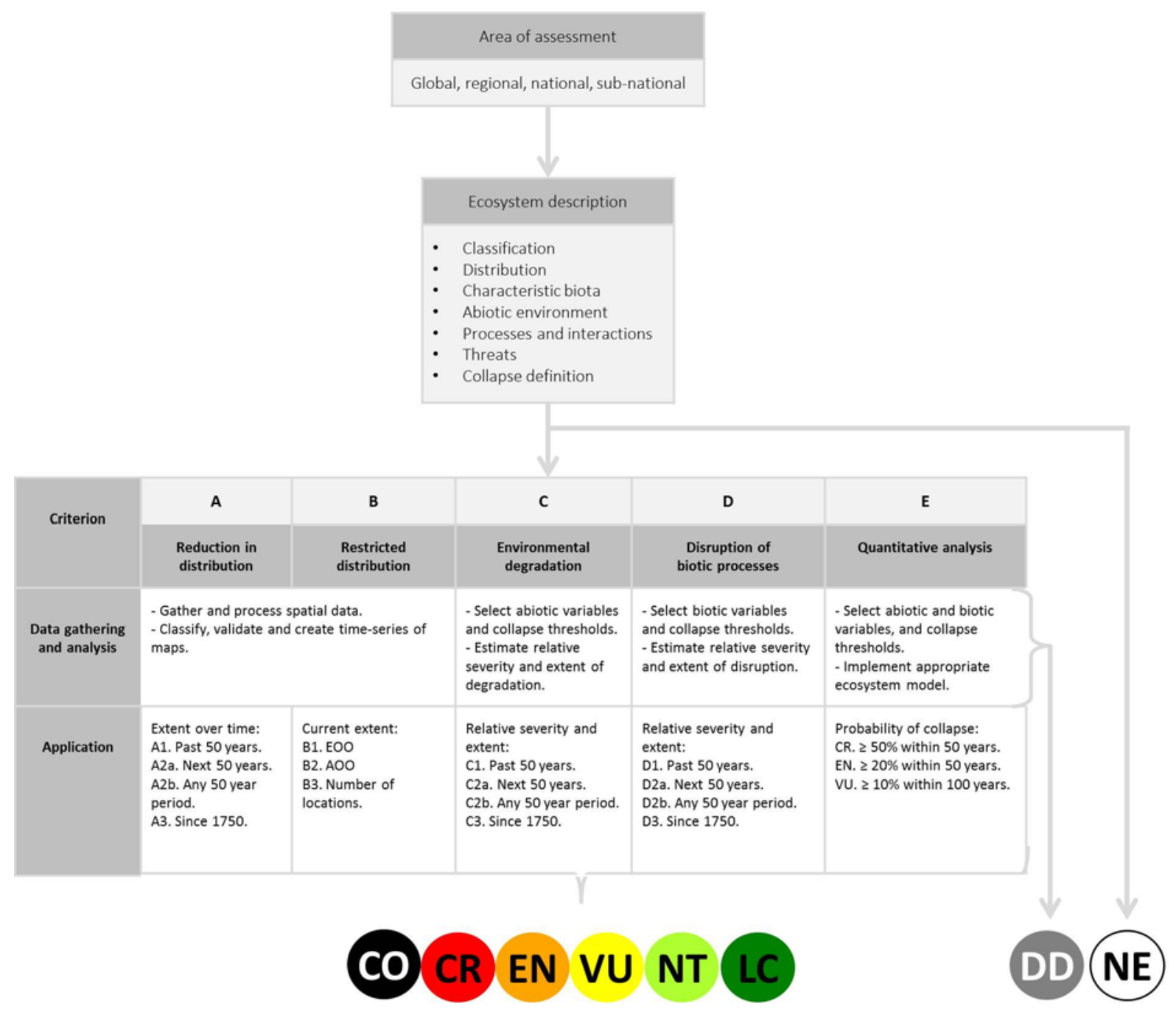

Figure 6. Process for assessing the risk of collapse of an ecosystem type. 


\subsection{Area of assessment}

Red List of Ecosystems (RLE) assessments may be undertaken within different geographic areas. Global assessments consider all occurrences of an ecosystem type throughout the world. This is essential for the set of broadly defined ecosystem types that will form the global RLE, and for informing international biodiversity targets and conservation strategies. Sub-global assessments are possible: they are typically defined by political (continental, national or state assessments) or ecoregional boundaries (ocean basins or catchments). Many sub-global lists of ecosystems already exist, such as lists of threatened ecosystems for Germany (Blab et al., 1995), Western Australia (DEC, 2007), Finland (Kontula \& Raunio, 2009), Venezuela (Rodríguez et al., 2010), Austria (Essl \& Egger, 2010), Norway (Lindgaard \& Henriksen, 2011), South Africa (Driver et al., 2012), New Zealand (Holdaway et al., 2012) and El Salvador (Crespin \& Simonetti, 2015), although only the latter used Version 2.0 of the IUCN Red List of Ecosystems Categories and Criteria.

For assessments of sub-global areas, it will usually be appropriate to assess ecosystem types of finer thematic resolution than those for global assessments, as sub-global assessments will usually require finer detail to support land and water use decision-making. For example, a national RLE may have a larger number of more finely divided assessment ecosystem types for a given area, compared to a global-level RLE assessment.

The same ecosystem type may be assigned to different risk categories in sub-global and global assessments. Differences in status depend on the distribution of threatening processes across the range of the ecosystem type in relation to the boundaries of the subglobal assessment. Although regional guidelines for applying the IUCN Red List of Ecosystems Categories and Criteria have not yet been developed, some general rules apply:

1. Comprehensive description of the assessment unit (ecosystem type) is still required. The area of assessment (e.g. political boundaries) must be clearly defined and supported with maps or other spatial data.

2. No modifications of the categories or criteria $A, C, D$ or $E$ are required when making sub-global assessments of ecosystems. Therefore, all thresholds, time frames, definitions and data requirements remain unchanged for sub-global applications of the RLE.

3. Application of subcriterion B1 and its thresholds remains unchanged (Section 5.2). A minimum convex polygon that encloses all occurrences of an ecosystem type is applied, regardless of whether the edges cross the bounds of the area of assessment. No holes or cutting of the minimum convex polygon are permitted, regardless of the bounds of the area of assessment.

4. When the area of assessment is similar to or smaller than the EOO or AOO thresholds for the Vulnerable category, listing of ecosystem types under criterion $B$ will depend solely on meeting the subcriteria. Research to support specific guidelines and tools for applying criterion B in small assessment areas is currently in progress. 


\subsection{Describing the unit of assessment}

To ensure repeatable application of the IUCN Red List of Ecosystems Categories and Criteria, detailed description and definition of the assessment units is an essential component of the assessment process. The description and assessment is based on a comprehensive compilation of all available information about the ecosystem type under consideration. The description of an ecosystem type must provide contextual information on its classification; clearly describe four elements that define the ecosystem type (characteristic native biota; abiotic environment; key processes and interactions; and spatial distribution); and describe the threats and collapsed states.

Assessors should use the description template for ecosystem types (Table 4) and justify why the unit selected for assessment is recognised as a separate ecosystem type from adjacent or similar ecosystem types. What are the key features that distinguish the focal ecosystem type from other ecosystem types? Information supporting the description of the ecosystem type should be included in the assessment documentation, and will be assessed by peer review. It is expected that all submissions to the global RLE will include relevant supporting information including a fully populated reference list, maps, geographic coordinates, exemplar photographs and any other information that will facilitate repeatability of the assessment. These submissions will be openly accessible on the IUCN Red List of Ecosystems website (www.iucnrle.org). 
Table 4. Description template for ecosystem types.

\begin{tabular}{|c|c|}
\hline Elements & Description \\
\hline Classification & $\begin{array}{l}\text { Cross-references to relevant ecological classifications: } \\
\text { a. Source classification. } \\
\text { b. IUCN Habitats Classification Scheme. } \\
\text { c. Ecoregional classifications. }\end{array}$ \\
\hline Spatial distribution & $\begin{array}{l}\text { Describe distribution and extent: } \\
\text { a. Accurate spatial distribution data. } \\
\text { b. Estimates of area. } \\
\text { c. Time series, projections (past, present, future). }\end{array}$ \\
\hline Characteristic native biota & $\begin{array}{l}\text { Identify defining biotic features: } \\
\text { a. Diagnostic native taxa and their relative abundance in } \\
\text { comparison to other ecosystem types. } \\
\text { b. Functional components of characteristic biota and } \\
\text { their roles in the focal system compared to others. } \\
\text { c. Limits of spatial and temporal variability in the } \\
\text { ecosystem biota. } \\
\text { d. Exemplar photographs. }\end{array}$ \\
\hline Abiotic environment & $\begin{array}{l}\text { Identify defining abiotic features: } \\
\text { a. Text descriptions and citations for characteristic states } \\
\text { or values of abiotic variables. } \\
\text { b. Graphical descriptions of abiotic variables. } \\
\text { c. Exemplar photographs. }\end{array}$ \\
\hline $\begin{array}{l}\text { Processes and interactions: } \\
\text { - among biota } \\
\text { - between biota and } \\
\text { environment }\end{array}$ & $\begin{array}{l}\text { Describe key ecosystem drivers: } \\
\text { a. Text descriptions and citations. } \\
\text { b. Conceptual model. } \\
\text { c. Exemplar photographs. }\end{array}$ \\
\hline Threats & $\begin{array}{l}\text { Describe major threats and impacts on ecosystem functioning: } \\
\text { a. Text descriptions and citations. } \\
\text { b. Diagnosis based on IUCN Threats Classification } \\
\text { Scheme. } \\
\text { c. Exemplar photographs. }\end{array}$ \\
\hline Collapse definition & $\begin{array}{l}\text { Describe ecosystem-specific collapsed state(s) and } \\
\text { threshold(s). }\end{array}$ \\
\hline
\end{tabular}

\subsubsection{Classification}

Ecosystem types should be cross-referenced to any relevant ecosystem classifications, including source classifications (such as vegetation classifications for terrestrial systems), ecoregional classifications, and the IUCN Habitats Classification Scheme (www.iucnredlist.org/technical-documents/classification-schemes/habitats-classificationscheme-ver3). Further guidance is available for the use of the IUCN Habitats Classification Scheme. Cross-referencing with the global RLE typology will be required when it becomes available (3.1.1 Ecosystem typologies). 


\subsubsection{Spatial distribution}

Information on the spatial distribution of an ecosystem type is best represented by maps or inventories of locations. They can be derived from remote sensing, biophysical distribution models, field observations or a combination of all three (Box 2). The spatial features of some ecosystems (such as pelagic environments) are inherently dynamic over relatively short time frames, so spatial distributions can only be described at very coarse levels of resolution. Given the diversity of methods and maps available, an important aspect of the description is to justify why a particular spatial dataset is an adequate representation of the ecosystem distribution. Further information on clearly describing the spatial distribution of an ecosystem type is provided in Sections 5.1 and 5.2. Assessors are encouraged to deposit the ecosystem map in a suitable online repository.

Box 2. Distribution map of the Yellow Sea tidal flat ecosystem.

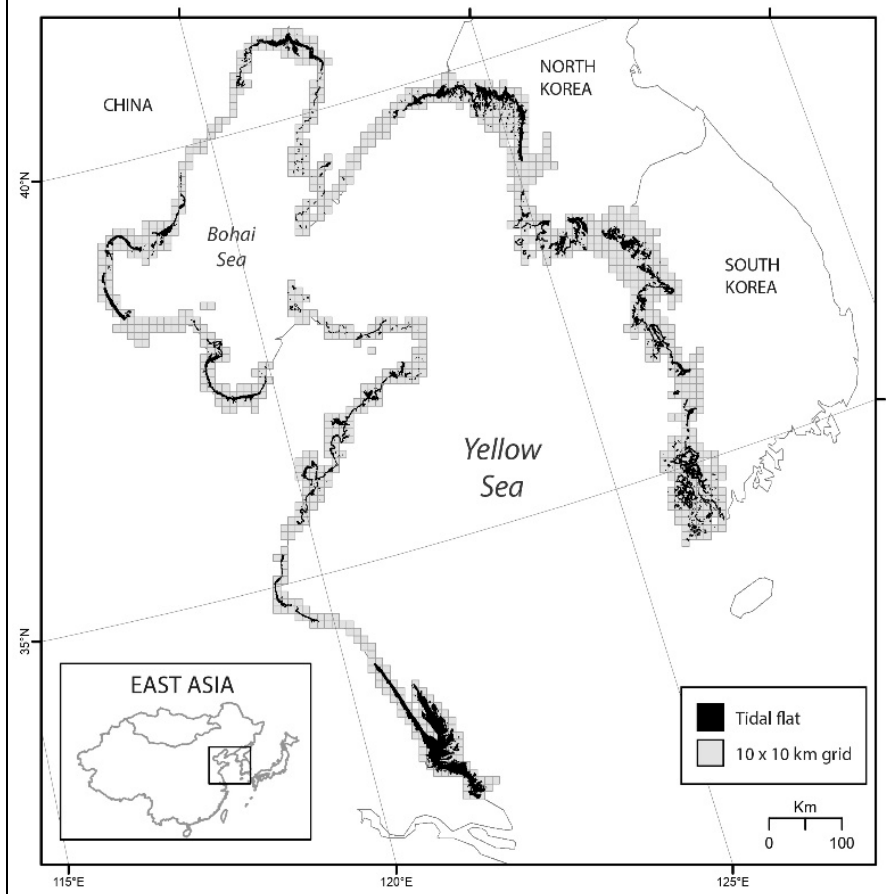

The distribution of the Yellow Sea tidal flat ecosystem was mapped by applying a peer-reviewed remote sensing classification method to Landsat Archive satellite imagery (Murray et al., 2012; Murray et al. 2014; Murray \& Fuller, 2015). The classified map has an overall accuracy of $>94 \%$ when assessed using a confusion matrix, a widely implemented method for assessing the accuracy of classified maps (Murray et al., 2014; Congalton \& Green, 2008). Estimates of the area of the ecosystem type for criterion $A$ are derived from the distribution of the ecosystem (black), whereas the area of occupancy (AOO) is determined by counting the number of $10 \times 10 \mathrm{~km}$ cells in which $>1 \mathrm{~km}^{2}$ of the ecosystem type occurs (Murray et al., 2015).

\subsubsection{Characteristic native biota}

The concept of characteristic native biota is central to ecosystem risk assessment and is therefore an important component of their description (Box 3). The characteristic native biota include the genes, populations, species, assemblages of species and their key interactions that: (i) compositionally distinguish an ecosystem type from others (diagnostic components); and (ii) are central in driving ecosystem dynamics and function, such as ecosystem engineers, trophic or structural dominants, or functionally unique elements (functional components). The diagnostic components of characteristic native biota should demonstrate a level a compositional uniqueness and identify functionally important elements. In general, the description need not include exhaustive species inventories. 
Characteristic native biota are crucial in the diagnosis of ecosystem collapse because they define part of the 'identity' of the ecosystem type. Thus, the loss of characteristic native biota or processes in which they play a functional role signals a transformation of identity, collapse of the ecosystem type and replacement by a novel system.

Characteristic native biota may be defined in terms of taxonomy or functional traits (e.g. guild composition, trait spectra, structural features such as architecture of trees or corals) and excludes exotic species and uncommon or vagrant species that contribute little to ecosystem function. Examples of characteristic native biota include species that are endemic or nearendemic to the ecosystem type, predators that structure the animal communities, tree species that create microclimates in their canopies or at ground level, reef-building corals and oysters that promote niche diversity for cohabiting fish and macro-invertebrates, nurse plants and those that provide sites for predator avoidance, burrowing animals, guilds of nitrogen fixers, key dispersal agents responsible for movement of biota or resources, peatforming plants, detritivore guilds, and flammable plants that promote recurring fires.

Box 3. Describing characteristic native biota (adapted from Appendix S2 in Keith et al., 2013).

Raised Bogs, Germany

This ecosystem type is characterised by vegetation dominated by peat mosses (e.g. Sphagnum magellanicum, Sphagnum fuscum) and insectivorous plants like sundew (Drosera sp.). The dominance by peat mosses together with geomorphic and hydrological processes distinguishes raised bogs from other ecosystem types. Other typical species for raised bogs in Germany are the vascular plants bog-rosemary (Andromeda polifolia) and cranberry (Vaccinium oxycoccos), the butterfly species Boloria aquilonaris (Cranberry Fritillary), the moth Carsia sororiata (Manchester Treble-Bar) and the ground beetle Agonum ericeti (Blab et al., 1995).

\section{Great Lakes Alvar, North America}

This ecosystem type is characterised by a variable physiognomy, from open perennial (rarely annual) grassland or shrubland and nonvascular pavement (5-25\% herb and or shrub cover) to dense grassland or shrubland (>25\%) with scattered evergreen needleleaf (more rarely broad-leaf deciduous) trees (Reschke et al., 1999; Catling \& Brownell, 1995). Species composition contains a mix of tallgrass prairie graminoids and forbs and sub-boreal to boreal shrubs and trees. Key dominants and differentials include the perennials Schizachyrium scoparium, Sporobolus heterolepis, Danthonia spicata and Deschampsia caespitosa; less commonly with Sporobolus neglectus, Sporobolus vaginiflorus, and Panicum philadelphicum. Key shrubs, when present, are Juniperus communis, J. horizontalis, Dasiphora fruticosa ssp. floribunda and Rhus aromatica. Trees, when present, include Thuja occidentalis, Picea glauca, Pinus banksiana, and Abies balsamea (in more northern sites) and Juniperus virginiana, Quercus macrocarpa or Quercus muehlenbergii (more southern sites).

Giant Kelp Forests, Alaska

Alaskan kelp forests are structurally and functionally diverse assemblages. They are characterised by species of brown algae in the Order Laminariales including Nereocystis luetkeana, Laminaria groenlandica, Alaria fistulosa, Agarum fimbriatum and Thalassiophyllum sp. (Steneck et al., 2002). These create a complex and dynamic layered forest architecture up to $15 \mathrm{~m}$ tall that provides substrate, shelter and foraging resource for a diverse fauna assemblage of epibenthic invertebrate herbivores and pelagic vertebrate predators (Steneck \& Watling, 1982; Estes et al., 2009). Characteristic invertebrates include urchins, Strongylocentrotus franciscanus, S. purpuratus and S. droebachiensis, limpets, and starfish, Solaster spp. Fish, including the Pacific cod (Gadus 
macrocephalus) and rock greenling (Hexagrammos lagocephalus, are important predators that depend directly or indirectly on the ecosystem (Reisewitz et al., 2006). Characteristic mesopredators include sea otters, (Enhydra lutris), harbour seals (Phoca vitulina), Steller sea lions (Eumetopias jubatus) and northern fur seals (Callhorinus ursinus). Steller's sea cow (Hydrodamalis gigas), now extinct, was a functionally unique herbivorous member of the vertebrate assemblage (Domning, 1972). Large pelagic predators are also important components of the ecosystem, including killer whales (Orcinus orca) and over 15 species of great whales including sperm (Physeter macrocephalus) and fin whales (Balaenoptera physalus). Kelp forests are generally separated geographically by continental land masses or deep sea. The Alaskan kelp forests are continuous with those of California, but differ compositionally in their more diverse assemblage of macroalgae, including Macrocystis pyrifera.

Shallow under-ice benthic invertebrate communities, Antarctica (source: Clark et al., 2015) Under-ice communities are typically composed of a mix of sessile suspension feeders and mobile macro-invertebrates, elements of which are reminiscent of deep-sea fauna but occur at depths as shallow as a few metres. Sessile fauna include Porifera (Demospongia, Hexactinellida, Calcaria), Gorgonaria, Pennatularia, Alcyonaria, Stolonifera, Hydrozoa, Actiniaria, Bryozoa, Brachiopoda, Polychaeta, and both solitary and colonial Ascidiacea (Dayton, 1990; Gili et al., 2006). Dominance of some sessile taxa is known to occur at local scales, such as by sponges (Dayton, 1979, McClintock et al., 2005) and ascidians (pers. obs). Fauna with fragile skeletons are distinctly abundant, which is thought to be due to the lack of durophagous (skeleton crushing) predators (Aronson \& Blake, 2001) but may also relate to low wave energy in ice-protected coasts. Mobile invertebrates occur with these sessile fauna or can dominate in some areas. Commonly occurring taxa include Echinodermata (Echinoidea, Asteroidea, Ophiuroidea, Holothurioidea) and Peracarida (Amphipoda, Isopoda, Tanaidacea, Mysidacea, Cumacea) both of which are very successful in Antarctica and can exhibit high abundances or dominance of particular species. Other common mobile epifauna include Pycnogonida, Ostracoda, Caridea, Teleostei, Prosobranchia, Opisthobranchia, Polyplacophora, Bivalvia and Nemertinea (Dayton, 1990; Gili et al., 2006). Many of these are symbionts and use sessile invertebrates as habitat, including specialised predators such as nudibranches, asteroids, and gastropods. Some fauna such as the pycnogonids display gigantism, where individuals grow to much larger sizes than related taxa in non-polar regions (Chapelle \& Peck, 1999).

\subsubsection{Abiotic environment}

Descriptions should identify salient abiotic features that influence the distribution or function of an ecosystem type, define its natural range of variability, sustain its characteristic native biota, and differentiate it from other systems. For terrestrial ecosystems, salient abiotic features may include substrates, soils and landforms, as well as ranges of key climatic variables, while those of freshwater and marine ecosystems may include key aspects of water regimes, light regimes, tides, currents, climatic factors and physical and chemical properties of the water column (Box 4). 
Box 4. Describing the abiotic environment (adapted from Appendix S2 in Keith et al., 2013)

Gnarled Mossy Cloud Forest, Lord Howe Island, Australia (source: Auld \& Leishman, 2015)

The Lord Howe Island Gnarled Mossy Cloud Forest occurs on the summit plateau and ridgetops of two mountains on Lord Howe Island. The climate is temperate, and sea level parts of the island have a mean annual temperature of $19.2^{\circ} \mathrm{C}$, ranging from $17^{\circ} \mathrm{C}-25^{\circ} \mathrm{C}$ in summer to $14^{\circ} \mathrm{C}-18^{\circ} \mathrm{C}$ in winter (Mueller-Dombois \& Fosberg, 1998). At sea level, average annual rainfall is $1,717 \mathrm{~mm}$, with a maximum of 2,886 mm and a minimum of $998 \mathrm{~mm}$ (Mueller-Dombois \& Fosberg, 1998). Temperature decreases with altitude in the southern mountains $\left(0.9^{\circ} \mathrm{C}\right.$ for every $100 \mathrm{~m}$ rise in altitude; Simmons et al., 2012). Cloud forests on Pacific islands typically occur between 800 and $900 \mathrm{~m}$ a.s.l. (Meyer, 2011), and on Lord Howe Island, the Gnarled Mossy Cloud Forest ecosystem occurs from 750 to $875 \mathrm{~m}$ a.s.l. The annual rainfall in Gnarled Mossy Cloud Forest is thought to be much higher than at sea level (although this has not been quantified) and spread throughout the year (DECC, 2007). The two southern mountains (Mounts Gower and Lidgbird) obtain significant moisture from both rainfall and direct canopy interception of cloud water (horizontal precipitation or cloud stripping), and their peaks are often shrouded in cloud (Auld \& Hutton, 2004). Cloud forests are characterised by increased rainfall and cooler temperatures than forest with no cloud (Jarvis \& Mulligan, 2011), and this is thought to also apply to the Gnarled Mossy Cloud Forest ecosystem (Auld \& Leishman, 2015).

Yellow Sea Tidal Flats, East Asia (source: Murray et al., 2015)

The Yellow Sea is a shallow (mean depth c. $45 \mathrm{~m}$ ), semi-enclosed sea with surrounding geography varying from mountain ranges in South Korea to low-elevation coastal plains across much of the northern and western regions (Healy et al., 2002; MacKinnon et al., 2012). As such, tidal flats in the Yellow Sea are among the largest on Earth; in areas with high tidal amplitude (macrotidal, $>4 \mathrm{~m}$ ) they may attain a width of nearly $20 \mathrm{~km}$ when exposed at low tide (Healy et al., 2002). A key feature of the Yellow Sea tidal flats is the seasonal switching from an erosion- to accretion-dominated system in some areas, depending on the occurrence of the monsoon season (Wang \& Zhu, 1994). The ecosystem is dependent on the continuing operation of a suite of coastal processes that are focused on sediment transport and dynamics. Sediments are transported to tidal flats by coastal and tidal currents, where the deposition process is influenced by factors such as sediment texture and size, occurrence of vegetation, wave dynamics, rainfall and the composition of the benthic community, which facilitates local bioturbation, biodeposition and biotransportation (Wang et al., 2012). Storms, wind and wave action cause seaward erosion of tidal flats, and compaction and subsidence reduce their elevation, so sediment trapping and replenishment are required to offset these processes and maintain tidal flat extent. However, a feature that distinguishes tidal flats in the Yellow Sea from adjacent regions is that the tidal flat ecosystem is largely erosion-dominated, requiring ongoing sediment replenishment and transport to persist (Healy et al., 2002). Therefore, disruption of sediment provision via reduced supply from sources such as rivers, and interruption of sediment transport and deposition mechanisms, are considered the primary processes that lead to degradation of the ecosystem (Wang et al., 2012).

\subsubsection{Processes and interactions}

A qualitative understanding of ecosystem dynamics is essential for assessing risks related to functional declines. Generic mechanisms of ecosystem dynamics can often be inferred from related systems if the ecosystem type under assessment lacks direct studies. For example, pelagic marine systems are typically dominated by trophic interactions in which elements of 
the main trophic levels are known, even if particular predator-prey relationships are not (Estes et al., 2009). Tree and grass dynamics in savannahs across the world are influenced by fire regimes, herbivores and rainfall, although their relative roles may vary among savannah types (Lehmann et al., 2014). All descriptions of ecosystem types should include a narrative account of ecosystem dynamics that addresses key ecological processes defining the identity and behaviour of the ecosystem type and the threats that may cause their loss or disruption.

A conceptual model of key ecosystem dynamics is required for each ecosystem type as part of its assessment. A conceptual model is a diagram of key ecosystem processes and threats, and serves four purposes. First, the creation of a conceptual model compels assessors to think through and clarify their assumptions and understanding of ecosystem processes. Second, the conceptual model provides a basis for conducting the risk assessment, by informing selection of relevant variables for assessing criteria $C$ and $D$ (5.3.3 Application). Third, the conceptual model is a communication tool that effectively summarises key features of an ecosystem type for risk managers, conservation practitioners, peer reviewers and the wider community. Finally, the conceptual model is useful for underpinning the development of a quantitative model for criterion $\mathrm{E}$.

Two types of conceptual models are particularly useful for RLE assessments: cause-effect models and state-and-transition models (Box 5). Cause-effect models depict the interaction and dependencies among model components, such as characteristic biota, the abiotic environment and threats (Box 5a). State-and-transition models depict switches between ecosystem states due to changes in the abiotic environment or ecosystem processes (Box $5 b)$. For example, changes in the average water level determine transitions between the degraded hypersaline and unhealthy hypersaline states in the Coorong lagoon (Appendix S2 in Keith et al., 2013; Lester \& Fairweather, 2011; Lester \& Fairweather, 2009).

A standard visual repertoire can help develop consistent cause-effect models (Fig. 7). Characteristic biota are represented by green hexagons, the elements of the abiotic environment by blue hexagons, biotic processes by green ovals, abiotic processes by blue ovals, and threats by red rectangles. Positive, negative and hypothesised relationships can be represented by appropriate symbols. The use of arrows accompanied by plus and minus signs is discouraged. Distinct ecosystem components functioning together should form part of a compartment. For example, the Gonakier forest in Senegal (Appendix S2 in Keith et al., 2013) can be described by two faunal and floral compartments, driven by abiotic processes that are influenced by threats (Box $5 c$ ).

General guidelines for developing conceptual models for RLE assessments include:

1. Conceptual models of ecosystem types should be complete, unambiguous and easy to understand. They should be consistent with the narrative description of ecosystem processes and functions, and should not introduce elements which have not been described in the narrative. They should focus on processes especially relevant to the application of criteria $C$ and $D$, and to the definition of the collapsed state of the ecosystem type. 
2. Overly complex conceptual models should be avoided, so models will typically include fewer details than the narrative text. Assessors are encouraged to think carefully about the level of complexity and hierarchical organisation of the conceptual model, revisiting the purpose of developing conceptual model described above if necessary. Overall, the least complex model covering all ecosystem processes will be the most appropriate (typically fewer than 12 elements).

3. The inclusion of processes relevant to other ecosystem types (but not to the ecosystem type of interest) is discouraged.

4. Repetition of components and relationships should be avoided.

5. Assessors are encouraged to use the IUCN Threats Classification Scheme to select appropriate threats for their system. The inclusion of generic drivers such as human population growth or economic factors is not recommended.
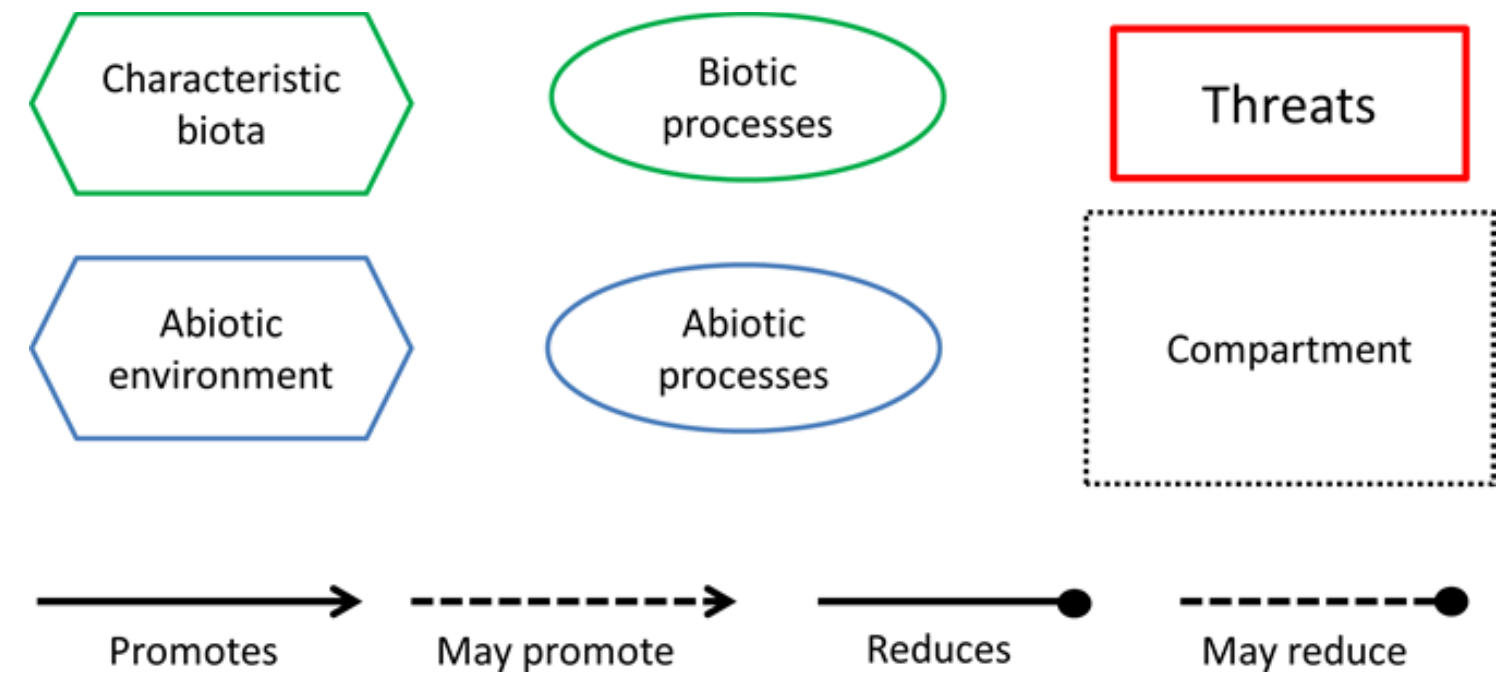

Figure 7. A common visual repertoire for cause-effect models.

Development of the conceptual model may reveal uncertainties in the understanding of ecosystem processes. It may be necessary to draft two or more alternative conceptual model to represent this uncertainty. Refining the model multiple times may help to explore and refine ecosystem processes and clarify the layout of the model. An effort should be made to reach a consensus conceptual model for the ecosystem type, using the narrative text to highlight the greatest sources of uncertainty. When assessing criterion $\mathrm{E}$, it may be useful to include a second, more complex model to describe selected indicators and modelled relationships among components. Tools to assist in construction of conceptual models are in development, including a computer programme to support the development of internally consistent conceptual models. The programme will allow users to save and retrieve conceptual models for a range of ecosystems, use a common visual repertoire and evaluate the effects of threats on ecosystem processes. 


\section{(A) Cause-effect model}

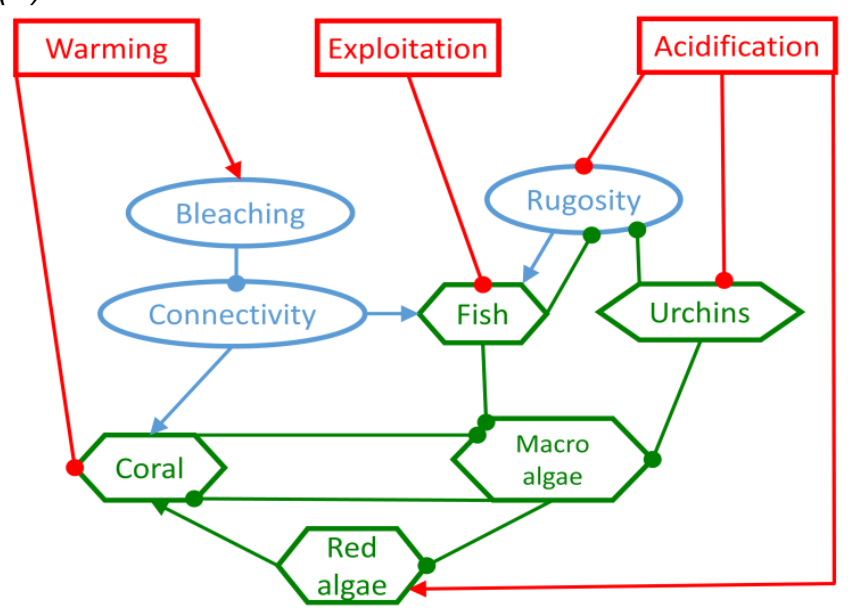

Cause-effect model of a Caribbean coral reef (Appendix S2 in Keith et al., 2013). Warming, pollution, exploitation and acidification are direct threats. Bleaching, rugosity and connectivity are key ecosystem processes. The system alters between coral and algae-dominated patches.
(B) State-and-transition model

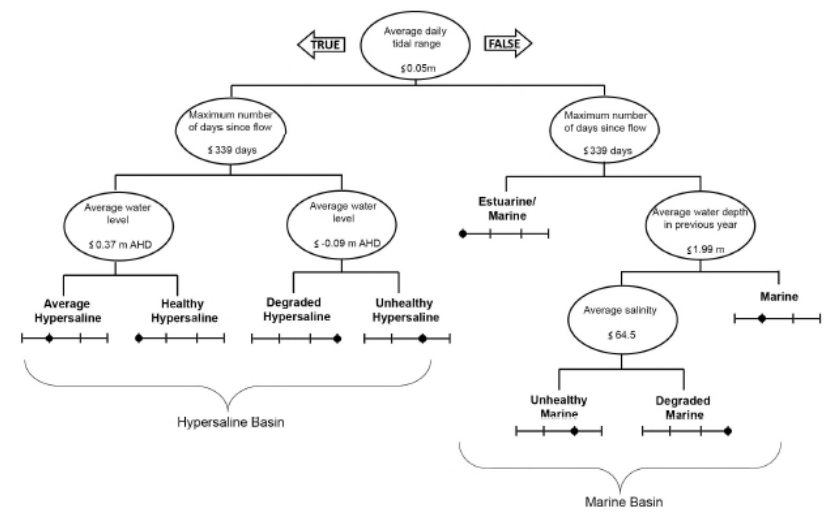

State-and-transition model of the Coorong lagoon in Australia (Appendix S2 in Keith et al., 2013). Average salinity determines shifts between the unhealthy marine and degraded marine states.
(C) Cause-effect model with compartments

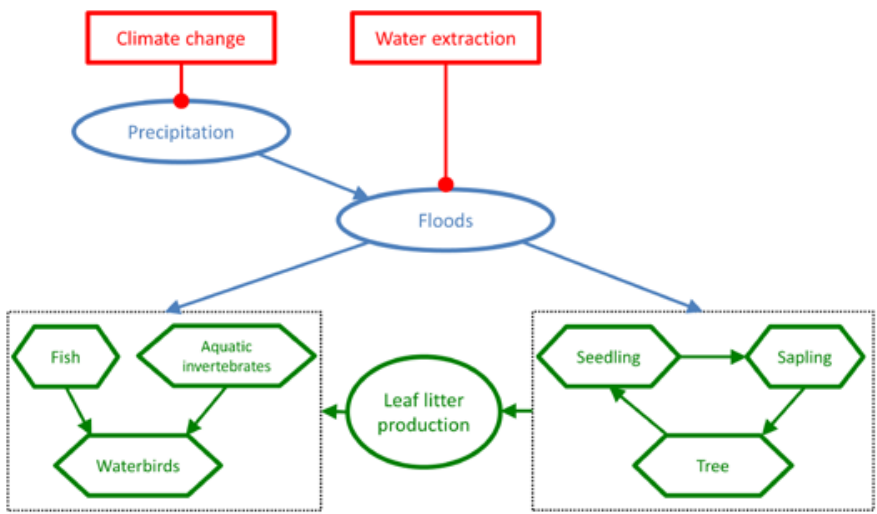

Cause-effect model of the Gonakier forest in Senegal (Appendix S2 in Keith et al., 2013).). The model is composed of two compartments. Forest regeneration depends on floods, and contributes to leaf litter production. Leaf litter production in turn provides nutrients for the aquatic fauna. 


\subsubsection{Threats}

Accompanying the description of an ecosystem type should be a full review of threatening processes that cause ecosystem change. Describing the threats to an ecosystem type requires two elements: (i) a brief description and explanation of the primary threats causing ecosystem change; (ii) identification of threats with reference to the Threats Classification Scheme, used in The IUCN Red List of Threatened Species (IUCN, 2015). When combined, the description of threatening processes and stresses, the threat classification under the IUCN Threats Classification Scheme, and the conceptual model for an ecosystem type will assist in identifying collapsed states and key variables for assessing change in abiotic and biotic function. The framework below (drivers, threats and stresses) outlines how threats affect ecosystems.

\section{Background}

Consistent terms for drivers, threats and stresses are needed for ecosystem assessment (Table 5). A direct threat for one ecosystem type or organism can be an indirect threat for another or pose no threat to other organisms. For example, unsustainable fishing will directly threaten target and by-catch species and may also have indirect effects (negative or positive) on species that prey upon, compete with or are preyed upon by targeted species. This complexity of effects requires careful consideration and definition of threats for each ecosystem type.

Table 5. Definitions of threats, drivers and stresses (Salafsky et al., 2008).

\begin{tabular}{|c|c|c|}
\hline Term & Definition & Synonyms \\
\hline Driver & $\begin{array}{l}\text { The ultimate factors, usually social, economic, political, } \\
\text { institutional, or cultural that enable or otherwise add to the } \\
\text { occurrence or persistence of proximate direct threats. There is } \\
\text { typically a chain of drivers behind any given direct threat. }\end{array}$ & $\begin{array}{l}\text { Contributing factors, } \\
\text { underlying factors, } \\
\text { root causes, indirect } \\
\text { threat, pressures }\end{array}$ \\
\hline Threat & $\begin{array}{l}\text { Direct threats are the proximate activities or processes that have } \\
\text { impacted, are impacting, or may impact the status of the } \\
\text { ecosystem being assessed (e.g., unsustainable fishing or } \\
\text { logging). Threats can be past (historical), ongoing, and/or likely } \\
\text { to occur in the future. Natural phenomena are also regarded as } \\
\text { direct threats in some situations. }\end{array}$ & $\begin{array}{l}\text { Direct threats, } \\
\text { sources of stress, } \\
\text { pressures, proximate } \\
\text { pressures, stressors }\end{array}$ \\
\hline Stress & $\begin{array}{l}\text { Stresses are the effects on ecosystem features that are impaired } \\
\text { directly by threats (e.g. reduced abundance of keystone species, } \\
\text { fragmentation of habitat). A stress is not a threat in and of itself, } \\
\text { but rather a degraded condition or symptom of the target that } \\
\text { results from a direct threat. The RLE risk protocol aims to } \\
\text { quantify these symptoms to assess declines towards collapsed } \\
\text { states. }\end{array}$ & $\begin{array}{l}\text { Symptoms, key } \\
\text { degraded attributes. }\end{array}$ \\
\hline
\end{tabular}




\section{Description of threats}

A summary of the main threats currently affecting or likely to affect the ecosystem type is required supporting information for all ecosystem types. The description provides a brief explanation of the major threats (past, present and future), the drivers of those threats, and the resultant stresses or symptoms of the ecosystem. Identifying stresses is highly informative for defining collapsed states and assessing criteria $C$ and $D$. The geographic extent of threats should also be described. Assessors can base their description on regional and/or national threats classifications, but these cannot be used directly within the IUCN Threats Classification Scheme. In cases where a national threats classification must be used, assessors should report both the national designation and the IUCN Threats Classification Scheme. Graphs, figures and exemplary photographs are encouraged to illustrate the impact of threats on the characteristic native biota, physical environment and interactions among them. An example of threats description is provided in Box 6.

\section{Threats Classification Scheme}

The RLE adopts the IUCN Threats Classification Scheme (www.iucnredlist.org/technicaldocuments/classification-schemes/threats-classification-scheme) for consistency with The IUCN Red List of Threatened Species. The Threats Classification Scheme is hierarchical, consisting of three levels with increasing detail, and contains 12 main threat categories. For a RLE assessment, the description of threats to an ecosystem type must correspond with threats from the IUCN Threats Classification Scheme. Coding for the major threats affecting an ecosystem type is required as supporting information for all ecosystem types except where there are no known threats to those assigned to the Data Deficient or Least Concern categories. Assessors should diagnose and record threats to the lowest possible level in the Threats Classification Scheme.

Coding of timing, scope and severity for each major threat is not required but can be provided. If assessors decide to also record minor threats (threats affecting only a very small proportion of the distribution), then it is essential that the timing, scope and severity be described for all of the threats recorded. This will allow major and minor threats to be clearly identified for the ecosystem type and assist higher level analyses of the RLE. Guidance for using the IUCN Threat Impact Scoring System (www.iucnredlist.org/documents/Dec_2012_Guidance_on_Threat_Impact_Scoring.pdf) is available on the The IUCN Red List of Threatened Species website (www.iucnredlist.org). The Threat Impact Scoring System for the RLE is currently under review, so use of the current Threat Impact Scoring System is not required within a RLE assessment at this stage.

Although recording stresses from the IUCN Stresses Classification Scheme (www.iucnredlist.org/technical-documents/classification-schemes/stresses-classificationscheme) for each threat selected is not required, this is highly recommended supporting information for an assessment. This information is useful for demonstrating how threats are impacting ecosystem types listed on the RLE, and may provide useful guidance for policy makers to address ultimate causes. It is possible to record multiple stresses, simply by selecting threat code. 
Box 6. Describing threats

The Coolibah - Black Box Woodlands of south-eastern Australia is a flood-dependent woodland ecosystem type affected by five main threats (Appendix S2 in Keith et al., 2013; NSW Scientific Committee, 2004). Expansion and intensification of agricultural land use has replaced large areas of woodland with crops and pastures in recent decades (Keith et al., 2009). Furthermore, extraction of water from rivers for irrigation has altered flood regimes and their spatial extent, reducing opportunities for reproduction and dispersal of characteristic flora and fauna (Thoms \& Sheldon, 2000; Thoms, 2003; Kingsford \& Thomas, 1995; Kingsford \& Johnson, 1998; Kingsford \& Auld, 2005). Future climate change may also affect the spatial and temporal availability of water in the system. Invasive plants have spread with agricultural intensification and are reducing the diversity and abundance of native biota. Additionally, invasion of the mat-forming forb Phyla canescens reduces the diversity of native ground layer plants (Taylor \& Ganf, 2005). This species has spread rapidly in response to altered water regimes and persistent heavy livestock grazing (Earl, 2003). Finally, overgrazing by feral goats, rabbits and domestic livestock has altered the composition and structure of the woodland vegetation, through selective consumption of palatable native ground layer plants and seedlings of trees and shrubs (Reid et al., 2011; Robertson \& Rowling, 2000). These effects are most marked beneath trees and around watering points where livestock concentrate their activities.

The threats affecting this ecosystem type correspond with five threats (underlined) and their hierarchical categories in the IUCN Threats Classification Scheme:

2. Agriculture \& Aquaculture:

2.1 Annual \& Perennial Non-Timber Crops:

2.1.3 Agro-industry Farming;

2.3 Livestock Farming \& Ranching:

2.3.3 Agro-industry Grazing, Ranching or Farming

7. Natural System Modifications:

7.2 Dams \& Water Management/Use:

7.2.3 Abstraction of Surface Water (agricultural use)

8. Invasive \& Other Problematic Species, Genes \& Diseases:

8.1 Invasive Non-Native/Alien Species/Diseases:

8.1.2 Named Species - Phyla canescens

11. Climate change \& severe weather

11.2 Droughts

The description of threats and stresses underpinned the selection of variables for assessing criteria $C$ and $D$ and clarified their link to collapse of this ecosystem type. Under criteria A and $B$, the ecosystem type was "assumed to have collapsed when its mapped distribution has declined to zero as a consequence of clearing for agriculture". Because flood regimes are fundamental to ecosystem dynamics and water extraction for irrigation is a major threat, median daily river flow was identified as a suitable variable for assessing environmental degradation under criterion $\mathrm{C}$. 


\subsubsection{Describing collapsed states}

Ecosystem collapse is a key concept in the RLE (Section 3.2) and underpins the application of the IUCN Red List of Ecosystems Categories and Criteria. Assessors should describe the collapsed state(s) of an ecosystem, based on the information summarised in the description of the ecosystem type and the conceptual model. If multiple states of collapse are possible (e.g. due to different threats), all of these should be described with similar levels of detail. Descriptions should focus on the key defining features of the ecosystem type. Collapse thresholds for the application of criteria A and B are typically defined as $100 \%$ loss of spatial distribution of the ecosystem type (i.e. $100 \%$ decline under criterion $A$; $E O O=0 \mathrm{~km}^{2}$ and/or $\mathrm{AOO}=$ no $10 \times 10 \mathrm{~km}$ grid cells occupied under criterion $\mathrm{B}$ ). Choosing a different collapse threshold for criterion A or B must be thoroughly justified. Collapse thresholds for the application of criteria C, D, and E should be identified as part of the assessment of those criteria (5.3.3 Application). Assessors are encouraged to provide examples of locally collapsed occurrences of the ecosystem type to support their descriptions of collapsed states.

Box 7. Defining ecosystem collapse

The Mountain Ash Forest of south-eastern Australia is a unique ecosystem dominated by the world's tallest flowering plant species (Eucalyptus regnans). Mountain ash supports a wide range of plant species and a rich array of native mammals and birds, including the Endangered Leadbeater's possum and the Vulnerable yellow-bellied glider (Lindenmayer, 2009). The availability of old-growth forest and natural tree hollows is a critical factor in the survival of cavitydwelling animals (Keith et al., 2013; Burns et al., 2015).

Ecosystem collapse is considered to occur under any of the following (Burns et al., 2015):

1. $100 \%$ of the area where the ecosystem currently occurs is no longer bioclimatically suitable (criterion $\mathrm{C}$ ).

2. The abundance of hollow-bearing trees drops below one per hectare averaged across the entire ecosystem distribution (subcriterion D2 and criterion E).

3. Less than $1 \%$ of old-growth forest remains in the ecosystem (subcriteria D1 and D3).

\subsection{Evaluating the criteria}

Each ecosystem type must be assessed against all of the RLE criteria so far as the available data permit. To assist this purpose, Section 5 provides detailed information on how to gather data, perform an assessment, consider data quality and uncertainty, and document an assessment outcome. At the onset of an assessment, all ecosystem types are considered Not Evaluated (NE) for all criteria. The next step is to determine whether adequate data exist for application of the criteria (Fig. 6), which requires data searches of the scientific literature, unpublished reports, expert opinion, historical accounts, past and present maps, satellite imagery or any other source of relevant data. If an assessor chooses not to apply a criterion, the risk assessment outcome for this criterion remains Not Evaluated. If a reasonable search effort indicates that adequate data are not available to assess under a criterion, the risk 
assessment outcome for this criterion is Data Deficient (DD). The difference between Not Evaluated and Data Deficient is that reporting Not Evaluated for any criterion implies that no attempt was made to obtain relevant data and assess the ecosystem type under that criterion. If a decent attempt was made, but data were not available or inadequate, then Data Deficient should be used. The search efforts for appropriate data should be briefly described.

\subsection{Assessment outcome}

A summary table for each ecosystem type reports the assessment outcome for all criteria (and subcriteria) as well as the overall status (Box 8). There are a total of 20 subcriteria in the IUCN Red List of Ecosystems Categories and Criteria, each of which can be assigned one of the eight risk categories (Fig. 1). The results for all subcriteria under criteria A, B, C, and $\mathrm{D}$, as well as which method was used to assess the subcriteria (i,ii or iii), must be reported during the assessment process.

Some ecosystem types will be Data Deficient or Not Evaluated for some of the subcriteria; this must be included in the summary table (Box 8). If all subcriteria are Data Deficient, the overall outcome of the assessment is Data Deficient. If all subcriteria are Not Evaluated, the overall outcome of the assessment is Not Evaluated. If all subcriteria are either Not Evaluated or Data Deficient, the overall outcome of the assessment is Data Deficient.

Following the precautionary principle and to ensure that the most severe symptoms of risk determine the assessment outcome, the highest risk category obtained by any of the assessed criteria will be the overall risk status of the ecosystem. The main method currently used for representing uncertainty in ecosystem assessment is to use bounded estimates ( 4.4.1 Dealing with uncertainty). The lower bound of the overall status is the highest lower bound across any of the subcriteria that return the same category as the overall status. The upper bound of the overall status is the highest upper bound across any of the subcriteria that return the same category as the overall status. For example, if an ecosystem type qualifies for EN (plausible bounds EN-CR) under criterion B, EN (plausible bounds VU-CR) under criterion $D$, and lower categories under other criteria (e.g. NT under criterion A, LC under criterion $\mathrm{C}$, and DD under criterion $\mathrm{E}$ ), then its overall status will be $\mathrm{EN}$ (plausible bounds VU-CR). 
Box 8. Assessment outcome (adapted from Appendix S2 in Keith et al., 2013)

Caribbean Coral Reefs

Caribbean coral reefs are primarily fringing reefs and bank barrier reefs separated from island and mainland shorelines by reef flats, shallow waters or slightly deeper lagoons (Alevizon, 2010). Due to the difficulties of remotely measuring the distribution of live coral and mosaic marine ecosystems, the ecosystem is listed as Data Deficient under all subcriteria of criterion A. The ecosystem is assessed as Least Concern under all subcriteria of criterion $B$ due to its large extent of occurrence, area of occupancy and number of locations. The data for criterion C are currently under review; at the time of writing, the ecosystem is assessed as Not Evaluated under all subcriteria of criterion C. Data on coral cover and reef rugosity both lead to similar estimates for subcriterion D1: Endangered (plausible range Vulnerable - Critically Endangered). No projections are available for future disruptions to biotic interactions, so the ecosystem is listed as Data Deficient under D2. The ecosystem is listed as Endangered under subcriterion D3 based on historical data. No quantitative analysis has been carried out to assess criterion $\mathrm{E}$, so the status is Not Evaluated under criterion E. The most appropriate overall risk status of Caribbean coral reefs is determined to be Endangered (plausible range Endangered - Critically Endangered).

\begin{tabular}{lllllll}
\hline Criterion & A & B & C & D & E & Overall \\
\hline Subcriterion 1 & DD & LC & NE & EN (VU-CR) & NE & EN (EN-CR) \\
Subcriterion 2 & DD & LC & NE & DD & & \\
Subcriterion 3 & DD & LC & NE & EN & & \\
\hline
\end{tabular}

\section{Coastal Sandstone Upland Swamps of south-eastern Australia}

The Coastal Sandstone Upland Swamps of south-eastern Australia are treeless bogs that form relatively abrupt boundaries with surrounding eucalypt-dominated forests and woodlands that occupy more freely draining soils (Keith \& Myerscough, 1993). They are strongly associated with high rainfall and moisture. Interactions between hydrological processes and fire regimes are crucial to the development of upland swamps and maintenance of their diverse and characteristic biota. To assess potential future decline due to climate change, Keith et al. (2013) used a range of plausible bioclimatic distribution models for the ecosystem to predict its distribution under future climate scenarios. Based on these models and scenarios, the distribution of the ecosystem was projected to decline by 58-90\% (median 74\%) over the next 50 years. The most appropriate status of the ecosystem was therefore determined to be Endangered (plausible range Endangered Critically Endangered) under subcriterion A2. The same distribution models used to assess future change in distribution were also used to assess trends in climatic suitability under criterion $\mathrm{C}$. From 1983 to 2009, the summed abundance of woody re-sprouters declined by a mean of $37 \%$ at $72 \%$ of sampled sites. These are just below the severity and extent thresholds, respectively, for Vulnerable under criterion D1, assuming that zero abundance of re-sprouters marks the point of ecosystem collapse. No data are available prior to 1983, but if current declines were initiated prior to that time, they may exceed the threshold for Vulnerable status. The status of the ecosystem type is likely to be Near Threatened (plausible range Near Threatened - Vulnerable) under subcriterion D1. The most appropriate overall risk status of the Coastal Sandstone Upland Swamps of South-Eastern Australia is Endangered (plausible range Endangered - Critically Endangered).

\begin{tabular}{lllllll}
\hline Criterion & A & B & C & D & E & Overall \\
\hline Subcriterion 1 & LC & EN & LC & NT(NT-VU) & DD & EN(EN-CR) \\
Subcriterion 2 & EN(EN-CR) & EN & EN(EN-CR) & DD & & \\
Subcriterion 3 & LC & LC & DD & DD & & \\
\hline
\end{tabular}




\subsubsection{Dealing with uncertainty}

Uncertainty in any information used to evaluate the criteria should be propagated through the assessment and reported as part of the outcome. Reporting both the most likely risk category and other plausible categories, given the uncertainties in the data, is more useful than simply reporting the most likely category. The simplest means of characterising uncertainty is through bounded estimates. Bounded estimates represent a range of plausible alternative values for a measure. They can take into account uncertainty in thresholds describing collapsed states (Fig. 3 and Box 1), mapped estimates of change in distribution (Box 9), and estimates of variables for measuring relative severity in criteria $C$ and $D$ (Boxes 11 and 12). The upper and lower bounds of an estimate may be propagated through an assessment by repeating the same analysis for the best estimate, and the lower and upper bounds. For example, if the decline in an ecosystem type's distribution is estimated to be between $75-85 \%$ in the last 50 years, it could plausibly be either Endangered (decline between $50-80 \%$ based on the lower bound) or Critically Endangered ( $\geq 80 \%$ based on the best estimate and upper bound) under subcriterion A1. Dealing with uncertainty in ecosystem risk assessment draws largely on the experiences of The IUCN Red List of Threatened Species (Newton, 2010; Regan \& Colyvan, 2000; Akcakaya et al., 2000).

\subsection{Documentation}

All assessments must be accompanied by documentation and supporting information, which should undergo peer review by appropriate experts (6. Peer review and publication), and must be readily available when the assessment is completed (see the_IUCN Red List of Ecosystems website for examples: www.iucnrle.org). All required fields in the online RLE database should also be completed (see the_IUCN Red List of Ecosystems website). The documentation must include the following sections:

1. Summary. A brief abstract ( 200 words) that describes the complete assessment in summarised form, including the area of assessment, the focal ecosystem type and its defining features, threatening processes and the assessment outcome.

2. Ecosystem description. A complete description of the ecosystem type, including the elements listed in Table 4.

3. Risk assessment. This section must include specific information on the application and outcome of each criterion e.g. inferences, statistical analyses and spatial analyses. It should also include a discussion of assumptions, limitations or further data required. Further guidance is available in Section 5.

4. References. A complete reference list showing the sources of information used for the assessment must be provided. 


\section{Criteria and thresholds}

The IUCN Red List of Ecosystems (RLE) risk assessment model includes five criteria for assessing the risk of ecosystem collapse (Table 6). This section outlines the theory, thresholds and subcriteria relevant for the application of each criterion. A summary table of the current IUCN Red List of Ecosystems Categories and Criteria is provided in Appendix 2.

Table 6. Purpose of the IUCN Red List of Ecosystems criteria.

\begin{tabular}{|lll|}
\hline \multicolumn{2}{|c|}{ Criterion } & \multicolumn{1}{c|}{ Purpose } \\
\hline A & Reduction in geographic distribution & $\begin{array}{l}\text { Identifies ecosystems that are undergoing } \\
\text { declines in area, most commonly due to threats } \\
\text { resulting in ecosystem loss and fragmentation. }\end{array}$ \\
\hline B & Restricted geographic distribution & $\begin{array}{l}\text { Identifies ecosystems with small distributions that } \\
\text { are susceptible to spatially explicit threats and } \\
\text { catastrophes. }\end{array}$ \\
\hline C & Environmental degradation & $\begin{array}{l}\text { Identifies ecosystems that are undergoing } \\
\text { environmental degradation. }\end{array}$ \\
\hline D & $\begin{array}{l}\text { Disruption of biotic processes or } \\
\text { interactions }\end{array}$ & $\begin{array}{l}\text { Identifies ecosystems that are undergoing loss or } \\
\text { disruption of key biotic processes or interactions. }\end{array}$ \\
\hline E & $\begin{array}{l}\text { Quantitative analysis that estimates the } \\
\text { probability of ecosystem collapse }\end{array}$ & $\begin{array}{l}\text { Allows for an integrated evaluation of multiple } \\
\text { threats, symptoms, and their interactions. }\end{array}$ \\
\hline
\end{tabular}




\subsection{Criterion A. Reduction in geographic distribution}

\subsubsection{Theory}

A decline in geographic distribution-defined as all spatial occurrences of an ecosystem type-influences its risk of collapse by: (i) reducing the ability of an ecosystem to sustain its characteristic native biota; and (ii) predisposing it to additional threats (Keith et al., 2013). The loss of characteristic native biota due to a declining distribution typically occurs through a combination of reduced carrying capacity, niche diversity, spatial partitioning of resources, and increased susceptibility to competition, predation and threats (MacArthur \& Wilson, 1967; Shi et al., 2010; Harpole \& Tilman, 2007; Hanski, 1998; McKnight et al., 2007). The rate of decline in an ecosystem distribution indicates its trajectory towards collapse, with ecosystem collapse typically occurring when no spatial occurrences of the ecosystem type remain (extent of distribution collapses to zero).

\subsubsection{Thresholds and subcriteria}

An ecosystem may be listed under criterion $A$ if it meets the thresholds for any of four subcriteria (A1, A2a, A2b or A3), quantified as a reduction in geographic distribution over the following time frames:

\begin{tabular}{|ll|ccc|}
\hline Subcriterion & Time frame & CR & EN & VU \\
\hline A1 & Past (over the past 50 years) & $\geq 80 \%$ & $\geq 50 \%$ & $\geq 30 \%$ \\
A2a & Future (over the next 50 years) & $\geq 80 \%$ & $\geq 50 \%$ & $\geq 30 \%$ \\
A2b & Any 50 year period (including the past, present and & $\geq 80 \%$ & $\geq 50 \%$ & $\geq 30 \%$ \\
& future) & $\geq 90 \%$ & $\geq 70 \%$ & $\geq 50 \%$ \\
A3 & Historical (since approximately 1750) & & \\
\hline
\end{tabular}

\subsubsection{Application}

\section{Data requirements}

The rate of decline in distribution is typically estimated from time-series datasets appropriate for the focal ecosystem type. Ecosystem maps - such as those derived from remote sensing classifications, distribution models, field observations, or historical data - are a principal data source for assessing criterion A. When more than one source of data is available, such as different vegetation maps or estimates produced with different methods, assessors should first critically evaluate the efficacy of the alternatives as representations of the distribution of the ecosystem type. If more than one data source is suitable, assessors should calculate estimates from each data source, and explore the sensitivity of ecosystem status to data uncertainty (Section 4.4.1 Dealing with Uncertainty). The net reduction in distribution will form an interval of estimates generated from each data source.

Remote sensing is a central data source for mapping distributions of many terrestrial and marine ecosystems that have interpretable signatures on different forms of imagery (e.g. Fig. 8). Where regional or local data sets are lacking, global data sets, such as those available for forests (Hansen et al., 2013), mangroves (Giri et al., 2011), and coral reefs (Andréfouët 
et al., 2006) may be suitable templates for superimposing appropriate classifications of ecosystem types.
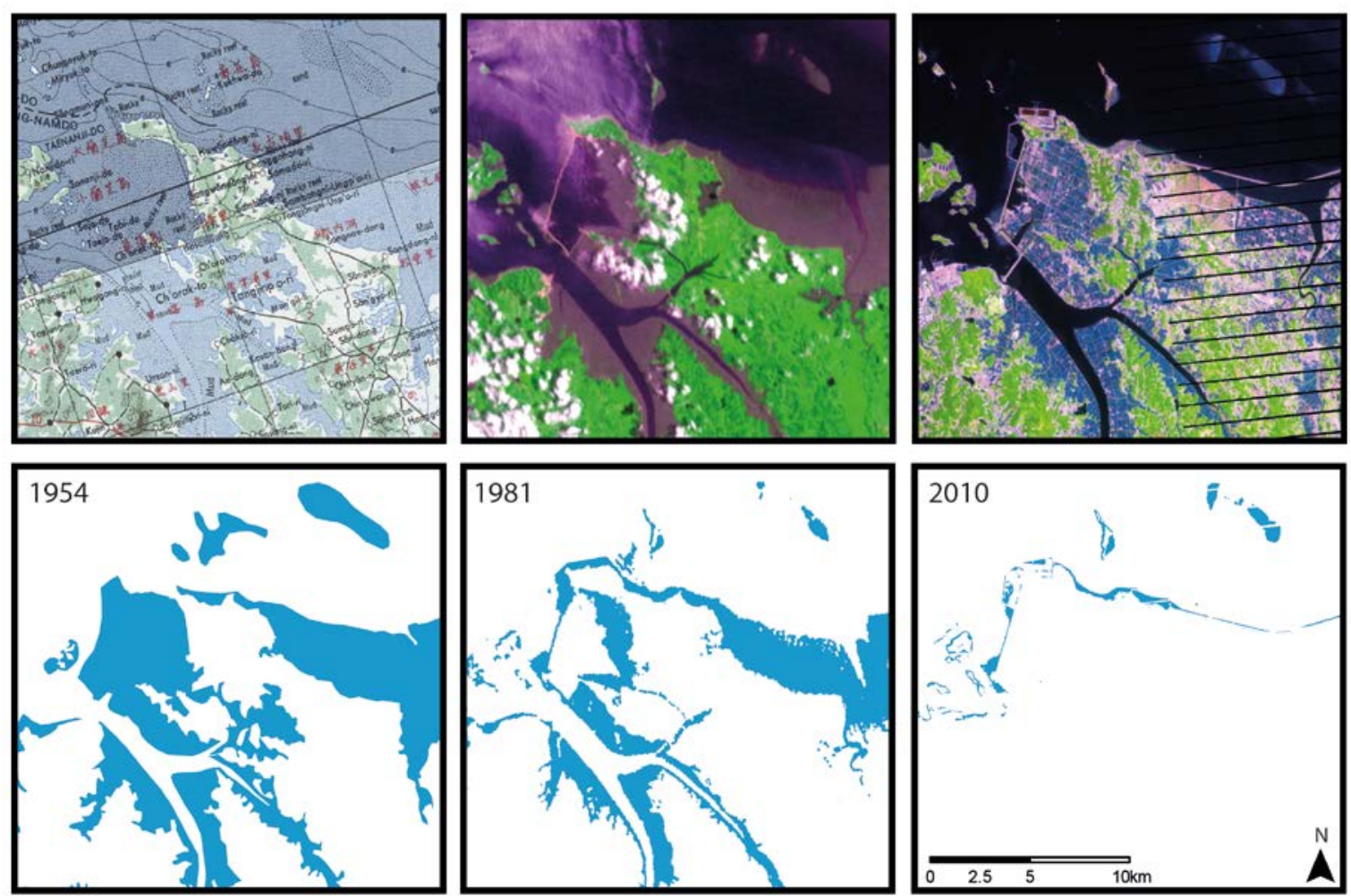

Figure 8. Time series maps of an ecosystem distribution inform the risk of ecosystem collapse. Here, historical topographic maps (1954) and Landsat Archive satellite imagery $(1981,2010)$ allowed a standardised time-series of the area of the Yellow Sea tidal flat ecosystem to be developed for assessment under criterion A (Murray et al., 2014; Murray et al., 2015; Murray et al., 2012).

In some cases, spatial proxies for ecosystem distributions may be used, such as field observations of organism assemblages, keystone species, climate, substrate, topography, bathymetry, ocean currents, flood regimes, aquifers or some synthesis of these that can be justified as valid representations of the distribution of ecosystem biota or its niche space. For example, maps of physical factors such as sea floor characteristics, ocean currents, water temperatures and water chemistry may be appropriate for marine ecosystems. In some subterranean, freshwater and marine ecosystems, trends in the depth dimension may be appropriate proxies of declines in distribution, so long as they reflect trends in carrying capacity and niche diversity for characteristic biota (Keith et al., 2013).

Spatial distribution models offer an opportunity to formally select and combine the most suitable set of spatial proxies to predict ecosystem distributions. For example, Clark et al. (2015) used bathymetric spatial data and remote sensing data on sea ice concentration to model the distribution of suitable light conditions for under-ice marine benthic invertebrate communities in Antarctica. Models are especially useful for projecting time series of ecosystem distributions into the future for assessing criterion A2. Keith et al. (2014) modelled the distribution of a mire ecosystem under future climate scenarios using a remotely sensed map of present day mires, in combination with hydrologically-based 
climate, substrate and terrain predictor variables. In both studies, a mechanistic understanding of the relationship between occurrence of the ecosystem and limiting environmental factors was central to developing an adequate ecosystem map.

\section{Methods}

To apply criterion A, at least two comparable estimates of the distribution of the ecosystem type at different points in time are required. It is beyond the scope of these guidelines to provide detailed information on the acquisition, classification and accuracy assessment of spatial data. Nevertheless, it is assumed that spatial data used for assessments under criterion A are suitable for the purpose in being: (i) comparable across time periods (unbiased); (ii) sufficiently accurate (Congalton \& Green, 2008); and (iii) of a suitable grain size for the ecosystem type being assessed. Although assessments can be completed with just two data points (see below), efforts should be made to ensure appropriate power in a suitable statistical model of ecosystem change and that all model assumptions are addressed in the analysis. Good practices in data processing and analysis (Olofsson et al., 2014; Olofsson et al., 2013; Fuller et al., 2003) must be employed to minimise bias in estimates of areal change from a time-series spatial dataset for assessing criterion $A$.

Subcriterion A1 may be directly assessed if data are available for 50 years ago and the present. However, it is rare for the raw data to be available for precisely the time frames required in an RLE assessment. More typically, assessors must use methods of interpolation, extrapolation, or prediction to calculate estimates of distribution change over the last 50 years (A1), the next 50 years (A2), and/or since 1750 (A3). This will involve assumptions about the nature or pattern of change, which must be explained and justified in the documentation. To assist calculations, a spreadsheet tool is available on the IUCN Red List of Ecosystems website (www.iucnrle.org). Several tools for assisting in this step are in development and will become available on the website in the future.

\section{Assumptions}

Whether inferences are made from time series of satellite images or from other data sources, two important aspects will fundamentally influence assessments: (i) assumptions about the rate of decline; (ii) the number of points in the time series. When the rate of decline is estimated from two observations (e.g. maps) over a specified time frame, assessors should use information about the causes and context of the decline to deduce the likely trajectory (Fig. 9).

Although criterion A can be applied correctly with only two data points, more data will enable a more certain diagnosis of the shape of the trajectory, the fitting of alternative statistical models, and hence more accurate interpolation, extrapolation or prediction. Selection of candidate statistical models should always be informed by the causes and context of the decline. Assessors should ensure that the assumptions of the model are adequately met. At least two plausible alternative scenarios should be explored. 


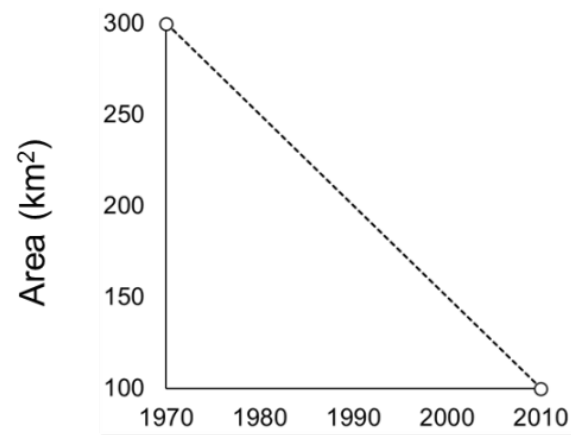

Year

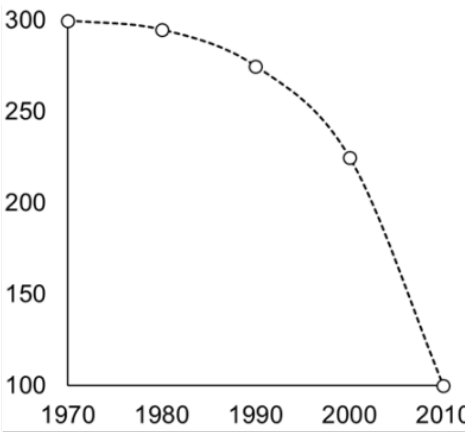

Year

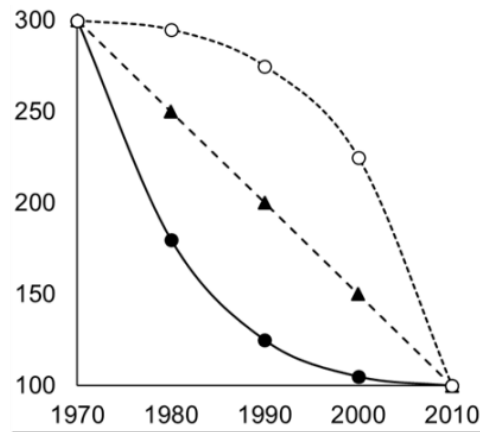

Year

Figure 9. All distribution size trajectories in this figure have the same endpoints: $300 \mathrm{~km}^{2}$ in 1970 and $100 \mathrm{~km}^{2}$ in 2010. A simple interpolation between the two extremes assumes linear decline (left panel). Addition of intermediate distribution size estimates could reveal that the decline is not linear (middle panel). Different ecosystem types could also exhibit contrasting trajectories with identical endpoints: future projections of distribution considering these trajectories would clearly differ (right panel).

Figure 10 illustrates two alternative scenarios of decline for a model ecosystem type based on Coolibah - Black Box Woodland, an ecosystem on a semi-arid floodplain in eastern Australia (Keith et al., 2009). In one scenario (PRD), the rate of decline is proportional, whereby a constant fraction of the remaining distribution is lost each year. The area lost reduces over time (Fig. 10). In the other scenario (ARD), a constant area is lost each year, producing a linear pattern of decline. These scenarios may be modelled using exponential (PRD) and linear (ARD) functions, respectively. The predicted changes of these alternative models become more different, the further they are extrapolated into the future. In the absence of any other information, examining rates of decline as proportional (PRD) or absolute (ARD) permits an assessment of ecosystem status under these two relatively optimistic and pessimistic scenarios (Box 9). However, a longer time series of observations - together with an understanding of the drivers of change, the regulatory context, regional variability in land suitability, and the extent of protected tenures across the distribution of the ecosystem - can help to select more realistic models. These models will produce narrower bounds of uncertainty on the estimated change in distribution. For example, ecosystems in the early stages of large-scale exploitation may be more likely to exhibit linear patterns of decline (ARD) than those in an advanced stage of decline. 


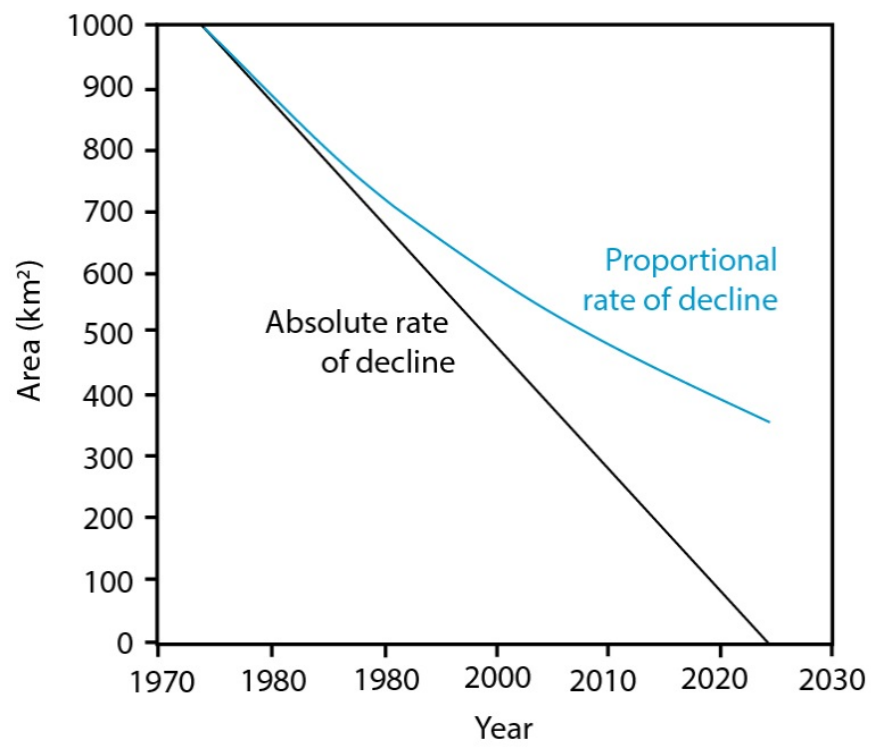

Figure 10. Alternative scenarios for decline in distribution of a model ecosystem (Keith et al., 2009; Keith et al., 2013). The figure shows an ecosystem with an initial area (1974) of 1,000 $\mathrm{km}^{2}$. It declined at rate of $2 \%$ per year during the following 50 years, but the outcome was substantially different if the decline was proportional (PRD) or absolute (ARD). In a PRD, the decline is a fraction of the previous year's remaining area $(0.02 \times$ last year's area), whereas in an ARD the area subtracted each year is a constant fraction of the area of the ecosystem at the beginning of the decline $\left(0.02 \times 1000=20 \mathrm{~km}^{2} /\right.$ year $)$. Under a PRD scenario, this ecosystem would be considered Endangered under A2b (50\% decline over any 50 year period including the present and future), while under an ARD scenario if would have disappeared by 2024 , and be assessed as Collapsed.

Box 9. Proportional and absolute rate of decline (criterion A)

Sierra de Perijá is the mountain range that separates north-western Venezuela from north-eastern Colombia. The humid forests in the Venezuelan side of Perijá are threatened by the expansion of large-scale commercial agriculture, primarily of a tuber, the arrowleaf elephant ear (Xanthosoma saggittifolium). Using Landsat satellite images, it was estimated that in 1986 the humid forests of the watersheds of the Guasare, Socuy and Cachirí rivers occupied $328 \mathrm{~km}^{2}$, while in 2001 they had decreased to $198 \mathrm{~km}^{2}$. These two estimates allow assessment of ecosystem status under subcriterion A2b, using 1986-2001 to first estimate an observed rate of change over 15 years, and then extrapolating projected losses to 2036.

Different assumptions about the rate and type of decline lead to different estimates of the extent of these humid forests by 2036 . The forests in 2001 occupied $198 \mathrm{~km}^{2}$ or $60.4 \%$ of their area in 1986 , thus declining at a mean proportional rate of $3.3 \%$ per year. The next step is considering how this rate may change over time to project losses at 2036. Assuming a proportional rate of decline (PRD) between 2001 and 2036 results in a total decline of $81.5 \%$ between 1986 and 2036 . Assuming an absolute rate of decline (ARD) it is predicted to decline by $100 \%$ by 2024 . Therefore, under criterion A2b PRD leads to a classification of Critically Endangered ( $\geq 80 \%$ decline over any 50 year period including the present and future), while ARD leads to a classification of at least Critically Endangered ( $\geq 80 \%$ decline over any 50 year period including the present and future), although it seems unlikely to collapse entirely if fragments of forest remain in less accessible mountain terrain. In conclusion, the ecosystem is considered Critically Endangered (CR) under subcriterion A2b. Information on the most likely shape of decline can help determine which of these two plausible categories should be reported as the best estimate. 
Assessors should: (i) cite data repositories for time-series maps of ecosystem distributions used in the assessment (see the IUCN Red List of Ecosystems website for a list of preferred spatial data repositories: www.iucnrle.org); (ii) provide full bibliographic references; (iii) justify why the spatial data used are an adequate representation of distribution of the focal ecosystem type; (iv) justify assumptions and alternative scenarios used to interpolate, extrapolate or predict changes in distribution from the available data; (v) explain the methods of calculation including the assumed threshold of collapse. In addition, assessors are encouraged to describe the source of the spatial data (such as satellite sensor type) and its spatial resolution (grain size), and comment on the accuracy of all classified maps. 


\subsection{Criterion B. Restricted geographic distribution}

\subsubsection{Theory}

The size of the geographic distribution of an ecosystem influences its risk of collapse when confronted with a spatially explicit threat or catastrophe (Keith et al., 2013). In general, ecosystems that are widely distributed or exist across multiple independent patches are at lower risk from catastrophes, disturbance events or any other threats that exhibit a degree of spatial contagion (e.g. invasions, pollution, fire, forestry operations, and hydrological or regional climate change). The primary role of criterion $B$ is to identify ecosystems whose distribution is so restricted that they are at risk of collapse from the chance occurrence of single or few interacting threatening events (Rodríguez et al., 2015). Criterion B also includes an approximation for an estimate of occupied habitat for component biota, which is positively related to population viability irrespective of exposure to catastrophic events.

\subsubsection{Thresholds and subcriteria}

An ecosystem may be listed under criterion $B$ if it meets the thresholds for either of three subcriteria (B1, B2 and B3), which indicate restricted geographic distribution as follows:

\begin{tabular}{|c|c|c|c|c|}
\hline Subcriterion & Measure of geographic distribution & CR & EN & VU \\
\hline \multirow[t]{12}{*}{ B1 } & $\begin{array}{l}\text { Extent of a minimum convex polygon }\left(\mathrm{km}^{2}\right) \\
\text { enclosing all occurrences (extent of occurrence, } \\
\text { EOO) is: }\end{array}$ & $\leq 2,000$ & $\leq 20,000$ & $\leq 50,000$ \\
\hline & $\begin{array}{l}\text { AND at least one of the following (a-c): } \\
\text { (a) An observed or inferred continuing decline in }\end{array}$ & & & \\
\hline & ANY OF: & & & \\
\hline & $\begin{array}{l}\text { i. a measure of spatial extent appropriate to } \\
\text { the ecosystem; OR }\end{array}$ & & & \\
\hline & ii. a measure of environmental quality & & & \\
\hline & $\begin{array}{l}\text { appropriate to the characteristic biota of the } \\
\text { ecosystem; OR }\end{array}$ & & & \\
\hline & iii. a measure of disruption to biotic interactions & & & \\
\hline & $\begin{array}{l}\text { appropriate to the characteristic biota of the } \\
\text { ecosystem. }\end{array}$ & & & \\
\hline & (b) Observed or inferred threatening processes that & & & \\
\hline & are likely to cause continuing declines in geographic & & & \\
\hline & $\begin{array}{l}\text { distribution, environmental quality or biotic } \\
\text { interactions within the next } 20 \text { years. }\end{array}$ & & & \\
\hline & (c) Ecosystem exists at: & $\begin{array}{c}1 \\
\text { location }\end{array}$ & $\begin{array}{l}\quad \leq 5 \\
\text { locations }\end{array}$ & $\begin{array}{l}\leq 10 \\
\text { locations }\end{array}$ \\
\hline \multirow[t]{3}{*}{ B2 } & The number of $10 \times 10 \mathrm{~km}$ grid cells occupied (area of & $\leq 2$ & $\leq 20$ & $\leq 50$ \\
\hline & occupancy, AOO) are: & & & \\
\hline & AND at least one of a- & & & \\
\hline B3 & \multicolumn{3}{|c|}{$\begin{array}{l}\text { A very small number of locations (generally fewer than 5) AND prone to } \\
\text { the effects of human activities or stochastic events within a very short } \\
\text { time period in an uncertain future, and thus capable of Collapse or } \\
\text { becoming Critically Endangered (CR) within a very short time period (B3 } \\
\text { can only lead to a listing as Vulnerable, VU). }\end{array}$} & VU \\
\hline
\end{tabular}




\subsubsection{Application}

\section{Data requirements}

The geographic distribution of an ecosystem type is assessed under criterion B with two standardised metrics: the extent of occurrence (EOO) and the area of occupancy (AOO) (Gaston \& Fuller, 2009; Keith et al., 2013). In addition, assessment of criterion B requires a qualitative evaluation of whether continuing declines in spatial extent, environmental quality, or increasing disruption of biotic interactions are occurring or likely to occur as a result of threats. Lastly, it requires an estimate of the number of locations at which an ecosystem occurs. Thus, accurate maps of the current distribution of an ecosystem, information about the direction of current trends, and an understanding of the threats influencing the ecosystem are needed (Keith et al., 2013). For further information on data sources and the requirements of distribution maps for application in the RLE, refer to Section 5.1.3.

In some cases, spatial data may be insufficient to estimate EOO or AOO, but there is evidence that a small number of plausible threatening events may cause an ecosystem to become Critically Endangered or Collapsed within the near future. Such ecosystems may be eligible for listing as Vulnerable under criterion B3 if they occupy few locations relative to the extent of threatening events. Distribution maps, locality records or expert knowledge are required to determine the number of locations in which an ecosystem occurs.

\section{Methods}

\section{Assessing spatial metrics for criteria B1 and B2}

The two standardised measures of ecosystem distribution represent conceptually different aspects of geographic range size for both species (Gaston, 1994; Gaston \& Fuller, 2009) and ecosystems (Rodríguez et al., 2015; Keith et al., 2013). The EOO (subcriterion B1) measures the spread of risk over a contiguous area that encloses all occurrences using a minimum convex polygon. In contrast, the AOO (subcriterion B2) measures the spread of risk among occupied patches through a count of occupied grid cells (Keith et al., 2013).

Ensuring standardized application of these methods is critical for objective measurement of the size of a spatial distribution. Thus, the same measurement protocols are appropriate for all assessment units, including ecosystem types with depth dimensions or particular distribution patterns, such as linearly occurring ecosystem types. In no cases should AOO or EOO be measured in ways that do not comply with the methods specified below:

1. Extent of occurrence (EOO). The EOO of an ecosystem is measured by determining the area $\left(\mathrm{km}^{2}\right)$ of a minimum convex polygon - the smallest polygon that encompasses all known occurrences of a focal ecosystem in which no internal angle exceeds 180 degrees - fitted to an ecosystem distribution. The minimum convex polygon (also known as a convex hull) must not exclude any areas, discontinuities or disjunctions, regardless of whether the ecosystem can occur in those areas or not. Regions such as oceans (for terrestrial ecosystems), land (for coastal or marine ecosystems), or areas outside the study area (such as in a different country) must 
remain included within the minimum convex polygon to ensure that this standardised method is comparable across ecosystem types. In addition, these features contribute to spreading risks across the distribution of the ecosystem by making different parts of its distribution more spatially independent.

2. Area of occupancy (AOO). Measures of $A O O$ are highly sensitive to the grain size (pixel resolution) at which the distribution is mapped (Nicholson et al., 2009), so all measures of $\mathrm{AOO}$ of an ecosystem type must be standardised to a common spatial grain. The AOO of an ecosystem defined in the RLE is determined by counting the number of $10 \times 10 \mathrm{~km}$ grid cells that contain the ecosystem. This relatively large grain size is applied for three reasons: (i) ecosystem boundaries are inherently vague (Regan et al., 2002), so it is easier to determine that an ecosystem occurrence falls within a larger grid cell than a smaller one; (ii) larger cells may be required to diagnose the presence of ecosystems characterised by processes that operate over large spatial scales, or possess diagnostic features that are sparse, cryptic, clustered or mobile (e.g. pelagic or artesian systems); (iii) larger cells allow AOO estimation even when high resolution distribution data are limited. A global 10×10 km gridded dataset suitable for this purpose is available on the IUCN Red List of Ecosystems website (www.iucnrle.org) in both raster and vector formats. Some ecosystem distributions comprise a highly skewed distribution of patch sizes. In these cases large numbers of small patches contribute a negligible risk-spreading effect to that of larger patches and a correction may be applied by excluding from the AOO those grid cells that contain patches of the ecosystem type that account for less than $1 \%$ of the grid cell area (i.e. $<1 \mathrm{~km}^{2}$ of the focal ecosystem type, Box 10). Research is in progress to support guidance on when to apply this correction.

Several spatial tools are in development to assist in measuring the EOO and AOO of an ecosystem type. These will become available on the IUCN Red List of Ecosystems website (www.iucnrle.org).

\section{Assessing subcriteria B1 and B2}

To be eligible for listing under subcriteria B1 or B2, an ecosystem must meet the EOO or AOO thresholds that delineate threat categories, as well as at least one of three subcriteria that address various forms of decline. These subcriteria distinguish restricted ecosystems at appreciable risk of collapse from those that persist over long time scales within small stable ranges (Keith et al., 2013). Only qualitative evidence of continuing decline is required to invoke the subcriteria, but relatively high standards of evidence should be applied.

Subcriteria B1a and B2a address continuing declines in ecosystem distribution, abiotic environment or biotic processes. To invoke this subcriterion, the declines must: (i) reduce the ability of an ecosystem to sustain its characteristic native biota; (ii) be non-trivial in magnitude; and (iii) be more likely than not (Table 3) to continue into the future. Episodic or intermittent declines qualify as continuing, so long as they are recurring and uncompensated by increases of comparable magnitude. Downward phases of cyclical changes or fluctuations do not qualify as continuing declines. These requirements imply an understanding of the causes of decline to support a correct inference. 
Subcriteria B1b and B2b do not require evidence of past or current declines, but may be invoked by future declines inferred from serious and imminent threats. For these subcriteria, assessors, must: (i) identify one or more specific threatening processes; (ii) present convincing and generally agreed evidence that such threats are very likely (Table 3 ) to cause continuing declines within the next two decades. These requirements imply an understanding of how the threats affect the defining features of the ecosystem and the timing of their effects. Speculation about generic threats with uncertain impacts or onset is discouraged. Relevant evidence includes observations of similar threats in the past or on similar ecosystems, as well as accumulated knowledge about the behaviour and nature of the threat itself.

Subcriteria B1C and B2C require an estimate of the number of locations that are occupied relative to the extent of serious plausible threats. A location is defined as a geographically or ecologically distinct area in which a single threatening event can rapidly affect all occurrences of an ecosystem type. The size of the location depends on the area covered by the threatening event and may include part of one or many separate patches of the ecosystem. Where an ecosystem type is affected by more than one threatening event, locations should be defined by considering the most serious plausible threat (IUCN, 2012). Where an ecosystem type is not affected by any threatening events, the number of locations will be zero. Box 11 contains further guidance and examples to support the interpretation of the location concept.

\section{Assessing subcriterion B3}

Subcriterion B3 requires only qualitative information on the distribution of an ecosystem and threats to its persistence. To compensate for this type of evidence (cf. quantitative estimates in other criteria), a higher standard of qualitative evidence is required and the highest category that can be invoked by subcriterion B3 is Vulnerable. Subcriterion B3 comprises two parts which must both be met for an ecosystem type to qualify for Vulnerable status. First, the ecosystem type must have a very restricted distribution, generally with fewer than five locations (Box 11). Second, the ecosystem type must be facing severe threats (human activities or stochastic events) within a very short time period in an uncertain future, and thus capable of collapse or becoming Critically Endangered within a very short time period. In other words, the impact of the threat is very likely (Table 3) to occur in the near future and its consequences are severe. Assessors have some flexibility to interpret the 'very short time period', but this generally means within the next two decades.

\section{Documentation}

For each assessment of an ecosystem type, assessors should: (i) provide the current maps of ecosystem distributions similar to those in Box 10 to show how the EOO, AOO and number of locations were determined; (ii) provide full bibliographic references; (iii) justify why the spatial data used is an adequate representation of distribution of the focal ecosystem type (if not already done so for criterion A); (iv) explain why a correction to AOO was justified if one was applied; (v) justify inferences about continuing declines, and threats that may lead to continuing declines within the next 20 years; (vi) justify estimates of the number of locations through reference to the most serious plausible threats and their spatial characteristics (Box 11). As with assessments under criterion A, description of the source of 
the spatial data (such as satellite sensor type), the accuracy of all mapped data, and the spatial resolution (grain size) of all data used in an assessment is strongly encouraged. Deposition of spatial data on the AOO and EOO into an appropriate data repository is encouraged and should be referenced in the documentation supporting the assessment. 
Box 10. The extent of occurrence (EOO) and area of occupancy (AOO) of an ecosystem (criterion $B$ )
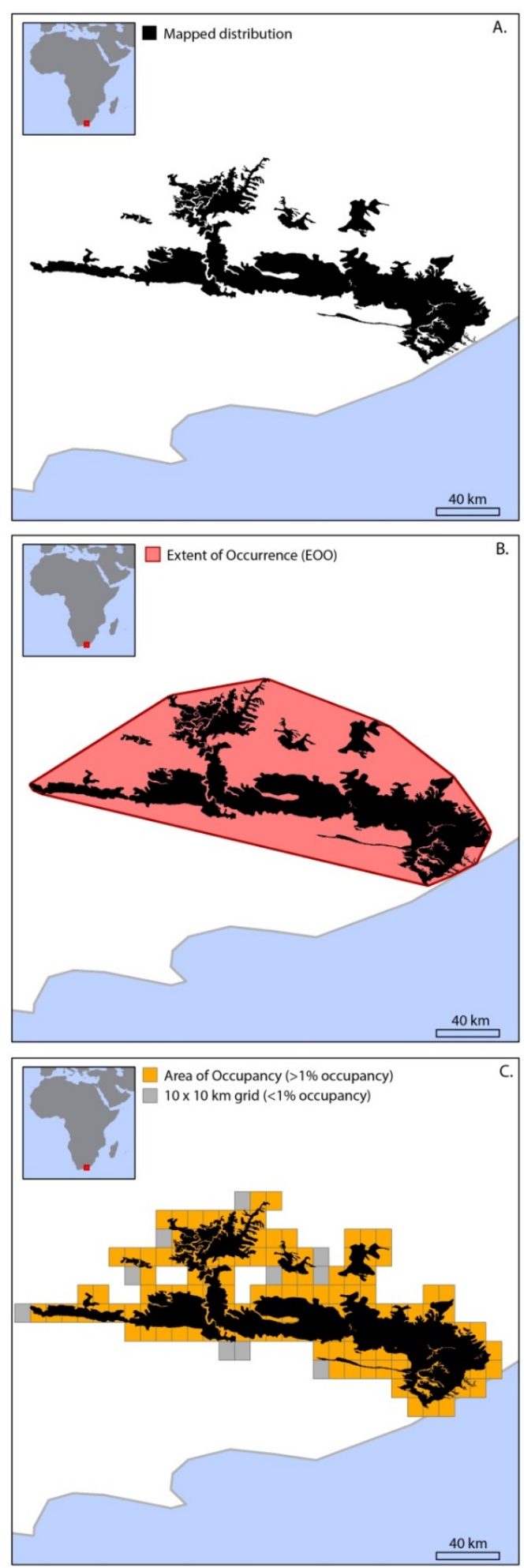

The distribution of the Great Fish Thicket, South Africa (Mucina \& Rutherford, 2006), is depicted by a raster dataset with a spatial resolution of $30 \times 30 \mathrm{~m}(\mathrm{~A})$. As mapped, the area of the Great Fish Thicket ecosystem type is $6,763.4 \mathrm{~km}^{2}$.

A minimum convex polygon-the smallest polygon that encompasses all known occurrences of the ecosystem type in which no internal angle exceeds 180 degrees-is applied to estimate the extent of occurrence (EOO) for assessment under criterion B1 (B). The area of the minimum convex polygon is $18,359.2 \mathrm{~km}^{2}$, meeting the initial requirements for an Endangered classification under criterion B1.

To estimate the area of occupancy (AOO) for assessment under criterion B2, the number of cells covered by the ecosystem type is required (C). The standardised measurement of AOO ensures that distribution data mapped at varying resolutions is generalised to a common $10 \times 10$ $\mathrm{km}$ grid, allowing consistent comparisons across ecosystem types. First, a $10 \times 10 \mathrm{~km}$ grid is applied to the ecosystem type, indicating that $15510 \times 10 \mathrm{~km}$ grid cells intersect the distribution map (shown in orange and grey). Second, when the number of cells that contain very small patches $\left(<1 \mathrm{~km}^{2}\right)$ that negligibly contribute to risk spreading are excluded (shown in grey), the AOO is measured as 145 grid cells (shown in orange). This AOO is greater than the thresholds for classification in a threatened category under B2.

Finally, to be eligible for listing in a threatened category under criterion $B$, qualitative evidence of continuing decline is also required. In this case, the Great Fish Thicket ecosystem type does not meet any of the additional subcriteria, and is thus assigned an overall classification of Least Concern. 
Box 11. Determining the number of locations (criterion B) (adapted from Appendix S2 in Keith et al., 2013)

Coolibah - Black Box Woodland of south-eastern Australia

In its mature state, Coolibah - Black Box Woodland has an open structure with widely scattered trees, a variable cover of shrubs and grassy ground layer. The characteristic vertebrate fauna includes diverse assemblages of woodland and wetland bird species, many of which depend on tree hollows, other features of large trees or standing water for breeding and foraging (NSW Scientific Committee, 2004). The most serious plausible threats are land clearing and changes to water regimes. Spatial patterns of land clearing show a high degree of contagion, with the best predictor of future clearing being the proximity of a patch to land parcels already cleared of native vegetation. A broad interpretation of locations under subcriterion B3 identifies three jurisdictional zones with different regulatory controls on land clearing: the leasehold Western Division of New South Wales; the freehold Central Division of New South Wales; and Queensland; this results in an estimate of three locations as defined by land clearing. A more narrow interpretation of locations based on neighbourhoods of contagion would produce an estimate of more than five. Small protected areas are excluded from these locations, as they are not threatened by land clearing. These areas were assessed by considering the next most serious plausible threat: changes to water regimes. As protected areas are located in at least two different sub-catchments with different water management infrastructure, there are at least two further locations. Hence the most precautionary interpretation produces an estimate of five locations, although it is likely that there are more. Based on current rates of depletion due to land clearing (subcriterion A1) and current rates of environmental degradation due to changes in water regime (subcriterion $\mathrm{C} 1$ ), the ecosystem is unlikely to collapse or become Critically Endangered within the near future (c. 20 years). The ecosystem type therefore does not meet subcriterion B3, so the status of the ecosystem type is Least Concern under this subcriterion.

\section{Cape Flats Sand Fynbos of South Africa}

Cape Flats Sand Fynbos is a species-rich, dense, moderately tall shrubland with scattered emergent shrubs (Rebelo et al., 2006). The ecosystem type is an edaphically determined species assemblage restricted to Tertiary acid, deep grey regic sands at low elevations (20-200 m) on flat to undulating terrain. Cape Flats Sand Fynbos is restricted to the Western Cape province of South Africa, almost entirely within the limits of the City of Cape Town. The most severe threat to the ecosystem type is habitat destruction associated with urban development (Rebelo et al., 2006; Wood et al., 1994). Occurrences that are currently within proclaimed reserves are protected from this threat, although these stands are threatened by invasion of exotic plants (Rebelo et al., 2006). As the entire distribution of the ecosystem type is within the City of Cape Town, the unproclaimed remnant vegetation is subject to the same development pressures, regulatory regimes and planning authority. The distribution is therefore interpreted as two semi-independent locations; one outside protected areas (threatened by habitat destruction and invasive plants) and one within protected areas (threatened by invasive plants, but not habitat destruction). Given the severe and immediate nature of the threats, the ecosystem type is prone to the effects of human activity or stochastic events such that it is capable of collapse or becoming Critically Endangered within a very short time period. The status of the ecosystem type is thus Vulnerable under subcriterion B3. 


\subsection{Criterion C. Environmental degradation}

\subsubsection{Theory}

The RLE risk model defines two criteria for assessing declines in ecosystem functions or processes. Two criteria are needed to assess abiotic (environmental) and biotic degradation because the causes, effects and mechanisms of functional decline differ fundamentally between them (Keith et al., 2013). Abiotic degradation is the deterioration of the physical, non-living attributes that have a defining role in ecological processes and/or the distribution of an ecosystem type. Abiotic degradation reduces the capacity of an ecosystem to sustain its characteristic biota. For example, declines in limiting resources (niche dimension) reduce species diversity in a range of terrestrial, freshwater and marine ecosystems (Harpole \& Tilman, 2007).

\subsubsection{Thresholds and subcriteria}

An ecosystem may be listed under criterion $C$ if it meets the thresholds for any of four subcriteria (C1, C2a, C2b, or C3), which express different levels of environmental degradation over the following time frames:

\begin{tabular}{|c|c|c|c|c|c|}
\hline Subcriterion & \multicolumn{2}{|l|}{ Time frame } & \multicolumn{3}{|c|}{ Relative severity (\%) } \\
\hline \multirow{4}{*}{ C1 } & \multirow{4}{*}{$\begin{array}{l}\text { The past } 50 \text { years based on change in an } \\
\text { abiotic variable affecting a fraction of the } \\
\text { extent of the ecosystem and with relative } \\
\text { severity, as indicated by the following table: }\end{array}$} & $\begin{array}{c}\text { Extent } \\
(\%)\end{array}$ & $\geq 80$ & $\geq 50$ & $\geq 30$ \\
\hline & & $\geq 80$ & CR & EN & $\mathrm{VU}$ \\
\hline & & $\geq 50$ & EN & VU & \\
\hline & & $\geq 30$ & VU & & \\
\hline \multirow{5}{*}{$\mathrm{C} 2$} & \multirow{4}{*}{$\begin{array}{l}\text { C2a. The next } 50 \text { years, based on change in } \\
\text { an abiotic variable affecting a fraction of the } \\
\text { extent of the ecosystem and with relative } \\
\text { severity, as indicated by the following table; } \\
\text { OR }\end{array}$} & $\begin{array}{c}\text { Extent } \\
(\%)\end{array}$ & $\geq 80$ & $\geq 50$ & $\geq 30$ \\
\hline & & $\geq 80$ & CR & EN & $\mathrm{VU}$ \\
\hline & & $\geq 50$ & EN & VU & \\
\hline & & $\geq 30$ & VU & & \\
\hline & $\begin{array}{l}\text { C2b. Any } 50 \text {-year period including the past, } \\
\text { present and future, based on change in an } \\
\text { abiotic variable affecting a fraction of the } \\
\text { extent of the ecosystem and with relative } \\
\text { severity, as indicated by the following table: }\end{array}$ & & & & \\
\hline \multirow{4}{*}{ C3 } & \multirow{4}{*}{$\begin{array}{l}\text { Since } 1750 \text { based on change in an abiotic } \\
\text { variable affecting a fraction of the extent of the } \\
\text { ecosystem and with relative severity, as } \\
\text { indicated by the following table: }\end{array}$} & $\begin{array}{c}\text { Extent } \\
(\%)\end{array}$ & $\geq 90$ & $\geq 70$ & $\geq 50$ \\
\hline & & $\geq 90$ & CR & EN & $\mathrm{VU}$ \\
\hline & & $\geq 70$ & EN & VU & \\
\hline & & $\geq 50$ & VU & & \\
\hline
\end{tabular}

\subsubsection{Application}

Data requirements

To assess criterion $\mathrm{C}$ it is necessary to select suitable abiotic variables that represent defining features of the ecosystem type. This choice is based on a number of considerations: 
1. There must be plausible evidence of a causal relationship between the process of environmental degradation and the loss of characteristic native biota. For example, an assessment of wetland degradation based on change in water quality would require evidence that declines in water quality are associated with loss of wetland biota, either through direct observation or inference from comparable ecosystem types. A carefully developed conceptual model can highlight key environmental processes and the transitions between healthy and collapsed states to be assessed in criterion C (Section 4.2.3).

2. Assessing abiotic degradation requires suitable scalar variables for estimating the severity of degradation, as well as suitable spatial variables for estimating the extent of degradation. The characteristics of the ecosystem and its threats will determine which variables are relevant. Variables with direct and clear cause-effect relationships and the greatest sensitivity to loss of characteristic native biota will be the most suitable.

3. The choice of a variable representing abiotic degradation should enable direct inferences about threshold values of the variable that define ecosystem collapse (Fig. $3)$.

4. Applying generic indices across functionally contrasting ecosystems is unlikely to assess degradation accurately if key processes differ among these ecosystems. The choice of abiotic variable should be underpinned by the ecology of a particular ecosystem (Table 7). If alternative variables representing different degradation processes are available, they should be examined independently and the one producing the greatest rate of decline should be used to assess status or the outcomes should contribute to a bounded estimate of the status.

5. Aggregation of multiple variables into a single index for assessment under criterion $\mathrm{C}$ can be problematic and is discouraged. Aggregation relies on statistical assumptions which may be unwarranted, especially in data-poor ecosystems. Aggregation can also confound different mechanisms of environmental degradation, making the index less sensitive than individual variables due to averaging effects. Assessors should therefore avoid aggregating variables when they are uncertain about ecosystem dynamics and the assumptions underpinning the aggregation. In these cases, the best effort should be made to select a variable that is relevant to ecosystem processes and sensitive to environmental degradation. The use of aggregated indices should be supported by critical evaluation of ecological and mathematical assumptions. A clear link between the change in index value and proximity to collapse must be demonstrated.

6. If the interaction between two or more variables is considered important, it is preferable to develop robust, expert-based rules to define states that are a combination of the variables, rather than use an index. For example, a severely degraded example of an ecosystem type might require two variables to have crossed a given threshold or be between two stated values, while moderate degradation may require either one to have crossed the threshold or both to be between a different set 
of values. Using a rule-based method requires the assessor to explicitly state and understand how the variables can be combined. In many indices these relationships are submerged, poorly understood, and have unintended effects on index values.

7. Estimating the extent of abiotic degradation can be based on expert-derived estimates, inferences or spatial data. For example, data on levels of water extraction and surface area for each wetland were combined to assess the relative severity of environmental degradation over the entire area of the swamps, marshes and lakes of the Murray-Darling Basin (Keith et al., 2013).

Table 7. Examples of variables potentially suitable for assessing the severity of environmental degradation under criterion $\mathrm{C}$.

\begin{tabular}{|c|c|}
\hline Environmental degradation & Variables \\
\hline $\begin{array}{l}\text { Desertification of } \\
\text { rangelands }\end{array}$ & $\begin{array}{l}\text { Proportional cover of bare ground, soil density, soil compaction } \\
\text { indices, remote sensing indices of change (Zhao et al., 2005; } \\
\text { Ludwig et al., 2007). }\end{array}$ \\
\hline $\begin{array}{l}\text { Eutrophication of soils, } \\
\text { freshwater streams or } \\
\text { lakes }\end{array}$ & $\begin{array}{l}\text { Levels of dissolved or soil nitrogen, phosphorus, cations, oxygen, } \\
\text { turbidity, bioassay (Carpenter, 2003). }\end{array}$ \\
\hline $\begin{array}{l}\text { Dehumidification of cloud } \\
\text { forests }\end{array}$ & Cloud cover, cloud altitude (Pounds et al., 1999). \\
\hline Deforestation by acid rain & Rain water chemistry (Likens, 1992). \\
\hline $\begin{array}{l}\text { Homogenisation of } \\
\text { microhabitats }\end{array}$ & $\begin{array}{l}\text { Diversity of micro-terrain features, spatial variance in inundation } \\
\text { depth and duration (Cabezas et al., 2009). }\end{array}$ \\
\hline $\begin{array}{l}\text { Changed water regime or } \\
\text { hydroperiod }\end{array}$ & $\begin{array}{l}\text { Field-based monitoring of stream flow volume, or piezometric water } \\
\text { table depth; remote sensing of spatial extent of surface water, } \\
\text { frequency and depth of inundation (Mac Nally et al., 2011). }\end{array}$ \\
\hline $\begin{array}{l}\text { Salinisation of soils or } \\
\text { wetlands }\end{array}$ & $\begin{array}{l}\text { Field monitoring of salinity of soils or groundwater, remote sensing } \\
\text { of ground surface albedo (Metternicht \& Zinck, 2003). }\end{array}$ \\
\hline $\begin{array}{l}\text { Sedimentation of streams, } \\
\text { coral reefs }\end{array}$ & $\begin{array}{l}\text { Sediment accumulation rates, sediment load of streams, discharge, } \\
\text { turbidity of water column, frequency and intensity of sediment plume } \\
\text { spectral signatures (Rogers, 1990). }\end{array}$ \\
\hline $\begin{array}{l}\text { Structural simplification of } \\
\text { benthic marine ecosystems }\end{array}$ & $\begin{array}{l}\text { Microrelief, abundance of benthic debris, trawling frequency and } \\
\text { spatial pattern (Watling \& Norse, 1998). }\end{array}$ \\
\hline Sea level rise & $\begin{array}{l}\text { Acoustic monitoring of sea level, extent of tidal inundation (Hannah } \\
\& \text { Bell, 2012). }\end{array}$ \\
\hline Retreat of ice masses & Remote sensing of sea ice extent (Hong \& Shin, 2010). \\
\hline
\end{tabular}

\section{Methods}

The key concept for assessing functional declines in either abiotic or biotic variables is relative severity. Relative severity is essential for comparing risks among ecosystems undergoing different types of degradation. Relative severity describes the proportional change observed in an environmental variable scaled between two values: one describing 
the initial state of the system (0\%), and one describing a collapsed state (100\%). Thus, if an ecosystem type undergoes degradation with a relative severity of $50 \%$ over an assessment time frame, this implies that that it has transformed half way to a collapsed state. Information on relative severity is combined with information on the proportion of the ecosystem affected (extent) to determine the risk category under criterion $\mathrm{C}$. Assessors may either estimate the extent of degradation that exceeds a threshold level of severity or estimate the average severity of degradation across the entire ecosystem distribution (100\% of extent; Fig. 11).

Ecosystems are listed as CR if environmental change is both extremely severe ( $\geq 80 \%$ relative severity) and extensive (across $\geq 80 \%$ of the distribution). Ecosystems may be eligible for listing in lower threat categories if they are undergoing very severe but localised degradation or less severe degradation over extensive areas (Fig. 11). Ecosystems that fail to meet the thresholds for the Vulnerable category may be assigned to the Near Threatened category. For example, an ecosystem undergoing $>80 \%$ decline in environmental quality over $20-30 \%$ of its distribution, or $>30 \%$ decline over $70-80 \%$ of its distribution could qualify as Near Threatened.

In the simplest case, relative severity may be calculated by range-standardising the raw values of the abiotic variable between its initial value and its collapse value. Assessors must: (i) estimate the value of the abiotic variable initial state (at the beginning of the assessment time frame); (ii) estimate the expected value in a collapsed state; (iii) measure or estimate the present or future value of the variable (i.e. at the end of the assessment time frame). Note that the calculated relative severity can be negative if the condition of the ecosystem has improved.

The following equations rescale an abiotic variable to a proportional change towards collapse suitable for assessing criterion $\mathrm{C}$ :

Relative severity $(\%)=($ Observed or predicted decline $/$ Maximum decline $) \times 100$

where

Observed or predicted decline $=$ Initial value - Present or future value and

Maximum decline $=$ Initial value - Collapse value

Next, assessors determine the extent of the degradation as a proportion of the total distribution of the ecosystem. With these two quantities assessors assign a risk category using the described thresholds. 

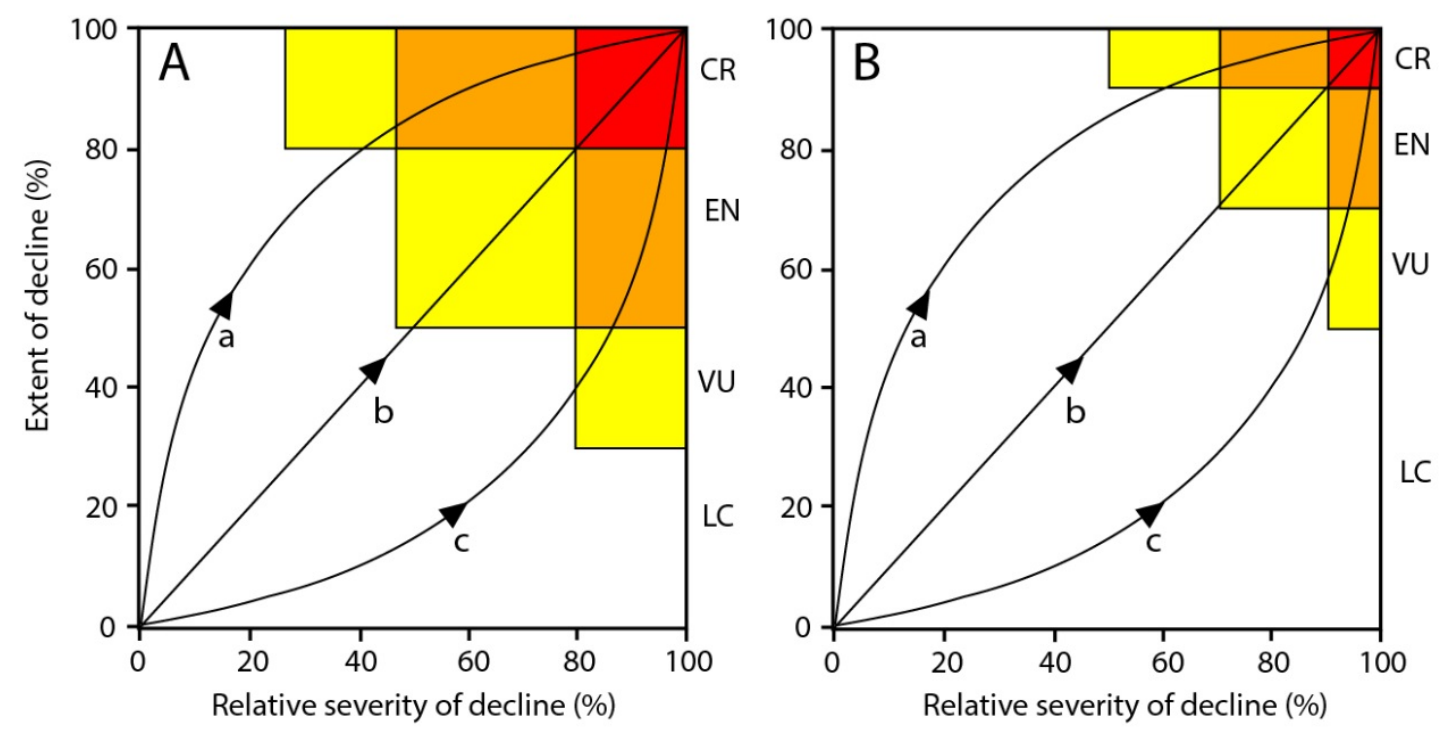

Figure 11. Contrasting pathways of environmental or biotic degradation and their corresponding risk classifications under criteria C1, C2, D1, D2 (A) or C3, D3 (B): (a) initially widespread and relatively benign degradation, which increases in severity, (b) severity and extent of degradation increase at similar rates, (c) localised but severe degradation, later becoming more widespread. 
Box 12. Assessing environmental degradation (criterion C) (adapted from Appendix S2 in Keith et al., 2013)

Flooding is a key ecological process that sustains the Gonakier Forests for the Senegal River Floodplain in Senegal-Mauritania (Keith et al., 2013). As floods occur only during the wet season months, the maximum annual river height was assumed to be indicative of the river's capacity to flood each year. River height data were available for 100 years from 1904 to 2003. To assess criterion $\mathrm{C}$, mean annual maximum river height across four gauging stations was used as a proxy for environmental degradation. River flows declined sharply, reaching a minimum during the late 1970 s and 1980s. Floods of $2,500 \mathrm{~m}^{3} / \mathrm{s}$, which are needed for floodplain inundation, would be very unlikely to occur based on river flows observed during 1986-1989. Extreme rates of tree mortality were observed between the mid-1970s and the mid-1980s, corresponding to the lowest maximum river heights $(473 \pm 27 \mathrm{~cm})$ observed during the 100 years of records.

Based on these observations, the collapse threshold was defined as the mean maximum river height for a 50-year period falling below $450-500 \mathrm{~cm}$, causing extensive tree mortality. To calculate the relative severity of hydrological decline, the time series was divided into the reference period (1904-1953) and the present period (1954-2003). Since the collapse threshold is an interval, relative severity was estimated for the lower and upper bounds of the interval.

For the lower bound $(450 \mathrm{~mm})$, relative severity is:

(Observed decline) $/($ Maximum decline $) \times 100=(712-619) /(712-450) \times 100=35 \%$

For the higher bound $(500 \mathrm{~mm})$, relative severity is

(Observed decline / Maximum decline $) \times 100=(712-619) /(712-500) \times 100=44 \%$

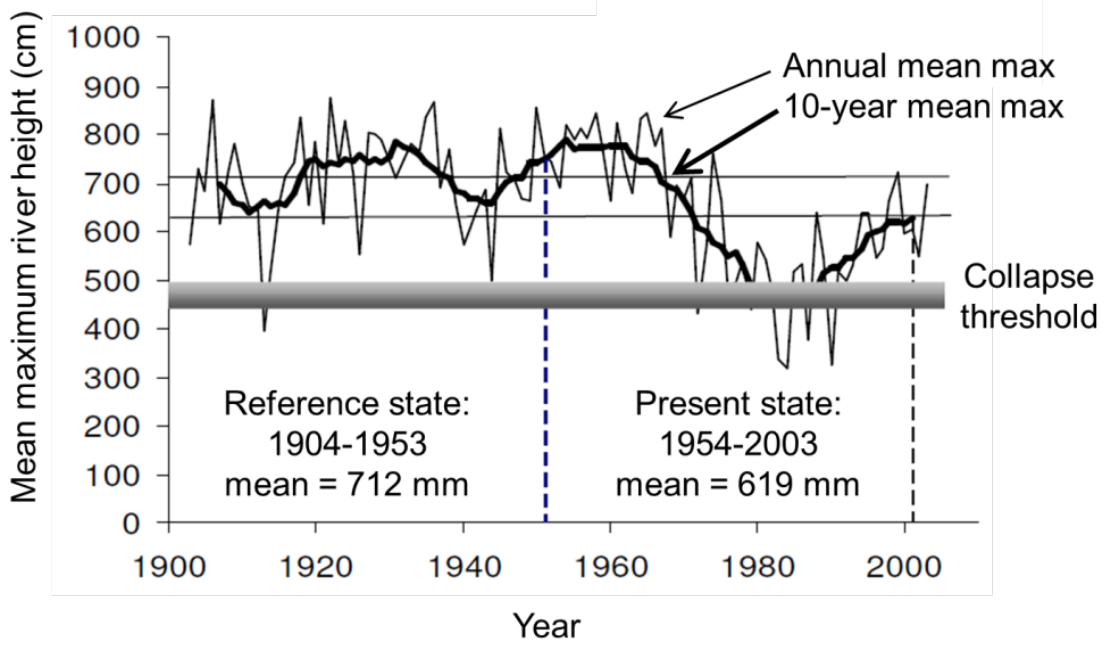

Figure 12. River height in the Gonakier forest.

Since hydrological decline affects the entire ecosystem, it was assumed that the extent of the threat was $>80 \%$, thus leading to the conclusion that the ecosystem is Vulnerable according Criterion $\mathrm{C} 1$ (degradation with relative severity $\geq 30 \%$ over an extent $\geq 80 \%$ in the last 50 years). 
Determining an initial and a collapsed value for the abiotic variable relies on assumptions about collapsed states of the ecosystem type. Such uncertainty in the collapse point can be represented with bounded thresholds of the values of the variable. The calculation of relative severity can be repeated with both values, providing a lower and upper estimate for the risk category (Box 12). Similarly, uncertainty in the extent of degradation can be assessed with the use of upper and lower estimates. The use of bounded values yields an estimate of the extent and severity of abiotic degradation while clearly expressing uncertainty.

Similar to the declines of extent required for assessing under criterion $\mathrm{A}$, the application of criterion $C$ assumes a functional form of decline. The simplest case illustrated above applies when there is a linear relationship between the assessment variable and the trajectory towards a collapsed state. Other scenarios are possible, for example, where collapse proceeds more slowly or more rapidly than indicated by changes in the assessment variable. In such cases a suitable transformation of the assessment variable should be used in the calculation of relative severity.

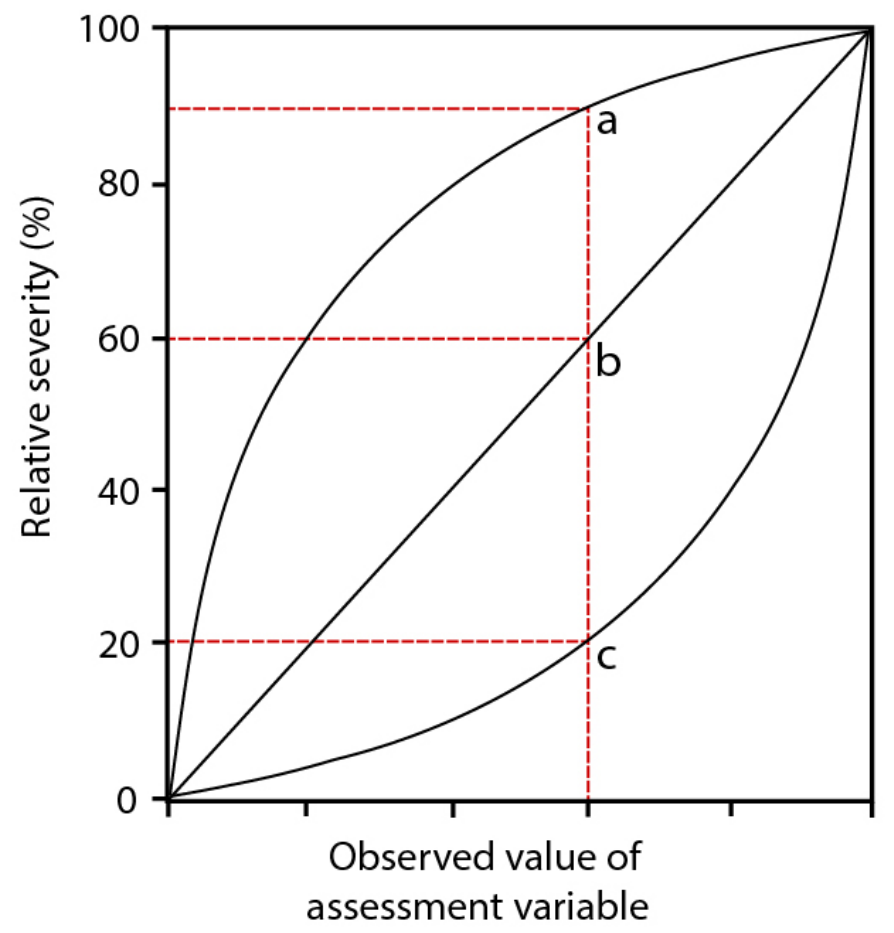

Figure 13. An observed value for a variable assessing degradation can be mapped to different values of relative severity depending on the functional form considered. The red line indicates an observed value which can be mapped to a relative severity of $20 \%, 60 \%$, or $90 \%$ depending on the functional form. This corresponds to a risk category of LC, EN, or CR if the degradation occurs over $\geq 80 \%$ of the ecosystem type.

Determining whether the degradation is constant, accelerating, or decelerating can be informed by time-series data. Assessors should evaluate whether the available data are sufficiently representative to characterise the shape of the decline in the abiotic variable, ideally through appropriate statistical methods (Di Fonzo et al., 2013; Connors et al., 2014). Where time-series data are unavailable, it may be possible to infer changes in degradation 
using expert elicitation or space-for-time substitution with appropriate reference sites (Pickett, 1989). To overcome uncertainty due to this assumption, sensitivity analyses that include estimates produced from multiple shapes of decline can provide a bounded estimate for the risk assessment outcome.

\section{Documentation}

Assessors should document: (i) the selection of the abiotic variable with respect to the conceptual model of ecosystem dynamics; (ii) the setting of a bounded collapse threshold for the abiotic variable; (iii) the calculation of relative severity; (iv) the estimation of the extent of degradation; (v) assumptions and appropriate sensitivity analyses (e.g. regarding the collapse definition or shape of decline); (vi) the final risk categories and plausible bounds. Temporal variation in degradation is best shown in a graph that depicts changes in the variable over time, and includes any interpolation or extrapolation to match the relevant time frame. 


\subsection{Criterion D. Disruption of biotic processes and interactions}

\subsubsection{Theory}

The persistence of biota within ecosystems depends on biotic processes and interactions. This includes: competitive, predatory, facilitatory, mutualistic, trophic and pathogenic processes; mobile links (e.g. seasonal migration); and species invasions. Biodiversity loss reduces the capacity of ecosystems to capture resources, produce biomass, decompose organic matter and recycle carbon, water and nutrients, and also reduces the stability of these functions through time (Cardinale et al., 2012). The identity of organisms within a system controls its functioning as key taxa make disproportionate contributions to ecosystem functions. The diversity of organisms is also important, because niche partitioning and positive species interactions promote complementary contributions to ecosystem functions.

Feedback interactions are crucial for an ecosystem type to absorb environmental change while maintaining characteristic biota and processes. Conversely, significant disruptions to biotic processes and interactions can cause collapse, regime shifts and re-organisation into novel ecosystems (Thébault \& Loreau, 2005). Disruption of interactions through trophic cascades is one of five major threats to biodiversity (Diamond, 1989), although non-trophic interactions also play important roles (Fontaine et al., 2005; Goudard \& Loreau, 2008). Certain ecosystem types may be especially sensitive to disruption of biotic processes and interactions, such as systems with strong top-down trophic regulation, with many mutualistic or facilitation interactions that are strongly dependent on mobile links, and where positive feedbacks operate between the biota and disturbance regimes.

\subsubsection{Thresholds and subcriteria}

An ecosystem may be listed under criterion $D$ if it meets the thresholds for any of four subcriteria (D1, D2a, D2b, or D3), which express different levels of biotic disruption over the following time frames: 


\begin{tabular}{|c|c|c|c|c|c|}
\hline Subcriterion & \multicolumn{2}{|l|}{ Time frame } & \multicolumn{3}{|c|}{ Relative severity (\%) } \\
\hline \multirow{4}{*}{ D1 } & \multirow{4}{*}{$\begin{array}{l}\text { The past } 50 \text { years based on change in a biotic } \\
\text { variable affecting a fraction of the extent of the } \\
\text { ecosystem and with relative severity, as } \\
\text { indicated by the following table: }\end{array}$} & $\begin{array}{c}\text { Extent } \\
(\%)\end{array}$ & $\geq 80$ & $\geq 50$ & $\geq 30$ \\
\hline & & $\geq 80$ & CR & EN & VU \\
\hline & & $\geq 50$ & EN & VU & \\
\hline & & $\geq 30$ & VU & & \\
\hline \multirow[b]{4}{*}{ D2 } & \multirow{3}{*}{$\begin{array}{l}\text { D2a. The next } 50 \text { years, based on change in a } \\
\text { biotic variable affecting a fraction of the extent } \\
\text { of the ecosystem and with relative severity, as } \\
\text { indicated by the following table; OR }\end{array}$} & $\begin{array}{c}\text { Extent } \\
(\%)\end{array}$ & $\geq 80$ & $\geq 50$ & $\geq 30$ \\
\hline & & $\geq 80$ & CR & EN & VU \\
\hline & & $\geq 50$ & EN & VU & \\
\hline & $\begin{array}{l}\text { D2b. Any } 50 \text {-year period including the past, } \\
\text { present and future, based on change in a biotic } \\
\text { variable affecting a fraction of the extent of the } \\
\text { ecosystem and with relative severity, as } \\
\text { indicated by the following table: }\end{array}$ & $\geq 30$ & VU & & \\
\hline \multirow{4}{*}{ D3 } & \multirow{4}{*}{$\begin{array}{l}\text { Since } 1750 \text { based on change in a biotic } \\
\text { variable affecting a fraction of the extent of the } \\
\text { ecosystem and with relative severity, as } \\
\text { indicated by the following table: }\end{array}$} & $\begin{array}{c}\text { Extent } \\
(\%)\end{array}$ & $\geq 90$ & $\geq 70$ & $\geq 50$ \\
\hline & & $\geq 90$ & CR & EN & VU \\
\hline & & $\geq 70$ & EN & VU & \\
\hline & & $\geq 50$ & VU & & \\
\hline
\end{tabular}

\subsubsection{Application}

\section{Data requirements}

Assessment of criterion D addresses the same data requirements as criterion $C$, except suitable biotic variables are used. Conceptual models provide a useful framework for selecting biotic variables linked to key ecosystem processes. A broad set of variables are potentially useful for quantifying biotic processes and associated functional declines. This includes changes in species richness, composition and dominance; relative abundance of species functional types, guilds or alien species; measures of interaction diversity; changes in identity and frequency of species movements; measures of niche diversity and structural complexity (Table 8).

Table 8. Examples of biotic variables potentially suitable for assessing the severity of disruption to biotic interactions under criterion $\mathrm{D}$.

\begin{tabular}{|lll|}
\hline Variable & $\begin{array}{l}\text { Role in ecosystem resilience and } \\
\text { function }\end{array}$ & Example \\
\hline $\begin{array}{l}\text { Species richness (the } \\
\text { number of species within a } \\
\text { taxonomic group per unit } \\
\text { area). }\end{array}$ & $\begin{array}{l}\text { Ecological processes decline at } \\
\text { an accelerating rate with loss of } \\
\text { species (Cardinale et al., 2011). } \\
\text { Species richness is related } \\
\text { indirectly to ecosystem function } \\
\text { and resilience through its } \\
\text { correlations with functional } \\
\text { diversity, redundancy and } \\
\text { complementarity. }\end{array}$ & $\begin{array}{l}\text { Response of species diversity } \\
\text { of grasses and relative } \\
\text { abundance to varying levels of } \\
\text { grazing in grassland (Walker et } \\
\text { al., 1999). }\end{array}$ \\
\hline Species composition and & Shifts in dominance and & Shift in diet of top predators \\
\hline
\end{tabular}




\begin{tabular}{|c|c|c|}
\hline Variable & $\begin{array}{l}\text { Role in ecosystem resilience and } \\
\text { function }\end{array}$ & Example \\
\hline dominance. & $\begin{array}{l}\text { community structure are } \\
\text { symptoms of change in } \\
\text { ecosystem behaviour and } \\
\text { identity. }\end{array}$ & $\begin{array}{l}\text { (killer whales) due to } \\
\text { overfishing effects on seals, } \\
\text { caused decline of sea otters, } \\
\text { reduced predation of kelp- } \\
\text { feeding urchins, causing their } \\
\text { populations to explode with } \\
\text { consequent collapse of giant } \\
\text { kelp, structural dominants of } \\
\text { the benthos (Estes et al., } \\
\text { 2009) (Box 13). }\end{array}$ \\
\hline $\begin{array}{l}\text { Abundance of key species } \\
\text { (ecosystem engineers, } \\
\text { keystone predators and } \\
\text { herbivores, dominant } \\
\text { competitors, structural } \\
\text { dominants, transformer } \\
\text { invasive species). }\end{array}$ & $\begin{array}{l}\text { Invasions of certain alien species } \\
\text { may alter ecosystem behaviour } \\
\text { and identity, and make habitat } \\
\text { unsuitable for persistence of } \\
\text { some native biota. Transformer } \\
\text { alien species are distinguished } \\
\text { from benign invasions that do not } \\
\text { greatly influence ecosystem } \\
\text { function and dynamics }\end{array}$ & $\begin{array}{l}\text { Invasion of crazy ants } \\
\text { simplifies forest structure, } \\
\text { reduces faunal diversity and } \\
\text { native ecosystem engineers } \\
\text { (Green et al., 2011). Invasion } \\
\text { of arid Australian shrublands } \\
\text { and grasslands by Buffel } \\
\text { Grass makes them more fire } \\
\text { prone and less favourable for } \\
\text { persistence of native plant } \\
\text { species (Clarke et al., 2005; } \\
\text { Miller et al., 2010). }\end{array}$ \\
\hline $\begin{array}{l}\text { Functional diversity } \\
\text { (number and evenness of } \\
\text { types). }\end{array}$ & $\begin{array}{l}\text { High diversity of species } \\
\text { functional types (e.g. resource } \\
\text { use types, disturbance response } \\
\text { types) promotes coexistence } \\
\text { through resource partitioning, } \\
\text { niche diversification and } \\
\text { mutualisms (Allen et al., 2005). } \\
\text { Mechanisms similar to functional } \\
\text { complementarity. }\end{array}$ & $\begin{array}{l}\text { High diversity of plant-derived } \\
\text { resources sustains } \\
\text { composition, diversity and } \\
\text { function of soil biota } \\
\text { (Eisenhauer et al., 2011). Fire } \\
\text { regimes promote coexistence } \\
\text { of multiple plant functional } \\
\text { types (Keith et al., 2007). }\end{array}$ \\
\hline $\begin{array}{l}\text { Functional redundancy } \\
\text { (number of taxa per type; } \\
\text { within- and cross-scale } \\
\text { redundancy; see Allen et } \\
\text { al., 2005). }\end{array}$ & $\begin{array}{l}\text { Functionally equivalent minor } \\
\text { species may substitute for loss or } \\
\text { decline of dominants if many } \\
\text { species perform similar functional } \\
\text { roles (functional redundancy). } \\
\text { Low species richness may be } \\
\text { associated with low resilience and } \\
\text { high risks to ecosystem function } \\
\text { under environmental change } \\
\text { (Allen et al., 2005; Walker et al., } \\
\text { 1999). }\end{array}$ & $\begin{array}{l}\text { Response of bird communities } \\
\text { to varying levels of land use } \\
\text { intensity (Fischer et al., 2007). }\end{array}$ \\
\hline $\begin{array}{l}\text { Functional complementarity } \\
\text { (dissimilarity between types } \\
\text { or species). }\end{array}$ & $\begin{array}{l}\text { Functional complementarity } \\
\text { between species (e.g. in resource } \\
\text { use, body size, stature, trophic } \\
\text { status, phenology) enhances } \\
\text { coexistence through niche } \\
\text { partitioning and maintenance of } \\
\text { ecosystem processes (Cardinale } \\
\text { et al., 2007). }\end{array}$ & $\begin{array}{l}\text { High functional } \\
\text { complementarity within both } \\
\text { plant and pollinator } \\
\text { assemblages promotes } \\
\text { recruitment of more diverse } \\
\text { plant communities (Fontaine et } \\
\text { al., 2005). }\end{array}$ \\
\hline $\begin{array}{l}\text { Interaction diversity } \\
\text { (interaction frequencies and } \\
\text { dominance, properties of } \\
\text { network matrices). }\end{array}$ & $\begin{array}{l}\text { Interactions shape the } \\
\text { organisation of ecosystems, } \\
\text { mediate evolution and } \\
\text { persistence of participating } \\
\text { species and influence ecosystem- } \\
\text { level functions, e.g. productivity } \\
\text { (Thompson, 1997). }\end{array}$ & $\begin{array}{l}\text { Overgrazing reduced diversity } \\
\text { of pollination interactions } \\
\text { (Vázquez \& Simberloff, 2003). }\end{array}$ \\
\hline Trophic diversity (number of & Compensatory effects of & Diverse carnivore \\
\hline
\end{tabular}




\begin{tabular}{|c|c|c|}
\hline Variable & $\begin{array}{l}\text { Role in ecosystem resilience and } \\
\text { function }\end{array}$ & Example \\
\hline $\begin{array}{l}\text { trophic levels, interactions } \\
\text { within levels, food web } \\
\text { structure). }\end{array}$ & $\begin{array}{l}\text { predation and resource } \\
\text { competition maintain coexistence } \\
\text { of inferior competitors and prey. } \\
\text { Loss or reduction of some } \\
\text { interactions (e.g. by } \\
\text { overexploitation of top predators) } \\
\text { may precipitate trophic cascades } \\
\text { via competitive elimination or } \\
\text { overabundance of generalist } \\
\text { predators. }\end{array}$ & $\begin{array}{l}\text { assemblages (i.e. varied } \\
\text { behaviour traits and densities) } \\
\text { promote coexistence of plant } \\
\text { species (Calcagno et al., } \\
\text { 2011), decline of primary prey } \\
\text { precipitates diet shifts and } \\
\text { phase shifts (Springer et al., } \\
\text { 2003). }\end{array}$ \\
\hline $\begin{array}{l}\text { Spatial flux of organisms } \\
\text { (rate, timing, frequency and } \\
\text { duration of species } \\
\text { movements between } \\
\text { ecosystems). }\end{array}$ & $\begin{array}{l}\text { Spatial exchanges among local } \\
\text { systems in heterogeneous } \\
\text { landscapes provide spatial } \\
\text { insurance for ecosystem function } \\
\text { (Loreau et al., 2003). Exchanges } \\
\text { may involve resources, genes or } \\
\text { involvement in processes } \\
\text { (Lundberg \& Moberg, 2003). }\end{array}$ & $\begin{array}{l}\text { Herbivorous fish and } \\
\text { invertebrates migrate into reefs } \\
\text { from seagrass beds and } \\
\text { mangroves, reducing algal } \\
\text { abundance on reefs and } \\
\text { maintaining suitable substrates } \\
\text { for larval establishment of } \\
\text { corals after disturbance } \\
\text { (Moberg \& Folke, 1999). }\end{array}$ \\
\hline $\begin{array}{l}\text { Structural complexity (e.g. } \\
\text { complexity indices, number } \\
\text { and cover of vertical strata } \\
\text { in forests, reefs, remote } \\
\text { sensing indices). }\end{array}$ & $\begin{array}{l}\text { Simplified architecture reduces } \\
\text { niche diversity, providing suitable } \\
\text { habitats for fewer species, greater } \\
\text { exposure to predators or greater } \\
\text { competition for resources (due to } \\
\text { reduced partitioning). }\end{array}$ & $\begin{array}{l}\text { Structurally complex coral } \\
\text { reefs support greater fish } \\
\text { diversity (Arias-González et } \\
\text { al., 2012), structurally complex } \\
\text { woodlands support greater bird } \\
\text { diversity (Huth \& Possingham, } \\
\text { 2011). }\end{array}$ \\
\hline
\end{tabular}

\section{Methods}

The evaluation of criterion $D$ follows the same procedure as with criterion $C$, but focuses on biotic variables rather than abiotic variables. Again, relative severity is calculated by rangestandardising the raw values of the biotic variable between its initial value and its collapse value (Section 2). Assessors must: (i) estimate the value of the biotic variable in an initial state; (ii) estimate the expected value in a collapsed state; (iii) measure or estimate the present or future value of the variable. These three quantities are then used to rescale the biotic variable to a proportional change towards collapse (Section 5.3.3). Next, assessors must determine the extent of the disruption as a proportion of the total distribution of the ecosystem. With these two quantities assessors proceed to assign a risk category using the described thresholds. Similarly to criterion $C$, the use of generic indices is discouraged (Section 5.3.3).

\section{Assumptions}

Assumptions in the application of criterion D are similar to assumptions for criterion C. Again, determining an initial and a collapsed value for the biotic variable relies on assumptions about initial and collapsed states of the ecosystem (Section 2.2). As in the application of criterion $A$ and $C$, application of criterion $D$ relies on an assumption about the functional form of decline. In all cases, the decisions made in relation to assumptions must be explicitly discussed in the documentation. 


\section{Documentation}

Assessors should document: (i) the selection of the biotic variable with respect to the conceptual model of ecosystem dynamics; (ii) the setting of a bounded collapse threshold for the biotic variable; (iii) the calculation of relative severity; (iv) the estimation of the extent of disruption; (v) assumptions and appropriate sensitivity analyses (regarding the definition of collapse or the assumed shape of decline); (vi) the final risk categories and plausible bounds. Temporal variation in biotic disruption is best shown in a graph depicting changes in the variable over time, and includes any interpolation or extrapolation to match the relevant time frame (Box 13). 
Box 13. Assessing disruption of biotic processes (criterion D)

Alaskan Giant Kelp Forests are structurally and functionally diverse assemblages, characterised by species of brown algae in the Order Laminariales. These create complex and dynamic layered forest architecture up to $15 \mathrm{~m}$ tall that provides substrate, shelter and foraging resources for a diverse fauna assemblage of epibenthic invertebrate herbivores and pelagic vertebrate predators.

The most serious disruption to biotic interactions occurs through trophic cascades involving sea otters, their predators (killer whales) and their prey (urchins, which consume kelp). Given that densities of kelp are inversely related to densities of urchins, and that phase shifts between forests and urchin barrens are related to a threshold abundance of otters (Estes et al., 2010), any of these variables is potentially suitable for assessing criterion $D$. Although data are available on population changes in great whales and pinnipeds (alternative prey for killer whales), these were not used because: (i) data on more proximal response variables are available; (ii) the causal relationship linking great whales and pinnipeds with otter abundance via killer whale predation is less certain than the link between otters, urchins and kelp.

Survey data for kelp stipe densities were available between 1987 and 2000 from seven islands (Estes et al., 2009). It was assumed that the seven islands, scattered across the Aleutian chain, were representative of the full distribution of the ecosystem. Ecosystem collapse occurs when kelp density is close to zero across all sites, consistent with kelp replacement by urchin barrens throughout the distribution. Rates of change in kelp density were calculated for each island assuming an exponential model. A weighted average across all sites indicated that kelp densities declined on average by $49.2 \%$ between 1987 and 2000 . Allowing for some decline prior to 1987 or after 2000 suggests that the decline in kelp density over the past 50 years was at least $50 \%$ across the full ecosystem extent.

Aerial survey data for sea otters were available for 55 islands along the Aleutian chain between 1959 and 2000 (Doroff et al., 2003). Ecosystem collapse occurs when otter populations reach zero across all sites. The total population was estimated to be $55,000-74,000$ prior to decline in the mid-1980s. By 2000 there were a total of 3,924-13,580 animals based on extrapolation from the aerial survey (Doroff et al., 2003). The lower and upper bounds of otter population decline are:

$$
\begin{aligned}
& 100 \times(55000-13580) / 55000=75.3 \% \\
& \text { and } 100 \times(74000-3924) / 74000=94.7 \%
\end{aligned}
$$

Evidence from trends in kelp density and sea otter sightings suggest a decline in biotic function of $50-95 \%$ relative severity across $100 \%$ of the ecosystem extent. The upper bound of this range may overestimate the severity of decline because: (i) the surveys may have underestimated the population due to detectability issues (Doroff et al., 2003); (ii) the calculations assume that otter and kelp populations have not recovered since 2000 , in spite of qualitative evidence for some recovery. The most likely status of the ecosystem under criterion D1 is Endangered, although a status of Critically Endangered is possible. No projections are currently available for any of the biotic variables. The status of the ecosystem is Data Deficient under criterion D2.

The otter population in 1750 was comparable or slightly larger than its peak in the mid-1980s (Doroff et al., 2003). Based on this assumption, the decline in otter populations throughout the distribution of the kelp forest was $75-95 \%$ since 1750 . The status of the ecosystem type under criterion D3 is therefore Endangered (plausible range Endangered - Critically Endangered). Thus, the Alaskan giant kelp forests ecosystem type is listed as Endangered (plausible range Endangered - Critically Endangered). 


\subsection{Criterion E. Quantitative risk analysis}

\subsubsection{Theory}

Criterion E serves two purposes. First it can be used to list an ecosystem type by implementing models that integrate multiple mechanisms of decline and their interactions into the risk assessment (as described below). Second, it provides an anchor for risk assessment and an overarching framework for the other criteria, as its analogue does in Red List criteria for species. Criterion $\mathrm{E}$ specifies the level of risk that corresponds to each category of threat, by defining the probability of collapse and the specified time frame for Critically Endangered (CR), Endangered (EN) and Vulnerable (VU) ecosystem types.

\subsubsection{Thresholds}

An ecosystem may be listed under Criterion $E$ if it meets the thresholds for the criterion, a quantitative analysis that estimates the probability of ecosystem collapse to be:

\begin{tabular}{|l|l|}
\hline CR & $\geq 50 \%$ within 50 years \\
\hline EN & $\geq 20 \%$ within 50 years \\
\hline VU & $\geq 10 \%$ within 100 years \\
\hline
\end{tabular}

\subsubsection{Application}

The probability of ecosystem collapse can be estimated with stochastic simulation models incorporating key ecosystem processes. The models should:

1. Produce estimates of an ecosystem variable for which a threshold of collapse has been estimated.

2. Produce quantitative estimates of risks of ecosystem collapse over a 50-100 year time frame.

3. Incorporate stochasticity in key processes that determine ecosystem properties.

4. Be applied with scenarios that represent plausible future scenarios of ecosystem dynamics.

A wide range of models can be used to apply criterion E. We provide broad recommendations for the application of criterion $E$ in the form of nine steps to ensure that models are based on sound assumptions, scientifically credible and transparent (Fig. 14). 


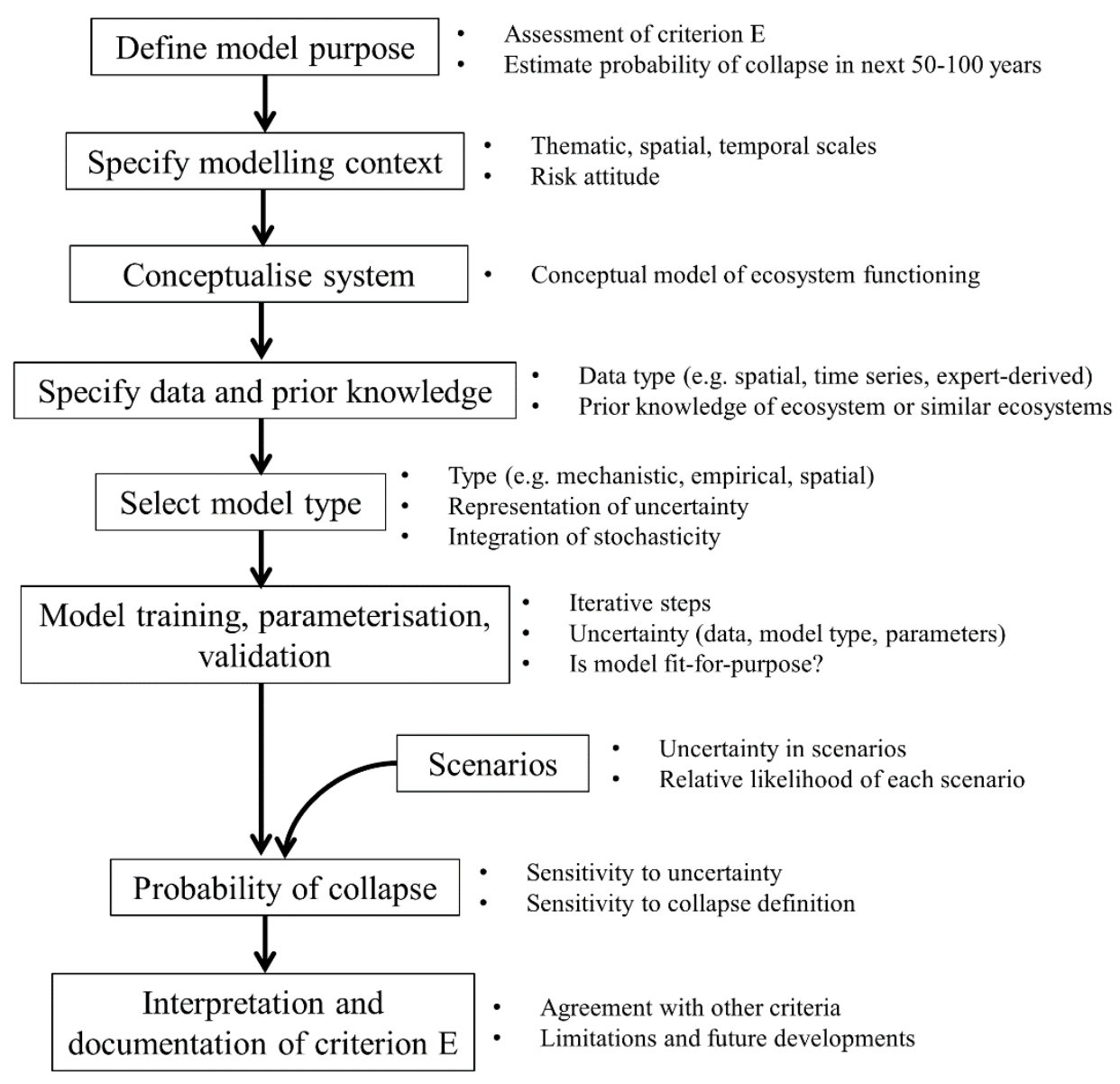

Figure 14. Nine steps to apply criterion E.

\section{Define model purpose}

Models for criterion $\mathrm{E}$ should provide an adequate prediction of the risk of collapse over a period of 50-100 years. If the model used for criterion $E$ is being adapted from a model with different objectives (e.g. providing guidance for management and decision-making), it may be necessary to modify its objectives and implementation. Although other objectives may be important in model-building, models for criterion $\mathrm{E}$ will be reviewed based on the quality of their predictions for the purpose of the RLE assessment.

\section{Specify modelling context}

Ecosystems are inherently scale-dependent, so the thematic, spatial and temporal scales of ecosystem processes may affect model-building and predictions.

Adequately defining the boundaries of the ecosystem under assessment is crucial external forcing and external outputs should be clearly labelled as such. The model should aim to spatially represent all occurrences of the ecosystem; if not, adequate inferences should be made to assess the representativeness of final predictions. The time frame of predictions for criterion $E$ is $50-100$ years, which is longer than other subcriteria (A2a, A2b, C2a, C2b, D2a, D2b) and may therefore require a different understanding of future threats. 
Modelling may involve decisions relying on the risk attitude of the assessor, i.e. the relative costs of under or overestimating the risk of collapse. A precautionary but realistic risk attitude is advocated when implementing criterion $\mathrm{E}$. Such decisions should be thoroughly documented within the criterion $\mathrm{E}$ documentation, and if possible underpinned by quantitative measures of risk aversion.

\section{Conceptualise system}

Models for criterion $E$ should rely on a sound understanding of ecosystem dynamics and function, underpinned by data and relevant inferences from similar ecosystems. Conceptual models can help identify key ecosystem processes and variables indicating collapse. The conceptual model may depict cause-and-effect relationships or transitions among reference and collapsed ecosystem states. The conceptual model used for criterion $\mathrm{E}$ may differ from the general conceptual model used in the ecosystem description (Section 6.2.3), as it may depict more complex relationships and include measurable variables. Deciding on an appropriate level of abstraction for key processes is a key component of conceptualisation and should consider the model purpose, context, required resolution of output and effort required for model building. A critical component of assessment under criterion $E$ is the explicit definition of collapse as it relates to the conceptual model of ecosystem dynamics and measured variables (Section 3.2).

\section{Specify data and prior knowledge}

Applying criterion $E$ requires the levels of key ecosystem variables to be predicted over specified time frames. These variables can represent spatial distribution (as in criteria $A$ and $B$ ), abiotic environment (criterion $C$ ), and/or biotic interactions (criterion D). Suitable variables can be selected by following the processes outlined in the Application sections relevant to each criterion. The data may be quantitative measurements (e.g. spatial data, time series) or expert-derived. At this stage the degree of spatial and temporal aggregation of data and predictions may be revised, to match ecosystem dynamics to the modelling context. For example, it may be appropriate to aggregate daily or monthly data to yearly time steps. In data-poor situations, it may be possible to infer processes and data from similar ecosystems (Maxwell et al., 2015). This should be clearly indicated and discussed within the model documentation.

\section{Select model type}

A diverse range of simulation models of ecosystem dynamics allow the probability of ecosystem collapse to be estimated directly. Selection of an appropriate model type will depend on: (i) ecosystem dynamics; (ii) data availability; (iii) representation of uncertainty; and (iv) integration of stochasticity. Some models may be more appropriate to represent specific ecosystems and their dynamics (e.g. hydrologic models for wetlands, global vegetation models for forests). The type of input data may also constrain model choice (e.g. some model types may be unable to handle missing data or expert-derived data). Models should be chosen or adapted so that appropriate uncertainty and sensitivity analyses can be conducted. Ideally, model uncertainty should be addressed by implementing multiple models representing alternative interpretations of ecosystem dynamics. Finally, ecosystem dynamics rely 
on stochastic processes, so models should be chosen or adapted so as to integrate stochasticity (see Coorong Lagoon case study in Appendix S2 in Keith et al., 2013).

Candidate model types for the application of criterion E include:

- state-and-transition models (Lester and Fairweather, 2009, Rumpff et al., 2011, Maxwell et al., 2015).

- mass-balance models (e.g. Ecopath, Models of Intermediate Complexity) (Christensen and Walters, 2004, Plagányi et al., 2014).

- bifurcation plots (Holdo et al., 2013).

- network theory (e.g. Community Viability Analysis) (de Visser et al., 2011).

- dynamic Global Vegetation Models (Scholze et al., 2006).

- dynamic species distribution and population models (Midgley et al., 2010, Keith et al., 2008).

- spatial models (e.g. cellular automata) (Soares-Filho et al., 2002).

- general ecosystem models (e.g. the Madingley model) (Harfoot et al., 2014).

6. Model training, parameterisation, validation

Models should follow best practice recommendations for each model type, and should be appropriately trained, parameterised and/or validated. For example, the data-derived state-and-transition model of the Coorong Lagoon was validated through multiple pathways, so that neither states nor transitions were determined a priori (Lester \& Fairweather, 2011). For some models full validation may not be possible; in these cases model performance can be evaluated with relevant performance indicators, e.g. satisfactory reproduction of observed behaviour, absence of correlation in model residuals (Jakeman et al., 2006). Model training, parameterisation and validation may occur in iterative steps that should be thoroughly documented. It may be appropriate to assess the effects of data uncertainty, parameter uncertainty and model uncertainty through sensitivity analyses. Overall, assessors should demonstrate that the model is fit for purpose for application in criterion $\mathrm{E}$.

7. Scenarios

Future scenarios representing likely threats and changes to ecosystem dynamics should be identified. It is important to recognise that concepts and data underpinning scenarios may be subject to high levels of uncertainty, the effects of which may be difficult to track in large models (e.g. climate change projections; Kujala et al., 2013). Often, the relative likelihood of each future scenario will not be known (Peterson et al., 2003), so the final likelihood of collapse may be expressed as a range of values rather than a single estimate.

8. Probability of collapse

The estimate of the probability of collapse may be a single value, but in most cases in may be expressed as a range of values representing uncertainty in model-building. Sensitivity analyses of the probability of collapse may be done relevant to: (i) data, model and parameters uncertainty; (ii) scenario uncertainty; and (iii) other forms of 
uncertainty that may affect modelling outcomes, e.g. the choice of variables to assess ecosystem collapse. A sensitivity analysis on the threshold of collapse should be conducted in all models, as the final outcome for criterion $E$ may be particularly sensitive to the definition of collapse. In simulations of the Mountain Ash forest (Burns et al., 2015), for example, the collapse threshold would need to decrease from an average of one hollow-bearing tree per hectare to 0.7 to change the risk assessment outcome.

9. Interpretation and documentation

Criterion E provides an overarching framework for the application of the other criteria, and includes ecosystem dynamics that may not be captured by other criteria. It may therefore be useful to compare the outcome for criterion $E$ with the outcomes of other criteria and provide insights into possible reasons for differences in assessment outcomes. A greater level of documentation is required for criterion $E$ than for other criteria, given the scientific nature of modelling and the effects of uncertainty. It is recommended that assessors publish their models in the peer-reviewed literature and place their materials (data, code) in data repositories to allow full scrutiny of models and their outcomes. Within the RLE peer review, risk assessment and modelling experts will review models against strict criteria and may request additional analyses. Specific guidance and examples of the application of criterion $E$ are currently under development, and will be made available on the IUCN Red List of Ecosystems website (www.iucnrle.org). 
Box 14. Developing a quantitative model of ecosystem dynamics (criterion E)

The probability of ecosystem collapse has been estimated for the Coorong Lagoon of South Australia, through the adaptation of an empirically derived state-and-transition model (Appendix S2 in Keith et al., 2013; Lester \& Fairweather, 2011). Ecosystem collapse occurred when half of the modelled years occurred either in degraded ecosystem states or in a period of recovery following the occurrence of degraded states.

The quantitative assessment of the likelihood of ecosystem collapse in the Coorong was undertaken with a chain-of-models (Lester \& Fairweather, 2011). Downscaled simulations from multiple global climate models were applied to hydrologic models for the Murray-Darling Basin to estimate a time series of flows. Six scenarios were investigated to quantify the likelihood of ecological collapse in the Coorong based on three climate projections for 2030 and two extraction levels (i.e. with, and without current infrastructure and extraction). All scenarios were run for a period of 114 years (Lester \& Fairweather, 2009). Given that each scenario should be interpreted as 114 years of possible variability due to climatic fluctuations, the proportion of years occurring in degraded or recovery states provides an assessment of the stochasticity within the system.

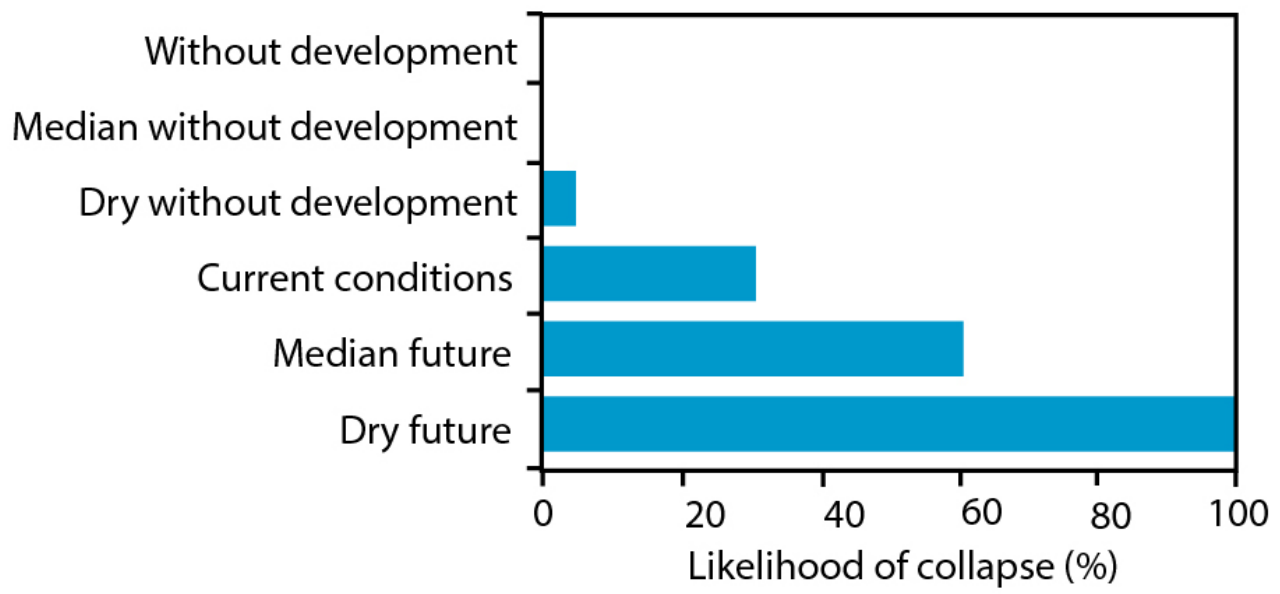

Figure 15. Likelihood of collapse of the Coorong Lagoon under six scenarios of climate change and water extraction. The three climate scenarios are: historical sequence since 1895; the median future climate projection based on three climate change scenarios from 15 global climate models; and a dry future climate projection based on the 10th percentile of the same models.

Of the six scenarios investigated, ecological collapse occurred in four. Water extraction will not cease in the Murray-Darling Basin, so the 'without development' scenarios can be discounted from the overall calculation of risk of collapse. The likelihood of ecological collapse ranges from $30 \%$ to $100 \%$ across three scenarios representing current levels of development. The Coorong Lagoon is thus listed as Critically Endangered (plausible range Endangered - Critically Endangered) under criterion $\mathrm{E}$. 


\section{Peer review and publication}

The IUCN Red List of Ecosystems Committee for Scientific Standards will coordinate independent peer reviews of risk assessments for the global IUCN Red List of Ecosystems. Reviews of sub-global assessments will be the responsibility of project managers, though they are encouraged to seek advice from the Committee for Scientific Standards. Assessments will be reviewed by at least two experts: one with expertise in the ecology of the ecosystem type under assessment, and another familiar with the IUCN Red List of Ecosystems Categories and Criteria.

The review criteria include:

1. Whether the ecosystem type is consistent with the conceptual definition of an ecosystem, and hence a valid unit for assessment using the IUCN Red List of Ecosystems criteria.

2. Whether documentation includes or references an adequate description of the ecosystem type. This includes crosswalks to relevant classifications, an account of key ecological processes and threats, a graphical conceptual model, and a quantitative evaluation of each criterion for which data exist.

3. Whether all accessible data and information relevant to IUCN Red List of Ecosystems assessment of the ecosystem type have been addressed.

4. Whether the quality of underlying data has been evaluated and found to be adequate.

5. Whether definitions and concepts in the Guidelines have been correctly interpreted and applied.

6. Whether methods and calculations have been validly applied, and whether alternative methods are more suitable.

7. Whether estimates of variables for past, present, future, and collapsed states are complete and supported by evidence.

8. Whether inferences related to the IUCN Red List of Ecosystems criteria are justified and transparently communicated.

9. Whether uncertainties have been adequately incorporated in the assessment. 


\section{References}

Akcakaya, H.R., Ferson, S., Burgman, M.A., Keith, D.A., Mace, G.M. and Todd, C.R. (2000). 'Making Consistent IUCN Classifications under Uncertainty'. Conservation Biology 14:1001-1013.

Aladin, N. \& Plotnikov, I. (1993). 'Large saline lakes of former USSR: a summary review'. Hydrobiologia 267:1-12.

Alevizon, W.S. (2010). Introduction To Caribbean Coral Reefs. Gainsville, USA: William Alevizon.

Allen, C., Gunderson, L. and Johnson, A.R. (2005). 'The Use of Discontinuities and Functional Groups to Assess Relative Resilience in Complex Systems'. Ecosystems 8: 958-966.

Allen, T.F. and Hoekstra, T.W. (1990). 'The confusion between scale-defined levels and conventional levels of organization in ecology'. Journal of Vegetation Science 1:5-12.

Andréfouët, S., Muller-Karger, F.E., Robinson, J.A., Kranenburg, C.J., Torres-Pulliza, D., Spraggins, S.A. and Murch, B. (2006). 'Global assessment of modern coral reef extent and diversity for regional science and management applications: a view from space'. In: Suzuki, Y., Nakamori, T., Hidaka, M., Kayanne, H., Casareto, B., Nadaoka, K., Yamano, H. and Tsuchiya, M. (eds.) Proceedings of 10th International Coral Reef Symposium, Okinawa, Japan, 28 June-2 July 2004, pp. 1732-1745. Tokyo, Japan: Japanese Coral Reef Society.

Arias-González, J.E., Acosta-González, G., Membrillo, N., Garza-Pérez, J.R. and CastroPérez, J.M. (2012). 'Predicting spatially explicit coral reef fish abundance, richness and Shannon-Weaver index from habitat characteristics'. Biodiversity and Conservation 21:115-130.

Aronson, R.B. and Blake, D.B. (2001). 'Global climate change and the origin of modern benthic communities in Antarctica'. American Zoologist 41:27-39.

Auld, T.D. and Hutton, I. (2004). 'Conservation issues for the vascular flora of Lord Howe Island'. Cunninghamia 8:490-500.

Auld, T.D. and Leishman, M.R. (2015). 'Ecosystem risk assessment for Gnarled Mossy Cloud Forest, Lord Howe Island, Australia'. Austral Ecology 40:364-372.

Barrett, S. and Yates, C.J. (2015). 'Risks to a mountain summit ecosystem with endemic biota in southwestern Australia'. Austral Ecology 40:423-432.

Beck, M.W., Brumbaugh, R.D., Airoldi, L., Carranza, A., Coen, L.D., Crawford, C., Defeo, O., Edgar, G.J., Hancock, B., Kay, M.C., Lenihan, H.S., Luckenbach, M.W., Toropova, C. L., Zhang, G. and Guo, X. (2011). 'Oyster Reefs at Risk and Recommendations for Conservation, Restoration, and Management'. BioScience 61:107-116.

Blab, J., Riecken, U. and Ssymank, A. (1995). 'Proposal on a criteria system for a National Red Data Book of Biotopes'. Landscape Ecology 10:41-50.

Burns, E.L., Lindenmayer, D.B., Stein, J., Blanchard, W., McBurney, L., Blair, D. and Banks, S.C. (2015). 'Ecosystem assessment of mountain ash forest in the Central Highlands of Victoria, south-eastern Australia'. Austral Ecology 40:386-399. 
Cabezas, A., Comín, F.A., Beguería, S. and Trabucchi, M. (2009). 'Hydrologic and landscape changes in the Middle Ebro River (NE Spain): implications for restoration and management'. Hydrology and Earth Systems Science 13:273-284.

Calcagno, V., Sun, C., Schmitz, O.J. and Loreau, M. (2011). 'Keystone Predation and Plant Species Coexistence: The Role of Carnivore Hunting Mode'. The American Naturalist 177(1):E1-E13.

Cardinale, B.J., Duffy, J.E., Gonzalez, A., Hooper, D.U., Perrings, C., Venail, P., Narwani, A., Mace, G.M., Tilman, D., Wardle, D.A., Kinzig, A.P., Daily, G.C., Loreau, M., Grace, J.B., Larigauderie, A., Srivastava, D.S. and Naeem, S. (2012). 'Biodiversity loss and its impact on humanity'. Nature 486:59-67.

Cardinale, B.J., Matulich, K.L., Hooper, D.U., Byrnes, J.E., Duffy, E., Gamfeldt, L., Balvanera, P., O'Connor, M.I. and Gonzalez, A. (2011). 'The functional role of producer diversity in ecosystems'. American Journal of Botany 98:572-592.

Cardinale, B.J., Wright, J.P., Cadotte, M.W., Carroll, I.T., Hector, A., Srivastava, D.S., Loreau, M. and Weis, J.J. (2007). 'Impacts of plant diversity on biomass production increase through time because of species complementarity'. Proceedings of the National Academy of Sciences 104:18123-18128.

Carpenter, S.R. (2003). Regime Shifts in Lake Ecosystems: Patterns and Variation. Excellence in Ecology Series, Volume 15. Olderdorf/Luhe, Germany: International Ecology Institute.

Carpenter, S.R. and Turner, M.G. (2001). 'Hares and Tortoises: Interactions of Fast and Slow Variables in Ecosystems'. Ecosystems 3:495-497.

Catling, P.M. and Brownell, V.R. (1995). 'A review of the alvars of the Great Lakes region: distribution, floristic composition, biogeography and protection'. Canadian Field Naturalist 109:143-171.

Chapelle, G. and Peck, L.S. (1999). 'Polar gigantism dictated by oxygen availability'. Nature 399:114-115.

Christensen, V. and Walters, C.J. (2004). 'Ecopath with Ecosim: methods, capabilities and limitations'. Ecological modelling 172:109-139.

Clark, G.F., Raymond, B., Riddle, M.J., Stark, J.S. and Johnston, E.L. (2015). 'Vulnerability of Antarctic shallow invertebrate-dominated ecosystems'. Austral Ecology 40:482491.

Clarke, P.J., Latz, P.K. and Albrecht, D.E. (2005). 'Long-term changes in semi-arid vegetation: Invasion of an exotic perennial grass has larger effects than rainfall variability'. Journal of Vegetation Science 16:237-248.

Commonwealth of Australia (2000). Environment Protection and Biodiversity Conservation Regulations, REG 7.02 Criteria for listing threatened ecological communities. Commonwealth of Australia, Canberra, ACT.

Congalton, R.G. and Green, K. (2008). Assessing the Accuracy of Remotely Sensed Data: Principles and Practices, $2^{\text {nd }}$ Edition. Boca Raton, Florida, USA: CRC Press/Taylor \& Francis Group.

Connors, B.M., Cooper, A.B., Peterman, R.M. and Dulvy, N.K. (2014). 'The false classification of extinction risk in noisy environments'. Proceedings of the Royal Society B 281:20132935. 
Council of the European Commission (1992). 'Council directive 92/43/EEC of 21 May 1992 on the conservation of natural habitats and of wild fauna and flora'. Official Journal of the European Communities, Series L 206:7-49.

Crespin, S.J. and Simonetti, J.A. (2015). 'Predicting ecosystem collapse: Spatial factors that influence risks to tropical ecosystems'. Austral Ecology 40:492-501.

Dayton, P. (1979). 'Observations of growth, dispersal and population dynamics of some sponges in McMurdo Sound, Antarctica'. In: Levi, C. and Boury-Esnault, N. (eds.) Biologie des Spongiares (Sponge Biology). Colloques Internationaux du Centre National de la Reserch Scientifique 291:271-282.

Dayton, P.K. (1990). 'Polar benthos'. In: W.O. Smith (ed.) Polar oceanography, pp. 631-685. London: Academic Press.

de Visser, S.N., Freymann, B.P. and Olff, H. (2011). 'The serengeti food web: empirical quantification and analysis of topological changes under increasing human impact'. Journal of Animal Ecology 80:484-494.

DEC (2007). Definitions, categories and criteria for threatened and priority ecological communities. Perth: Department of Environment and Conservation (DEC), Government of Western Australia.

DECC (2007). Lord Howe Island Biodiversity Management Plan. Sydney: Department of Environment and Climate Change (DECC), NSW.

Di Fonzo, M., Collen, B. and Mace, G.M. (2013). 'A new method for identifying rapid decline dynamics in wild vertebrate populations'. Ecology and Evolution 3:2378-2391.

Diamond, J. (2007). 'Easter Island revisited'. Science 317:1692-1694.

Diamond, J.M. (1989). 'The present, past and future of human-caused extinctions'. Philosophical Transactions of the Royal Society of London B 325:469-477.

Domning, D. (1972). 'Steller's sea cow and the origin of North Pacific aboriginal whaling'. Syesis 5:187-189.

Doroff, A.M., Estes, J.A., Tinker, M.T., Burn, D.M. and Evans, T.J. (2003). 'Sea otter population declines in the Aleutian archipelago'. Journal of Mammalogy 84:55-64.

Driver, A., Sink, K.J., Nel, J.N., Holness, S., Van Niekerk, L., Daniels, F., Jonas, Z., Majiedt, P.A., Harris, L. and Maze, K. (2012). National Biodiversity Assessment 2011: An assessment of South Africa's biodiversity and ecosystems. Synthesis Report'. Pretoria: South African National Biodiversity Institute and Department of Environmental Affairs.

Earl, J. (2003). The Distribution and Impacts of Lippia (Phyla canescens) in the Murray Darling System. Guyra: Murray Darling Basin Lippia Working Group.

Eisenhauer, N., Milcu, A., Sabais, A.C.W., Bessler, H., Brenner, J., Engels, C., Klarner, B., Maraun, M., Partsch, S., Roscher, C., Schonert, F., Temperton, V.M., Thomisch, K., Weigelt, A., Weisser, W.W. and Scheu, S. (2011). 'Plant Diversity Surpasses Plant Functional Groups and Plant Productivity as Driver of Soil Biota in the Long Term'. PLOS ONE 6:e16055.

Elith, J., Burgman, M.A. and Regan, H.M. (2002). 'Mapping epistemic uncertainties and vague concepts in predictions of species distribution'. Ecological Modelling 157:313329.

Essl, F. and Egger, G. (2010). Lebensraumvielfalt in Österreich - Gefährdung und Handlungsbedarf. Zusammenschau der Roten Liste gefährdeter Biotoptypen 
Österreichs. Klagenfurt: Naturwissenschaftlicher Verein für Kärnten und Umweltbundesamt GmbH.

Estes, J.A., Doak, D., Springer, A. and Williams, T. (2009). 'Causes and consequences of marine mammal population declines in southwest Alaska: a food-web perspective'. Philosophical Transactions of the Royal Society B 364:1647-1658.

Estes, J.A., Terborgh, J., Brashares, J.S., Power, M.E., Berger, J., Bond, W.J., Carpenter, S. R., Essington, T.E., Holt, R.D. and Jackson, J.B. (2011). 'Trophic downgrading of planet Earth'. Science 333:301-306.

Estes, J.A., Tinker, M. and Bodkin, J.L. (2010). 'Using ecological function to develop recovery criteria for depleted species: sea otters and kelp forests in the Aleutian archipelago'. Conservation Biology 24:852-860.

Faber-Langendoen, D., Keeler-Wolf, T., Meidinger, D., Tart, D., Hoagland, B., Josse, C., Navarro, G., Ponomarenko, S., Saucier, J.-P., Weakley, A. and Comer, P. (2014). 'EcoVeg: a new approach to vegetation description and classification'. Ecological Monographs 84:533-561.

Fischer, J., Lindenmayer, D.B., Blomberg, S.P., Montague-Drake, R., Felton, A. and Stein, J.A. (2007). 'Functional Richness and Relative Resilience of Bird Communities in Regions with Different Land Use Intensities'. Ecosystems 10:964-974.

Folke, C., Carpenter, S., Walker, B., Scheffer, M., Elmqvist, T., Gunderson, L. and Holling, C.S. (2004). 'Regime shifts, resilience, and biodiversity in ecosystem management'. Annual Review of Ecology, Evolution, and Systematics 35:557-581.

Fontaine, C., Dajoz, I., Meriguet, J. and Loreau, M. (2005). 'Functional diversity of plantpollinator interaction webs enhances the persistence of plant communities'. PLoS Biol 4(1), e1. [doi:10.1371/journal.pbio.0040001]

Foody, G.M. (2011). 'Impacts Of Imperfect Reference Data On The Apparent Accuracy Of Species Presence-Absence Models And Their Predictions'. Global Ecology And Biogeography 20(3):498-508.

Fuller, R.M., Smith, G.M. and Devereux, B.J. (2003). 'The characterisation and measurement of land cover change through remote sensing: problems in operational applications?'. International Journal of Applied Earth Observation and Geoinformation 4:243-253.

Gaston, K.J. (1994). Rarity. London, UK: Chapman and Hall.

Gaston, K.J. and Fuller, R.A. (2008). 'Commonness, population depletion and conservation biology'. Trends in Ecology \& Evolution 23:14-19.

Gaston, K.J. and Fuller, R.A. (2009). 'The sizes of species' geographic ranges'. Journal of Applied Ecology 46:1-9.

Gili, J.-M., Arntz, W.E., Palanques, A., Orejas, C., Clarke, A., Dayton, P.K., Isla, E., Teixidó, N., Rossi, S. and López-González, P.J. (2006). 'A unique assemblage of epibenthic sessile suspension feeders with archaic features in the high-Antarctic'. Deep Sea Research Part II: Topical Studies in Oceanography 53:1029-1052.

Giri, C., Ochieng, E., Tieszen, L., Zhu, Z., Singh, A., Loveland, T., Masek, J. and Duke, N. (2011). 'Status and distribution of mangrove forests of the world using earth observation satellite data'. Global Ecology and Biogeography 20:154-159.

Goudard, A. and Loreau, M. (2008). 'Nontrophic interactions, biodiversity, and ecosystem functioning: an interaction web model'. The American Naturalist 171:91-106. 
Government of Manitoba (2014). The Endangered Species and Ecosystems Act. <https://web2.gov.mb.ca/laws/statutes/ccsm/e111e.php?ccsm=e111>. Accessed 15 November 2015.

Grebmeier, J.M., Overland, J.E., Moore, S.E., Farley, E.V., Carmack, E.C., Cooper, L.W., Frey, K.E., Helle, J.H., McLaughlin, F.A. and McNutt, S.L. (2006). 'A major ecosystem shift in the northern Bering Sea'. Science 311:1461-1464.

Green, P.T., O'Dowd, D.J., Abbott, K.L., Jeffery, M., Retallick, K. and Mac Nally, R. (2011). 'Invasional meltdown: Invader-invader mutualism facilitates a secondary invasion'. Ecology 92:1758-1768.

Gregr, E.J., Ahrens, A.L. and Perry, R.I. (2012). 'Reconciling classifications of ecologically and biologically significant areas in the world's oceans'. Marine Policy 36:716-726.

Hannah, J. and Bell, R.G. (2012). 'Regional sea level trends in New Zealand'. Journal of Geophysical Research: Oceans 117:C01004.

Hansen, M.C., Potapov, P.V., Moore, R., Hancher, M., Turubanova, S.A., Tyukavina, A., Thau, D., Stehman, S.V., Goetz, S.J., Loveland, T.R., Kommareddy, A., Egorov, A., Chini, L., Justice, C.O. and Townshend, J.R.G. (2013). 'High-Resolution Global Maps of 21st-Century Forest Cover Change'. Science 342:850-853.

Hanski, I. (1998). 'Metapopulation dynamics'. Nature 396:41-49.

Harfoot, M.B.J., Newbold, T., Tittensor, D.P., Emmott, S., Hutton, J., Lyutsarev, V., Smith, M.J., Scharlemann, J.P.W. and Purves, D.W. (2014). 'Emergent Global Patterns of Ecosystem Structure and Function from a Mechanistic General Ecosystem Model'. PLoS Biol 12:e1001841.

Harpole, W.S. and Tilman, D. (2007). 'Grassland species loss resulting from reduced niche dimension'. Nature 446:791-793.

Hartley, S. and Kunin, W.E. (2003). 'Scale dependency of rarity, extinction risk, and conservation priority'. Conservation Biology 17:1559-1570.

Healy, T., Wang, Y. and Healy, J. (eds.) (2002). Muddy Coasts of the World: Processes, Deposits, and Function, Amsterdam, The Netherlands: Elsevier Science.

Hermoso, V., Januchowski-Hartley, S.R. \& Pressey, R.L. (2013). 'When the suit does not fit biodiversity: loose surrogates compromise the achievement of conservation goals'. Biological Conservation 159:197-205.

Hobbs, R.J., Arico, S., Aronson, J., Baron, J.S., Bridgewater, P., Cramer, V.A., Epstein, P.R., Ewel, J.J., Klink, C.A., Lugo, A.E., Norton, D., Ojima, D., Richardson, D.M., Sanderson, E.W., Valladares, F., Vilà, M., Zamora, R. and Zobel, M. (2006). 'Novel ecosystems: theoretical and management aspects of the new ecological world order'. Global Ecology and Biogeography 15:1-7.

Holdaway, R.J., Wiser, S.K. and Williams, P.A. (2012). 'Status assessment of New Zealand's naturally uncommon ecosystems'. Conservation Biology 26:619-629.

Holdo, R.M., Holt, R.D. and Fryxell, J.M. (2013). 'Herbivore-vegetation feedbacks can expand the range of savanna persistence: insights from a simple theoretical model'. Oikos 122:441-453.

Hong, S. and Shin, I. (2010). 'Global Trends of Sea Ice: Small-Scale Roughness and Refractive Index'. Journal of Climate 23:4669-4676.

Huth, N. and Possingham, H.P. (2011). 'Basic ecological theory can inform habitat restoration for woodland birds'. Journal of Applied Ecology 48:293-300. 
IUCN (2001). IUCN Red List Categories and Criteria: Version 3.1, Gland, Switzerland and Cambridge, UK: IUCN Species Survival Commission.

IUCN (2012). IUCN Red List Categories and Criteria: Version 3.1. Second edition. Gland, Switzerland and Cambridge, UK: IUCN.

IUCN (2015). The IUCN Red List of Threatened Species. Version 2015-4. <www.iucnredlist.org>. Accessed 19 November 2015.

IUCN Standards and Petitions Subcommittee (2014). Guidelines for Using the IUCN Red List Categories and Criteria. Version 11. Prepared by the Standards and Petitions Subcommittee. <www.iucnredlist.org/documents/RedListGuidelines.pdf>

Jakeman, A.J., Letcher, R.A. and Norton, J.P. (2006). 'Ten iterative steps in development and evaluation of environmental models'. Environmental Modelling \& Software 21:602-614.

Jarvis, A. and Mulligan, M. (2011). 'The climate of cloud forests'. Hydrological Processes 25:327-343.

Kauffman, A. and Gupta, M.M. (1991). Introduction to fuzzy arithmetic: theory and application. New York: VanNostrand Reinhold.

Keith, D. and Myerscough, P. (1993). 'Floristics and soil relations of upland swamp vegetation near Sydney'. Australian Journal of Ecology 18:325-344.

Keith, D.A. (2009). 'The interpretation, assessment and conservation of ecological communities'. Ecological Management \& Restoration 10:S3-S15.

Keith, D.A. (2015). 'Assessing and managing risks to ecosystem biodiversity'. Austral Ecology 40:337-346.

Keith, D.A., Akçakaya, H.R., Thuiller, W., Midgley, G.F., Pearson, R.G., Phillips, S.J., Regan, H.M., Araújo, M.B. and Rebelo, T.G. (2008). 'Predicting extinction risks under climate change: coupling stochastic population models with dynamic bioclimatic habitat models'. Biology Letters 4:560-563.

Keith, D.A., Elith, J. and Simpson, C.C. (2014). 'Predicting distribution changes of a mire ecosystem under future climates'. Diversity and Distributions 20:440-454.

Keith, D.A., Holman, L., Rodoreda, S., Lemmon, J. and Bedward, M. (2007). 'Plant functional types can predict decade-scale changes in fire-prone vegetation'. Journal of Ecology 95:1324-1337.

Keith, D.A., Orscheg, C., Simpson, C.C., Clarke, P.J., Hughes, L., Kennelly, S.J., Major, R.E., Soderquist, T.R., Wilson, A.L. and Bedward, M. (2009). 'A new approach and case study for estimating extent and rates of habitat loss for ecological communities'. Biological Conservation 142:1469-1479.

Keith, D.A., Rodríguez, J.P., Brooks, T.M., Burgman, M.A., Barrow, E.G., Bland, L., Comer, P.J., Franklin, J., Link, J., McCarthy, M.A., Miller, R.M., Murray, N.J., Nel, J., Nicholson, E., Oliveira-Miranda, M.A., Regan, T.J., Rodríguez-Clark, K.M., Rouget, M. and Spalding, M.D. (2015). 'The IUCN Red List of Ecosystems: Motivations, Challenges, and Applications'. Conservation Letters 8:214-226.

Keith, D.A., Rodríguez, J.P., Rodríguez-Clark, K.M., Nicholson, E., Aapala, K., Alonso, A., Asmussen, M., Bachman, S., Basset, A., Barrow, E.G., Benson, J.S., Bishop, M.J., Bonifacio, R., Brooks, T.M., Burgman, M.A., Comer, P., Comín, F.A., Essl, F., FaberLangendoen, D., Fairweather, P.G., Holdaway, R.J., Jennings, M., Kingsford, R.T., Lester, R.E., Nally, R.M., McCarthy, M.A., Moat, J., Oliveira-Miranda, M.A., Pisanu, P., Poulin, B., Regan, T.J., Riecken, U., Spalding, M.D. and Zambrano-Martínez, S. 
(2013). 'Scientific Foundations for an IUCN Red List of Ecosystems'. PLoS ONE 8(5):e62111.

Kingsford, R. and Johnson, W. (1998). 'Impact of water diversions on colonially-nesting waterbirds in the Macquarie Marshes of arid Australia'. Colonial Waterbirds 21(2):159-170.

Kingsford, R.T. and Auld, K.M. (2005). 'Waterbird breeding and environmental flow management in the Macquarie Marshes, arid Australia'. River Research and Applications 21:187-200.

Kingsford, R.T. and Thomas, R.F. (1995). 'The Macquarie Marshes in arid Australia and their waterbirds: a 50-year history of decline'. Environmental Management 19:867-878.

Kirby, M.X. (2004). 'Fishing down the coast: Historical expansion and collapse of oyster fisheries along continental margins'. Proceedings of the National Academy of Sciences of the United States of America 101:13096-13099.

Kontula, T. and Raunio, A. (2009). 'New method and criteria for national assessments of threatened habitat types'. Biodiversity and Conservation 18:3861-3876.

Kujala, H., Moilanen, A., Araújo, M.B. and Cabeza, M. (2013). 'Conservation planning with uncertain climate change projections'. PloS ONE 8:e53315.

Lehmann, C.E.R., Anderson, T.M., Sankaran, M., Higgins, S.I., Archibald, S., Hoffmann, W.A., Hanan, N.P., Williams, R.J., Fensham, R.J., Felfili, J., Hutley, L.B., Ratnam, J., San Jose, J., Montes, R., Franklin, D., Russell-Smith, J., Ryan, C.M., Durigan, G., Hiernaux, P., Haidar, R., Bowman, D.M.J.S. and Bond, W.J. (2014). 'Savanna vegetation-fire-climate relationships differ among continents'. Science 343:548-552.

Lester, R.E. and Fairweather, P.G. (2009). 'Modelling future conditions in the degraded semi-arid estuary of Australia's largest river using ecosystem states'. Estuarine, Coastal and Shelf Science 85:1-11.

Lester, R.E. and Fairweather, P.G. (2011). 'Ecosystem states: Creating a data-derived, ecosystem-scale ecological response model that is explicit in space and time'. Ecological Modelling 222:2690-2703.

Likens, G.E. (1992). The Ecosystem Approach: Its Use and Abuse. Excellence in Ecology Series, Volume 3. Olderdorf/Luhe, Germany: Ecology Institute

Lindenmayer, D. (2009). Forest pattern and ecological process: a synthesis of 25 years of research. Melbourne, Australia: CSIRO Publishing.

Lindgaard, A. and Henriksen, S. (eds.) (2011). The 2011 Norwegian Red List for Ecosystems and Habitat Types. Trondheim: Norwegian Biodiversity Information Centre.

Loreau, M., Mouquet, N. and Gonzalez, A. (2003). 'Biodiversity as spatial insurance in heterogeneous landscapes'. Proceedings of the National Academy of Sciences 100:12765-12770.

Ludwig, J.A., Bastin, G.N., Chewings, V.H., Eager, R.W. and Liedloff, A.C. (2007). 'Leakiness: A new index for monitoring the health of arid and semiarid landscapes using remotely sensed vegetation cover and elevation data'. Ecological Indicators 7:442-454.

Lundberg, J. and Moberg, F. (2003). 'Mobile Link Organisms and Ecosystem Functioning: Implications for Ecosystem Resilience and Management'. Ecosystems 6:87-98. 
Mac Nally, R., Cunningham, S.C., Baker, P.J., Horner, G.J. and Thomson, J.R. (2011). 'Dynamics of Murray-Darling floodplain forests under multiple stressors: The past, present, and future of an Australian icon'. Water Resources Research 47:W00G05.

MacArthur, R.H. and Wilson, E.O. (1967). The theory of island biogeography. Princeton, New Jersey: Princeton University Press.

Mace, G.M., Collar, N.J., Gaston, K.J., Hilton-Taylor, C., Akcakaya, H.R., Leader-Williams, N., Milner-Gulland, E.J. and Stuart, S.N. (2008). 'Quantification of extinction risk: IUCN's system for classifying threatened species'. Conservation Biology 22:1424-42.

MacKinnon, J., Verkuil, Y.I. \& Murray, N.J. (2012). IUCN situation analysis on East and Southeast Asian intertidal habitats, with particular reference to the Yellow Sea (including the Bohai Sea). Occasional Paper of the IUCN Species Survival Commission No. 47. Gland, Switzerland and Cambridge, UK: IUCN.

Mastrandrea, M.D., Field, C.B., Stocker, T.F., Edenhofer, O., Ebi, K.L., Frame, D.J., Held, H., Kriegler, E., Mach, K.J. and Matschoss, P.R. (2010). Guidance Note for Lead Authors of the IPCC Fifth Assessment Report on Consistent Treatment of Uncertainties. Intergovernmental Panel on Climate Change (IPCC).

Maxwell, P.S., Pitt, K.A., Olds, A.D., Rissik, D. and Connolly, R.M. (2015). 'Identifying habitats at risk: simple models can reveal complex ecosystem dynamics'. Ecological Applications 25:573-587.

McClintock, J.B., Amsler, C.D., Baker, B.J. and Van Soest, R.W. (2005). 'Ecology of Antarctic marine sponges: an overview'. Integrative and Comparative Biology 45:359-368.

McKnight, M.W., White, P.S., McDonald, R.I., Lamoreux, J.F., Sechrest, W., Ridgely, R.S. and Stuart, S.N. (2007). 'Putting beta-diversity on the map: broad-scale congruence and coincidence in the extremes'. PLoS Biol 5:e272.

Metternicht, G.I. and Zinck, J.A. (2003). 'Remote sensing of soil salinity: potentials and constraints'. Remote Sensing of Environment 85:1-20.

Meyer, J. (2011). 'Montane cloud forests on remote islands of Oceania: the example of French Polynesia (South Pacific Ocean)'. In: Bruijnzeel, L.A., Scatena, F.N. and Hamilton, L.S. (eds).Tropical Montane Cloud Forests: Science for Conservation and Management, pp. 121-129. Cambridge, UK: Cambridge University Press.

Micklin, P. and Aladin, N.V. (2008). 'Reclaiming the Aral Sea'. Scientific American 298:6471.

Midgley, G.F., Davies, I.D., Albert, C.H., Altwegg, R., Hannah, L., Hughes, G.O., O'Halloran, L.R., Seo, C., Thorne, J.H. and Thuiller, W. (2010). 'BioMove-an integrated platform simulating the dynamic response of species to environmental change'. Ecography 33:612-616.

Miller, G., Friedel, M., Adam, P. and Chewings, V. (2010). 'Ecological impacts of buffel grass (Cenchrus ciliaris L.) invasion in central Australia - does field evidence support a fireinvasion feedback?'. The Rangeland Journal 32:353-365.

Moberg, F. and Folke, C. (1999). 'Ecological goods and services of coral reef ecosystems'. Ecological Economics 29:215-233.

Mucina, L. and Rutherford, M.C. (eds.) (2006). The Vegetation of South Africa, Lesotho and Swaziland. Strelitzia 19. Pretoria: South African National Biodiversity Institute.

Mueller-Dombois, D. and Fosberg, F.R. (1998). Vegetation of the Tropical Pacific Islands. New York: Springer-Verlag. 
Murray, N.J., Clemens, R.S., Phinn, S.R., Possingham, H.P. and Fuller, R.A. (2014). 'Tracking the rapid loss of tidal wetlands in the Yellow Sea'. Frontiers in Ecology and the Environment 12:267-272.

Murray, N.J. and Fuller, R.A. (2015). 'Protecting stopover habitat for migratory shorebirds in East Asia'. Journal of Ornithology 156:217-225.

Murray, N.J., Ma, Z. and Fuller, R.A. (2015). 'Tidal flats of the Yellow Sea: A review of ecosystem status and anthropogenic threats'. Austral Ecology 40:472-481.

Murray, N.J., Phinn, S.R., Clemens, R.S., Roelfsema, C.M. and Fuller, R.A. (2012). 'Continental Scale Mapping of Tidal Flats across East Asia Using the Landsat Archive'. Remote Sensing 4:3417-3426.

Newton, A.C. (2010). 'Use of a Bayesian network for Red Listing under uncertainty'. Environmental Modelling \& Software 25:15-23.

Nicholson, E., Keith, D.A. and Wilcove, D.S. (2009). 'Assessing the threat status of ecological communities'. Conservation Biology 23:259-274.

Nicholson, E., Regan, T.J., Auld, T.D., Burns, E.L., Chisholm, L.A., English, V., Harris, S., Harrison, P., Kingsford, R.T., Leishman, M.R., Metcalfe, D.J., Pisanu, P., Watson, C.J., White, M., White, M.D., Williams, R.J., Wilson, B. and Keith, D.A. (2015). 'Towards consistency, rigour and compatibility of risk assessments for ecosystems and ecological communities'. Austral Ecology 40:347-363.

NSW Scientific Committee (2004). Coolibah - Black Box Woodland of the northern riverine plains in the Darling Riverine Plains and Brigalow Belt South bioregions endangered ecological community listing. Final Determination. Sydney: NSW Scientific Committee.

Olofsson, P., Foody, G.M., Herold, M., Stehman, S.V., Woodcock, C.E. and Wulder, M.A. (2014). 'Good practices for estimating area and assessing accuracy of land change'. Remote Sensing of Environment 148:42-57.

Olofsson, P., Foody, G.M., Stehman, S.V. and Woodcock, C.E. (2013). 'Making better use of accuracy data in land change studies: Estimating accuracy and area and quantifying uncertainty using stratified estimation'. Remote Sensing of Environment 129:122131.

Payet, K., Rouget, M., Esler, K.J., Reyers, B., Rebelo, T., Thompson, M.W. and Vlok, J.H. (2013). 'Effect of Land Cover and Ecosystem Mapping on Ecosystem-Risk Assessment in the Little Karoo, South Africa'. Conservation Biology 27:531-541.

Peterson, G.D., Cumming, G.S. and Carpenter, S.R. (2003). 'Scenario planning: a tool for conservation in an uncertain world'. Conservation Biology 17:358-366.

Pickett, S.T.A. (1989). 'Space-for-time substitution as an alternative to long-term studies'. In: Likens, G.E. (ed.) Long-term Studies in Ecology: Approaches and Alternatives, pp.110-135. New York: Springer-Verlag.

Pickett, S.T.A. and Cadenasso, M.L. (1995). 'Landscape ecology: spatial heterogeneity in ecological systems'. Science 269:331-334.

Plagányi, É.E., Punt, A.E., Hillary, R., Morello, E.B., Thébaud, O., Hutton, T., Pillans, R.D., Thorson, J.T., Fulton, E.A. and Smith, A.D. (2014). 'Multispecies fisheries management and conservation: tactical applications using models of intermediate complexity'. Fish and Fisheries 15:1-22.

Pounds, J.A., Fogden, M.P.L. and Campbell, J.H. (1999). 'Biological response to climate change on a tropical mountain'. Nature 398:611-615. 
Precautionary Principle Project (2005). Guidelines for Applying the Precautionary Principle to Biodiversity Conservation and Natural Resource Management. Cambridge, UK: The Precautionary Principle Project - a joint initiative of Fauna \& Flora International, IUCN, ResourceAfrica and TRAFFIC.

Rebelo, A.G., Boucher, C., Helme, N., Mucina, L., Rutherford, M.C. (2006). 'Fynbos biome'. In: Mucina, L. and Rutherford, M.C. (eds.) The Vegetation of South Africa, Lesotho and Swaziland. Strelitzia 19, pp.52-219. Pretoria: South African National Biodiversity Institute.

Regan, H.M. and Colyvan, M. (2000). 'Fuzzy Sets and Threatened Species Classification'. Conservation Biology 14:1197-1199.

Regan, H.M., Colyvan, M. and Burgman, M.A. (2002). 'A taxonomy and treatment of uncertainty for ecology and conservation biology'. Ecological Applications 12:618628.

Reid, M., Ogden, R. and Thoms, M. (2011). 'The influence of flood frequency, geomorphic setting and grazing on plant communities and plant biomass on a large dryland floodplain'. Journal of Arid Environments 75:815-826.

Reisewitz, S.E., Estes, J.A. and Simenstad, C.A. (2006). 'Indirect food web interactions: sea otters and kelp forest fishes in the Aleutian archipelago'. Oecologia 146:623-631.

Republic of South Africa (2004). 'National Environmental Management: Biodiversity Act, 2004'. Government Gazette Republic of South Africa Cape Town 467:1-84

Reschke, C., Reid, R., Jones, J., Feeney, T., and Potter, H. (1999). Conserving Great Lakes Alvars. Chicago, USA: The Nature Conservancy.

Riecken, U., Finck, P., Raths, U., Schröder, E. and Ssymank, A. (2009). German Red Data Book on endangered habitats (short version, July 2009). Bonn-Bad Godesberg, Germany: German Federal Agency for Nature Conservation (BfN).

Riecken, U., Heinzel, K., Schlumprecht, H., Boedeker, D. and für Naturschutz, B. (2006). Rote Liste der gefährdeten Biotoptypen Deutschlands: zweite fortgeschriebene Fassung 2006. Bonn, Germany: Bundesamt für Naturschutz.

Robertson, A.I. and Rowling, R.W. (2000). 'Effects of livestock on riparian zone vegetation in an Australian dryland river'. Regulated Rivers: Research \& Management 16:527541.

Rodríguez, J.P., Keith, D.A., Rodríguez-Clark, K.M., Murray, N.J., Nicholson, E., Regan, T.J., Miller, R.M., Barrow, E.G., Bland, L.M., Boe, K., Brooks, T.M., Oliveira-Miranda, M.A., Spalding, M. and Wit, P. (2015). 'A practical guide to the application of the IUCN Red List of Ecosystems criteria'. Philosophical Transactions of the Royal Society B 370: 20140003.

Rodríguez, J.P., Rodríguez-Clark, K.M., Baillie, J.E.M., Ash, N., Benson, J., Boucher, T., Brown, C., Burgess, N.D., Collen, B., Jennings, M., Keith, D.A., Nicholson, E., Revenga, C., Reyers, B., Rouget, M., Smith, T., Spalding, M., Taber, A., Walpole, M., Zager, I. and Zamin, T. (2011). 'Establishing IUCN Red List Criteria for Threatened Ecosystems'. Conservation Biology 25:21-29.

Rodríguez, J.P., Rodríguez-Clark, K.M., Keith, D.A., Barrow, E.G., Benson, J., Nicholson, E. and Wit, P. (2012a). 'IUCN Red List of Ecosystems'. S.A.P.I.EN.S [Online] 5.2 $<$ http://sapiens.revues.org/1286>.

Rodríguez, J.P., Rodríguez-Clark, K.M., Keith, D.A., Barrow, E.G., Comer, P. and OliveiraMiranda, M.A. (2012b). 'From Alaska to Patagonia: the IUCN Red List of the continental ecosystems of the Americas'. Oryx 46:170-171. 
Rodríguez, J.P., Rojas-Suárez, F. and Giraldo Hernández, D. (eds.) (2010). Libro Rojo de Ios Ecosistemas Terrestres de Venezuela. Caracas, Venezuela: Provita, Shell Venezuela y Lenovo (Venezuela).

Rogers, C.S. (1990). 'Responses of coral reef $s$ and reef organisms to sedimentation'. Marine Ecology Progress Series 62:185-202.

Rumpff, L., Duncan, D., Vesk, P., Keith, D. and Wintle, B. (2011). 'State-and-transition modelling for adaptive management of native woodlands'. Biological Conservation 144:1224-1236.

Salafsky, N., Salzer, D., Stattersfield, A.J., Hilton-Taylor, C., Neugarten, R., Butchart, S.H.M., Collen, B., Cox, N., Master, L.L., O'Connor, S. and Wilkie, D. (2008). 'A standard lexicon for biodiversity conservation: Unified classifications of threats and actions'. Conservation Biology 22:897-911.

Scheffer, M., Carpenter, S.R., Foley, J., Folke, C. and Walker, B.H. (2001). 'Catastrophic shifts in ecosystems'. Nature 413:591-596.

Scholze, M., Knorr, W., Arnell, N.W. and Prentice, I.C. (2006). 'A climate-change risk analysis for world ecosystems'. Proceedings of the National Academy of Sciences 103:13116-13120.

Shi, J., Ma, K., Wang, J., Zhao, J. and He, K. (2010). 'Vascular plant species richness on wetland remnants is determined by both area and habitat heterogeneity'. Biodiversity and Conservation 19:1279-1295.

Simmons, C.L., Auld, T.D., Hutton, I., Baker, W. J. and Shapcott, A. (2012). 'Will climate change, genetic and demographic variation or rat predation pose the greatest risk for persistence of an altitudinally distributed island endemic?'. Biology 1:736-765.

Soares-Filho, B.S., Coutinho Cerqueira, G. and Lopes Pennachin, C. (2002). 'DINAMICA-a stochastic cellular automata model designed to simulate the landscape dynamics in an Amazonian colonization frontier'. Ecological Modelling 154:217-235.

Spalding, M.D., Fox, H.E., Halpern, B.S., McManus, M.A., Molnar, J., Allen, G.R., Davidson, N., Jorge, Z.A., Lombana, A.L., Lourie, S.A., Martin, K.D., McManus, E., Recchia, C.A. and Robertson, J. (2007). 'Marine ecoregions of the world: A bioregionalization of coastal and shelf areas'. BioScience 57:573-583.

Springer, A.M., Estes, J.A., van Vliet, G.B., Williams, T.M., Doak, D.F., Danner, E.M., Forney, K.A. and Pfister, B. (2003). 'Sequential megafaunal collapse in the North Pacific Ocean: An ongoing legacy of industrial whaling?'. PNAS 100:12223-12228.

Steneck, R. and Watling, L. (1982). 'Feeding capabilities and limitation of herbivorous molluscs: a functional group approach'. Marine Biology 68:299-319.

Steneck, R.S., Graham, M.H., Bourque, B.J., Corbett, D., Erlandson, J.M., Estes, J.A. and Tegner, M.J. (2002). 'Kelp forest ecosystems: biodiversity, stability, resilience and future'. Environmental Conservation 29:436-459.

Tansley, A.G. (1935). 'The use and abuse of vegetational concepts and terms'. Ecology 16:284-307.

Taylor, B. and Ganf, G.G. (2005). 'Comparative ecology of two co-occurring floodplain plants: the native Sporobolus mitchellii and the exotic Phyla canescens'. Marine and Freshwater Research 56:431-440.

Thébault, E. and Loreau, M. (2005). 'Trophic Interactions and the Relationship between Species Diversity and Ecosystem Stability'. The American Naturalist 166:E95-E114. 
Thompson, J.N. (1997). Conserving Interaction Biodiversity. In: Pickett, S.T.A., Ostfeld, R.S. Shachak, M. and Likens, G.E. (eds.) The Ecological Basis of Conservation, pp.285293. Springer US.

Thoms, M. and Sheldon, F. (2000). 'Water resource development and hydrological change in a large dryland river: the Barwon-Darling River, Australia'. Journal of Hydrology 228:10-21.

Thoms, M.C. (2003). Floodplain-river ecosystems: lateral connections and the implications of human interference. Geomorphology, 56, 335-349.

UNEP (2001). Partow, H. The Mesopotamian marshlands: demise of an ecosystem. Early Warning and Assessment Technical Report, UNEP/DEWA/TR.01-3 Rev. 1. Division of Early Warning and Assessment. Nairobi, Kenya: United Nations Environment Programme.

Vázquez, D.P. and Simberloff, D. (2003). 'Changes in interaction biodiversity induced by an introduced ungulate'. Ecology Letters 6:1077-1083.

Walker, B., Kinzig, A. and Langridge, J. (1999). 'Plant Attribute Diversity, Resilience, and Ecosystem Function: The Nature and Significance of Dominant and Minor Species'. Ecosystems 2:95-113.

Wang, Y. and Zhu, D. (1994). 'Tidal flats in China'. Oceanology of China Seas 2:445-456.

Wang, Y.P., Gao, S., Jia, J., Thompson, C.E.L., Gao, J. and Yang, Y. (2012). 'Sediment transport over an accretional intertidal flat with influences of reclamation, Jiangsu coast, China'. Marine Geology 291-294:147-161.

Watling, L. and Norse, E.A. (1998). 'Disturbance of the seabed by mobile fishing gear: a comparison to forest clearcutting'. Conservation Biology 12:1180-1197.

Wiens, J.A. (1989). 'Spatial scaling in ecology'. Functional Ecology 3:385-397.

Wood, J., Low, A.B., Donaldson, J.S. and Rebelo, A.G. (1994). 'Threats to plant species diversity through urbanization and habitat fragmentation in the Cape Metropolitan Area, South Africa'. In: Huntley, B.J. (ed.) Botanical Diversity in Southern Africa. Strelitzia 1, pp.259-274. Pretoria: South African National Biodiversity Institute.

Zhao, H.L., Zhao, X.Y., Zhou, R.L., Zhang, T.H. and Drake, S. (2005). 'Desertification processes due to heavy grazing in sandy rangeland, Inner Mongolia'. Journal of Arid Environments 62:309-319. 


\section{Appendix 1. List of contributors}

\begin{tabular}{|c|c|c|}
\hline Name & Organisation & Country \\
\hline Kaisu Aapala & Finnish Environment Institute & Finland \\
\hline Alfonso Alonso & Smithsonian Conservation Biology Institute & USA \\
\hline Marianne Asmüssen & $\begin{array}{l}\text { Instituto Venezolano de Investigaciones } \\
\text { Científicas }\end{array}$ & Venezuela \\
\hline Steven Bachman & Royal Botanic Gardens, Kew & UK \\
\hline Jonathan Baillie & Zoological Society of London & UK \\
\hline Edmund G. Barrow & IUCN & Kenya / Ireland \\
\hline Alberto Bassett & University of Lecce & Italy \\
\hline John Benson & Royal Botanic Gardens and Domain Trust & Australia \\
\hline Melanie J. Bishop & Macquarie University & Australia \\
\hline Lucie M. Bland & University of Melbourne & Australia \\
\hline Kaia Boe & IUCN & Switzerland \\
\hline Ronald Bonifacio & $\begin{array}{l}\text { South Australian Department of Environment } \\
\text { and Natural Resources }\end{array}$ & Australia \\
\hline Tim Boucher & The Nature Conservancy & USA \\
\hline Thomas M. Brooks & IUCN & Switzerland \\
\hline Claire Brown & UNEP-WCMC & UK \\
\hline Neil Burgess & UNEP-WCMC & UK \\
\hline Mark A. Burgman & University of Melbourne & Australia \\
\hline Ben Collen & Zoological Society of London & UK \\
\hline Patrick Comer & NatureServe & USA \\
\hline Francisco A. Comín & Pyrenean Institute of Ecology-CSIC & Spain \\
\hline Franz Essl & Environment Agency & Austria \\
\hline Don Faber-Langendoen & NatureServe & USA \\
\hline Peter G. Fairweather & Flinders University & Australia \\
\hline Ariany García Rawlins & Provita & Venezuela \\
\hline Robert J. Holdaway & Landcare Research & New Zealand \\
\hline Michael Jennings & University of Idaho & USA \\
\hline David A. Keith & University of New South Wales & Australia \\
\hline Richard T. Kingsford & University of New South Wales & Australia \\
\hline Tytti Kontula & Finnish Environment Institute & Finland \\
\hline Rebecca E. Lester & Deakin University & Australia \\
\hline Ralph Mac Nally & Monash University & Australia \\
\hline Michael A. McCarthy & University of Melbourne & Australia \\
\hline Rebecca M. Miller & IUCN & UK \\
\hline Justin Moat & Royal Botanic Gardens, Kew & UK \\
\hline
\end{tabular}




\begin{tabular}{|c|c|c|}
\hline Name & Organisation & Country \\
\hline Nicholas J. Murray & University of New South Wales & Australia \\
\hline Emily Nicholson & Deakin University & Australia \\
\hline $\begin{array}{l}\text { María A. (Tina) Oliveira- } \\
\text { Miranda }\end{array}$ & Provita & Venezuela \\
\hline Phil Pisanu & $\begin{array}{l}\text { South Australian Department of Environment } \\
\text { and Natural Resources }\end{array}$ & Australia \\
\hline Brigitte Poulin & Tour du Valat Research Center & France \\
\hline Tracey J. Regan & Arthur Rylah Institute & Australia \\
\hline Belinda Reyers & Council for Scientific and Industrial Research & South Africa \\
\hline Uwe Riecken & $\begin{array}{l}\text { German Federal Agency for Nature } \\
\text { Conservation }\end{array}$ & Germany \\
\hline Jon Paul Rodríguez & $\begin{array}{l}\text { Instituto Venezolano de Investigaciones } \\
\text { Científicas }\end{array}$ & Venezuela \\
\hline $\begin{array}{l}\text { Kathryn M. Rodríguez- } \\
\text { Clark }\end{array}$ & $\begin{array}{l}\text { Instituto Venezolano de Investigaciones } \\
\text { Científicas }\end{array}$ & Venezuela \\
\hline Mark D. Spalding & $\begin{array}{l}\text { The Nature Conservancy and University of } \\
\text { Cambridge }\end{array}$ & UK \\
\hline Andrew Taber & The Wildlife Trust & USA \\
\hline Irene Zager & Provita & Venezuela \\
\hline $\begin{array}{l}\text { Sergio Zambrano- } \\
\text { Martínez }\end{array}$ & $\begin{array}{l}\text { Instituto Venezolano de Investigaciones } \\
\text { Científicas }\end{array}$ & Venezuela \\
\hline Carlos Zambrana-Torrelio & EcoHealth Alliance & USA \\
\hline Tara Zamin & Monash University & Australia \\
\hline
\end{tabular}




\section{Appendix 2. IUCN Red List of Ecosystems Criteria, Version 2.1}

A. Reduction in geographic distribution over ANY of the following time periods:

A2b. any 50 year

A1. the past 50 years A2a. the next 50 years period including the past, present and future

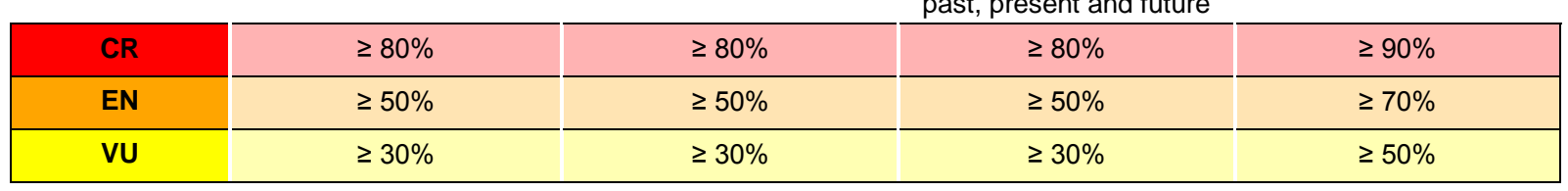

B. Restricted geographic distribution indicated by ANY OF B1, B2 or B3:

B1. Extent of a minimum convex polygon enclosing all occurrences (extent of occurrence, EOO) is no larger than:

\begin{tabular}{|c|c|c|c|}
\hline CR & $2,000 \mathrm{~km}^{2}$ & $\begin{array}{c}\text { AND at } \\
\text { least one of } \\
\text { the } \\
\text { following } \\
\text { (a-c): }\end{array}$ & $\begin{array}{l}\text { (a) An observed or inferred continuing decline in ANY OF: } \\
\text { i. a measure of spatial extent appropriate to the ecosystem; OR } \\
\text { ii. a measure of environmental quality appropriate to characteristic biota of the } \\
\text { ecosystem; OR } \\
\text { iii. a measure of disruption to biotic interactions appropriate to the characteristic } \\
\text { biota of the ecosystem. } \\
\text { (b) Observed or inferred threatening processes that are likely to cause continuing } \\
\text { declines in geographic distribution, environmental quality or biotic interactions within } \\
\text { the next } 20 \text { years. } \\
\text { (c) Ecosystem exists at } 1 \text { location }\end{array}$ \\
\hline EN & $20,000 \mathrm{~km}^{2}$ & $\begin{array}{l}\text { AND at } \\
\text { least one of } \\
\text { the } \\
\text { following } \\
\text { (a-c): }\end{array}$ & $\begin{array}{l}\text { (a) An observed or inferred continuing decline in ANY OF: } \\
\text { i. a measure of spatial extent appropriate to the ecosystem; OR } \\
\text { ii. a measure of environmental quality appropriate to characteristic biota of the } \\
\text { ecosystem; OR } \\
\text { iii. a measure of disruption to biotic interactions appropriate to the characteristic } \\
\text { biota of the ecosystem. } \\
\text { (b) Observed or inferred threatening processes that are likely to cause continuing } \\
\text { declines in geographic distribution, environmental quality or biotic interactions within } \\
\text { the next } 20 \text { years. } \\
\text { (c) Ecosystem exists at } \leqq 5 \text { locations }\end{array}$ \\
\hline VU & $50,000 \mathrm{~km}^{2}$ & $\begin{array}{l}\text { AND at } \\
\text { least one of } \\
\text { the } \\
\text { following } \\
\text { (a-c): }\end{array}$ & $\begin{array}{l}\text { (a) An observed or inferred continuing decline in ANY OF: } \\
\text { i. a measure of spatial extent appropriate to the ecosystem; OR } \\
\text { ii. a measure of environmental quality appropriate to characteristic biota of the } \\
\text { ecosystem; OR } \\
\text { iii. a measure of disruption to biotic interactions appropriate to the characteristic } \\
\text { biota of the ecosystem. } \\
\text { (b) Observed or inferred threatening processes that are likely to cause continuing } \\
\text { declines in geographic distribution, environmental quality or biotic interactions within } \\
\text { the next } 20 \text { years. } \\
\text { (c) Ecosystem exists at } \leqq 10 \text { locations }\end{array}$ \\
\hline
\end{tabular}


B2. The number of $10 \times 10 \mathrm{~km}$ grid cells occupied (area of occupancy, AOO) is no more than:

\begin{tabular}{|c|c|c|c|}
\hline CR & 2 & $\begin{array}{l}\text { AND at } \\
\text { least one of } \\
\text { the } \\
\text { following } \\
\text { (a-c): }\end{array}$ & $\begin{array}{l}\text { (a) An observed or inferred continuing decline in ANY OF: } \\
\text { i. a measure of spatial extent appropriate to the ecosystem; OR } \\
\text { ii. a measure of environmental quality appropriate to characteristic biota of the } \\
\text { ecosystem; OR } \\
\text { iii. a measure of disruption to biotic interactions appropriate to the characteristic } \\
\text { biota of the ecosystem. } \\
\text { (b) Observed or inferred threatening processes that are likely to cause continuing } \\
\text { declines in geographic distribution, environmental quality or biotic interactions within } \\
\text { the next } 20 \text { years. } \\
\text { (c) Ecosystem exists at } 1 \text { location }\end{array}$ \\
\hline EN & 20 & $\begin{array}{l}\text { AND at } \\
\text { least one of } \\
\text { the } \\
\text { following } \\
\text { (a-c): }\end{array}$ & $\begin{array}{l}\text { (a) An observed or inferred continuing decline in ANY OF: } \\
\text { i. a measure of spatial extent appropriate to the ecosystem; OR } \\
\text { ii. a measure of environmental quality appropriate to characteristic biota of the } \\
\text { ecosystem; OR } \\
\text { iii. a measure of disruption to biotic interactions appropriate to the characteristic } \\
\text { biota of the ecosystem. } \\
\text { (b) Observed or inferred threatening processes that are likely to cause continuing } \\
\text { declines in geographic distribution, environmental quality or biotic interactions within } \\
\text { the next } 20 \text { years. } \\
\text { (c) Ecosystem exists at } \leqq 5 \text { locations }\end{array}$ \\
\hline VU & 50 & $\begin{array}{l}\text { AND at } \\
\text { least one of } \\
\text { the } \\
\text { following } \\
(a-c):\end{array}$ & $\begin{array}{l}\text { (a) An observed or inferred continuing decline in ANY OF: } \\
\text { i. a measure of spatial extent appropriate to the ecosystem; OR } \\
\text { ii. a measure of environmental quality appropriate to characteristic biota of the } \\
\text { ecosystem; OR } \\
\text { iii. a measure of disruption to biotic interactions appropriate to the characteristic } \\
\text { biota of the ecosystem. } \\
\text { (b) Observed or inferred threatening processes that are likely to cause continuing } \\
\text { declines in geographic distribution, environmental quality or biotic interactions within } \\
\text { the next } 20 \text { years. } \\
\text { (c) Ecosystem exists at } \leqq 10 \text { locations }\end{array}$ \\
\hline
\end{tabular}

B3. The number of locations is:

Vu short time period in an uncertain future, and thus capable of Collapse or becoming Critically Endangered within a very short time period (B3 can only lead to a listing as VU).

C. Environmental degradation over ANY of the following time periods:

\begin{tabular}{|c|c|c|c|c|}
\hline \multirow{5}{*}{$\begin{array}{l}\text { C1. The past } 50 \text { years, based on change in an abiotic variable affecting } \\
\text { a fraction of the extent of the ecosystem and with relative severity, as } \\
\text { indicated by the following table: }\end{array}$} & \multirow[b]{2}{*}{ Extent (\%) } & \multicolumn{3}{|c|}{ Relative severity (\%) } \\
\hline & & $\geq 80$ & $\geq 50$ & $\geq 30$ \\
\hline & $\geq 80$ & CR & EN & VU \\
\hline & $\geq 50$ & EN & vu & \\
\hline & $\geq 30$ & Vu & & \\
\hline \multirow{5}{*}{$\begin{array}{l}\text { C2a. The next } 50 \text { years, based on change in an abiotic variable affecting } \\
\text { a fraction of the extent of the ecosystem and with relative severity, as } \\
\text { indicated by the following table; OR } \\
\text { C2b. Any } 50 \text {-year period including the past, present and future, based on } \\
\text { change in an abiotic variable affecting a fraction of the extent of the } \\
\text { ecosystem and with relative severity, as indicated by the following table: }\end{array}$} & & \multicolumn{3}{|c|}{ Relative severity (\%) } \\
\hline & Extent (\%) & $\geq 80$ & $\geq 50$ & $\geq 30$ \\
\hline & $\geq 80$ & CR & EN & VU \\
\hline & $\geq 50$ & EN & VU & \\
\hline & $\geq 30$ & Vu & & \\
\hline \multirow{5}{*}{$\begin{array}{l}\text { C3. Since } 1750 \text {, based on change in an abiotic variable affecting a } \\
\text { fraction of the extent of the ecosystem and with relative severity, as } \\
\text { indicated by the following table: }\end{array}$} & & \multicolumn{3}{|c|}{ Relative severity (\%) } \\
\hline & Extent (\%) & $\geq 90$ & $\geq 70$ & $\geq 50$ \\
\hline & $\geq 90$ & CR & EN & Vu \\
\hline & $\geq 70$ & EN & VU & \\
\hline & $\geq 50$ & VU & & \\
\hline
\end{tabular}


D. Disruption of biotic processes or interactions over ANY of the following time periods:

\begin{tabular}{|c|c|c|c|c|}
\hline \multirow{5}{*}{$\begin{array}{l}\text { D1. The past } 50 \text { years, based on change in a biotic variable affecting a } \\
\text { fraction of the extent of the ecosystem and with relative severity, as } \\
\text { indicated by the following table: }\end{array}$} & \multirow[b]{2}{*}{ Extent (\%) } & \multicolumn{3}{|c|}{ Relative severity (\%) } \\
\hline & & $\geq 80$ & $\geq 50$ & $\geq 30$ \\
\hline & $\geq 80$ & CR & EN & VU \\
\hline & $\geq 50$ & EN & vu & \\
\hline & $\geq 30$ & VU & & \\
\hline \multirow{5}{*}{$\begin{array}{l}\text { D2a. The next } 50 \text { years, based on change in a biotic variable affecting a } \\
\text { fraction of the extent of the ecosystem and with relative severity, as } \\
\text { indicated by the following table; OR } \\
\text { D2b. Any } 50 \text {-year period including the past, present and future, based on } \\
\text { change in a biotic variable affecting a fraction of the extent of the } \\
\text { ecosystem and with relative severity, as indicated by the following table: }\end{array}$} & & \multicolumn{3}{|c|}{ Relative severity (\%) } \\
\hline & Extent (\%) & $\geq 80$ & $\geq 50$ & $\geq 30$ \\
\hline & $\geq 80$ & CR & EN & VU \\
\hline & $\geq 50$ & EN & VU & \\
\hline & $\geq 30$ & VU & & \\
\hline \multirow{5}{*}{$\begin{array}{l}\text { D3. Since } 1750 \text {, based on change in a biotic variable affecting a fraction } \\
\text { of the extent of the ecosystem and with relative severity, as indicated by } \\
\text { the following table: }\end{array}$} & & \multicolumn{3}{|c|}{ Relative severity (\%) } \\
\hline & Extent (\%) & $\geq 90$ & $\geq 70$ & $\geq 50$ \\
\hline & $\geq 90$ & CR & EN & VU \\
\hline & $\geq 70$ & EN & Vu & \\
\hline & $\geq 50$ & vu & & \\
\hline
\end{tabular}

E. Quantitative analysis that estimates the probability of ecosystem collapse to be:

\begin{tabular}{|l|l|}
\hline CR & $\geq 50 \%$ within 50 years \\
\hline EN & $\geq 20 \%$ within 50 years \\
\hline VU & $\geq 10 \%$ within 100 years \\
\hline
\end{tabular}


Appendix 3. Colour codes

\begin{tabular}{llrll} 
& & \multicolumn{3}{c}{ RGB color code } \\
\cline { 3 - 5 } Category & Color & R & G & B \\
\hline CO & Black & 0 & 0 & 0 \\
EN & Red & 255 & 0 & 0 \\
VU & Orange & 255 & 165 & 0 \\
NT & Yellow & 255 & 255 & 0 \\
LC & Green-Yellow & 173 & 255 & 47 \\
DD & Green & 0 & 128 & 0 \\
NE & Grey & 128 & 128 & 128 \\
\hline
\end{tabular}



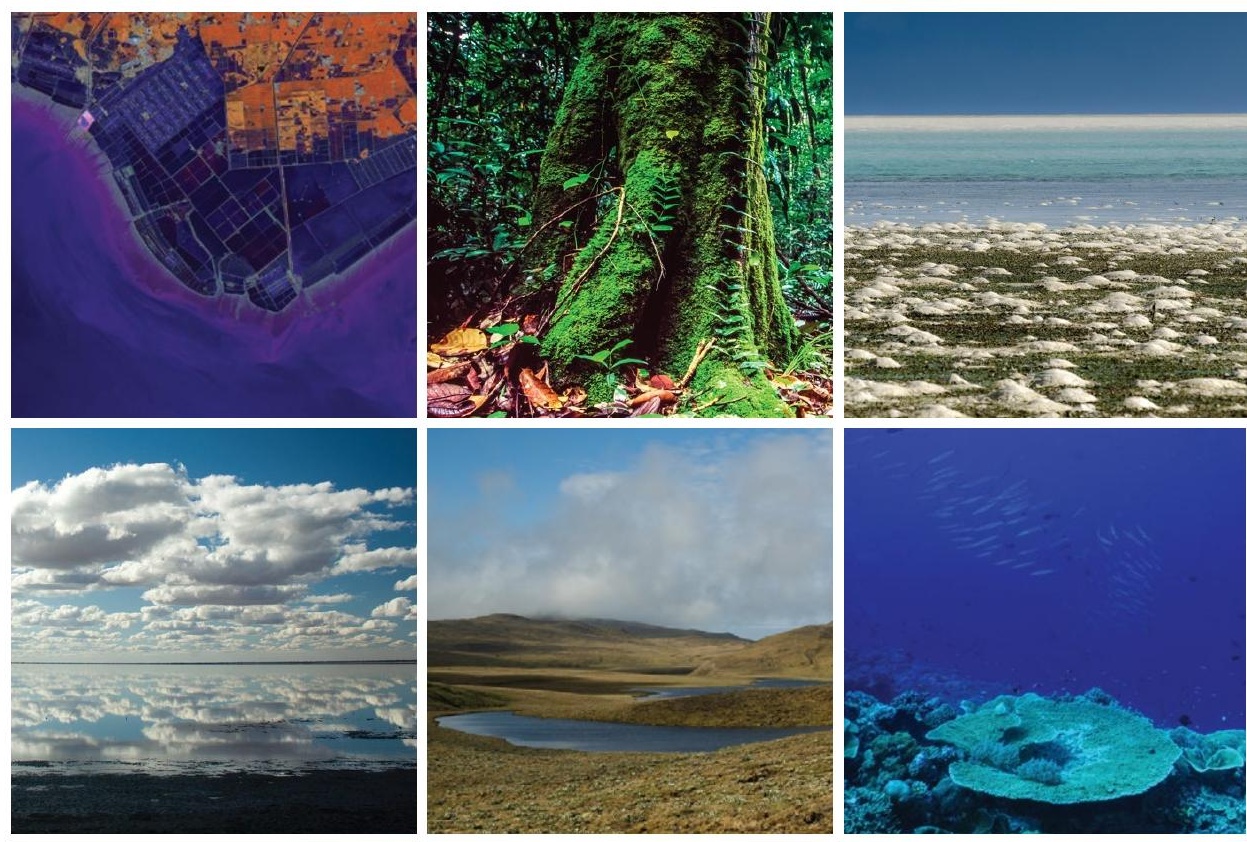

\section{IUCN}
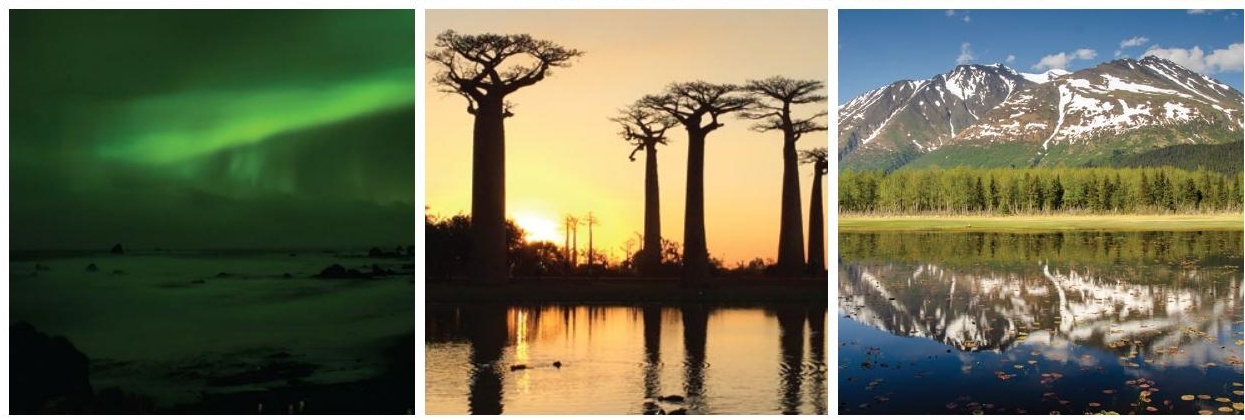

INTERNATIONAL UNION FOR CONSERVATION OF NATURE

WORLD HEADQUARTERS

Rue Mauverney 28

1196 Gland, Switzerland

Tel +41 229990000

www.iucn.org 